\title{
TITLE:
}

\section{Japanese Polychaetes of the Genera Eunice and Euniphysa : Taxonomy and Branchial Distribution Patterns}

\author{
$\operatorname{AUTHOR}(\mathrm{S})$ : \\ Miura, Tomoyuki
}

\section{CITATION:}

Miura, Tomoyuki. Japanese Polychaetes of the Genera Eunice and Euniphysa: Taxonomy and Branchial Distribution Patterns. PUBLICATIONS OF THE SETO MARINE BIOLOGICAL LABORATORY 1986, 31(3-6): 269-325

ISSUE DATE:

1986-11-29

URL:

http://hdl.handle.net/2433/176125

RIGHT: 


\title{
Japanese Polychaetes of the Genera Eunice and Euniphysa: Taxonomy and Branchial Distribution Patterns
}

\author{
By \\ Tomoyuki Miura \\ Ocean Research Institute, University of Tokyo, 1-15-1 \\ Minamidai, Nakano-ku, Tokyo 164, Japan
}

With Text-figures 1-39 and Tables 1-2

\begin{abstract}
All Japanese species attributed to the genera Eunice and Euniphysa are studied taxonomically with or without new records. The species erected by Moore (1903) are redescribed to correct his confusing descriptions caused by his unique counting method of body segments. Using the specimens collected chiefly by the cruise of $R / V$ "Tansei-Maru" of the Ocean Research Institute, five new species and one new subspecies are described. For several species with enough number of specimens, the variability of morphological characters such as the occurrence of branchiae and subacicular hooks, is examined statistically and the ontogenetic change of the branchial distribution is mentioned. For twenty species, their precise distribution of branchiae is shown. Possible pathways of modifications occurring in the branchial distribution patterns are discussed.
\end{abstract}

\section{Introduction}

The genus Eunice Cuvier, 1817 contains about 170 valid species (Fauchald, 1970 ; 1977). From Japanese coasts, twenty-five species have been nominally recorded. At first, two species, Eunice congesta and E. microprion were described by Marenzeller (1879) from southern Japan, and McIntosh (1885) erected E. kobiensis for a specimen collected from off Kobe. Using the collection of the U.S. "Albatross", Moore (1903) reported five new species, E. northioidea, E. quinquifida, E. mucronata, E. gracilis and E. medicina, and E. vittata (delle Chiaje, 1828). In his original descriptions, the segmental count in the terms of "numbers of somites" are basically counting the apodous rings as two segments, but occasionally as a single segment. By this counting method, the taxonomic comparison of the species erected by Moore with those of others is difficult. As suggested by Fauchald (1970), the segmental counts should be exclusively in the terms of numbers of setigers. The five species erected by Moore (1903) are thus redescribed in this study. Izuka (1912) mentioned twelve species among which four, i.e., E. aphroditois (Pallas, 1788), E. indica (Kinberg, 1865), E. tibiana (Poutales, 1863) and E. flavopicta Izuka, 1912, were newly added to the Japanese fauna. Some of the type specimens studied by Izuka are now deposited at the University Museum, University of Tokyo, but those of E. flavopicta have not been found. During an ecological study of serpulid worms (Miura

Publ. Seto Mar. Biol. Lab., 31 (3/6), 269-325 $1986 . \quad$ (Article 10) 
\& Kajihara, 1985), several specimens well corresponding to the description of $E$. flavopicta were captured from the type locality of this species and are presented in the present study. Fauvel (1936) worked on the polychaetes collected by Prof. K. Okada near Shirahama, Kii Peninsula and added three species to the fauna, i.e., E. tentaculata Quatrefages, 1865, E. antennata (Savigny, 1818) and E. ovalifera Fauvel, 1936. Okuda (1938) reported three species of the genus from the Izu Peninsula, one of which is now known as Palola siciliensis (Grube, 1840). He also found $E$. afra Peters, 1854 from the Ryukyu Islands (Okuda, 1940). Imajima and Hartman (1964) listed up all known Japanese species and also proposed to synonymize E. kobiensis McIntosh, 1885 with $E$. longicirrata Webster, 1884. On the above historical basis, I have reported thirteen intertidal to subtidal eunicid species containing two new species (Miura, 1977a; 1977b; 1979). In the present study, all Japanese species of the genus Eunice are mentioned, their branchial distribution is given and modifications of their distribution patterns are discussed. Full morphological characters are given only for the species not mentioned in my previous papers. One of the Japanese species is moved to the other genus, Euniphysa Wesenberg-Lund (1949). The key for the identification of Japanese species is also given for the practical application by scientists working on the marine benthic community and polychaetes in Japan.

\section{Material and Methods}

The specimens examined are listed in the description of each species with the catalogue number, the body composition, the maturity, the collecting site, date and method (unless the collection was not made by hand during diving or from the shore).

Body width was defined as the distance between both ends of parapodial lobes at the largest anterior segment between setigers 5-10. The body width was measured to the first decimal place in millimeters from the outline of each specimen drawn using a binocular scope and a camera lucida. In the counting of setigers, two apodous rings (peristomial rings) were excluded. In the description of some species, the variability of each numerical character and the linear regression between each character and the body width were calculated using the computing system "Basic Statistic System" by Nihon Joho Kenkyu Genter.

The abbreviations of institutes where the materials are deposited are as follows: AMBS: Amakusa Marine Biological Station, University of Kyushu; BM: British Museum, London; NSMT: National Science Museum, Tokyo; ORI: Ocean Research Institute, University of Tokyo; UGOA: Universite Catholique de l'Ouest, Angers; USNM: United States National Museum of Natural History, Smithsonian Institution, Washington D.C.; ZMC: Zoologisk Muesum, Copenhagen; ZMO: Zoologisk Museum, Oslo; ZUNT: Department of Zoology, University Muesum, University of Tokyo.

In the description of each species, the terminology followed chiefly that of Fauchald $(1970,1977)$ and Miura (1977a, 1977b, 1979).

\section{Taxonomic Account}

Genus Eunice Guvier, 1817

Eunice aphroditois (Pallas, 1788)

(Figs 1 \& 2)

Nereis aphroditois Pallas, 1788, p. 229. 
Leodice aphroditois: Treadwell, 1926, p. 17.

Eunice aphroditois: Fauvel, 1936, pp. 65-66; Miura, 1977, pp. 9-13, fig. 4, table 2. Eunice flavopicta Izuka, 1912, pp. 121-123, pl. 14, figs 1-5; Imajima \& Hartman, 1964, pp. 251-252. Eunice ovalifura Fauvel, 1936, pp. 67-69, fig. 1.

New records. (Adult) USNM, one complete \& one incomplete, Kominato, Chiba, $4 \mathrm{~m} \mathrm{\&} 1 \mathrm{~m}$ depth, rocky bottom, 15 Dec. 1981 \& 28 Apr. 1982, Dr. Ikuo Hayashi (IH). NSMT, incomplete, Hanase, Kaimon-cho, Kagoshima, intertidal rocky shore, 1 June 1984, Dr. Hiroshi Suzuki. BM, one complete \& one incomplete, Tsuji-shima, Amakusa, intertidal rocky shore, 03 June 1984, the present author (TM). (Juvenile) USNM, BM and NSMT, six complete or incomplete, Misaki, Aburatsubo Inlet, Kanagawa, Hydroides ezoensis assemblage on the buoys of Undaria culture ropes, 25 June, 12 July, 22 July, 10 Aug. \& 20 Sep. 1979, TM. NSMT, complete, Yogan-nagisa, Sakurajima, Kagoshima, intertidal rocky shore, 26 May 1984, TM. AMBS, complete, Shiraiwa-zaki, Tomioka, Amakusa, intertidal rocky shore, 5 Apr. 1943, Prof. Hiroshi Oshima. AMBS, incomplete, Tomoe Inlet, Amakusa, on the buoys, 13 Feb. 1964, Mr. A. Taki (AT). AMBS, two complete \& one incomplete, Tomioka, Amakusa, from the fouling community of a pier of Tomioka fishery cooperative, 29 Oct. 1966, AT. UCOA, holotype of Eunice ovalifera Fauvel, 1936, parapodia on slide preparation S 57, Mori, Kii, Wakayama, oyster bed, 7 Apr. 1931, Prof. K. Okada.

The adult specimens have been reported previously from Japan by several authors (Izuka, 1912; Treadwell, 1926; Fauvel, 1936; Imajima \& Hartman, 1964; Miura, 1977a). In this paper, morphology of the juvenile stage is described.

The collection from Misaki contains four complete specimens, one with regenerated posterior segments and the other without caudal segments. They measure 7.3-9.7 mm wide and 37-104 $\mathrm{mm}$ long with 100-150 setigers. The smallest specimen from Sakura-jima measuring $1.0 \mathrm{~mm}$ wide with 48 setigers, may be identified with this species. The collection of AMBS contains larger specimens and measures 12.0-15.0 $\mathrm{mm}$ wide. Although these worms were collected through all seasons, none of them were sexually matured (without any developing gamete in the coelum).

The color of dorsum is deep purple to black with metalic iridescence in life. It becomes reddish brown in alcohol. The fourth setiger is always white. The third is also white, but occasionally with only white cordate spots or a pale band (Fig. 1, a \& d). The first peristomial ring has a large white spot on the middle of the dorsum. The second apodous ring and setigers 1 and 2 have sometimes small white spots at the center of dorsum. The first setiger ordinarily has a white band. Most of other setigers have a dorso-central white spot and a pair of dorso-lateral spots (Fig. 1, b \& c). The tips of prostomial antennae, peristomial tentacles and dorsal cirri are white.

The first parapodium has a rod-like dorsal and a digitiform ventral cirri (Fig. 1, e). The dorsal cirri become long and slender on the following parapodia (Fig. 1, f-h). The ventral cirri are conical in the middle part of the body (Fig. 1, f \& $\mathrm{g}$ ), and become cylindrical on the posterior parapodia (Fig. 1, h).

Branchiae start on setiger 5 in the present specimens. The first branchia has two to four filaments (Fig. 1, f). The number of branchial filaments increases rapidly, becoming more than ten between setigers 10 to 60 , and then decreases gradually towards the posterior end of the body where a dozen preanal parapodia lack branchiae (Fig. 2). 

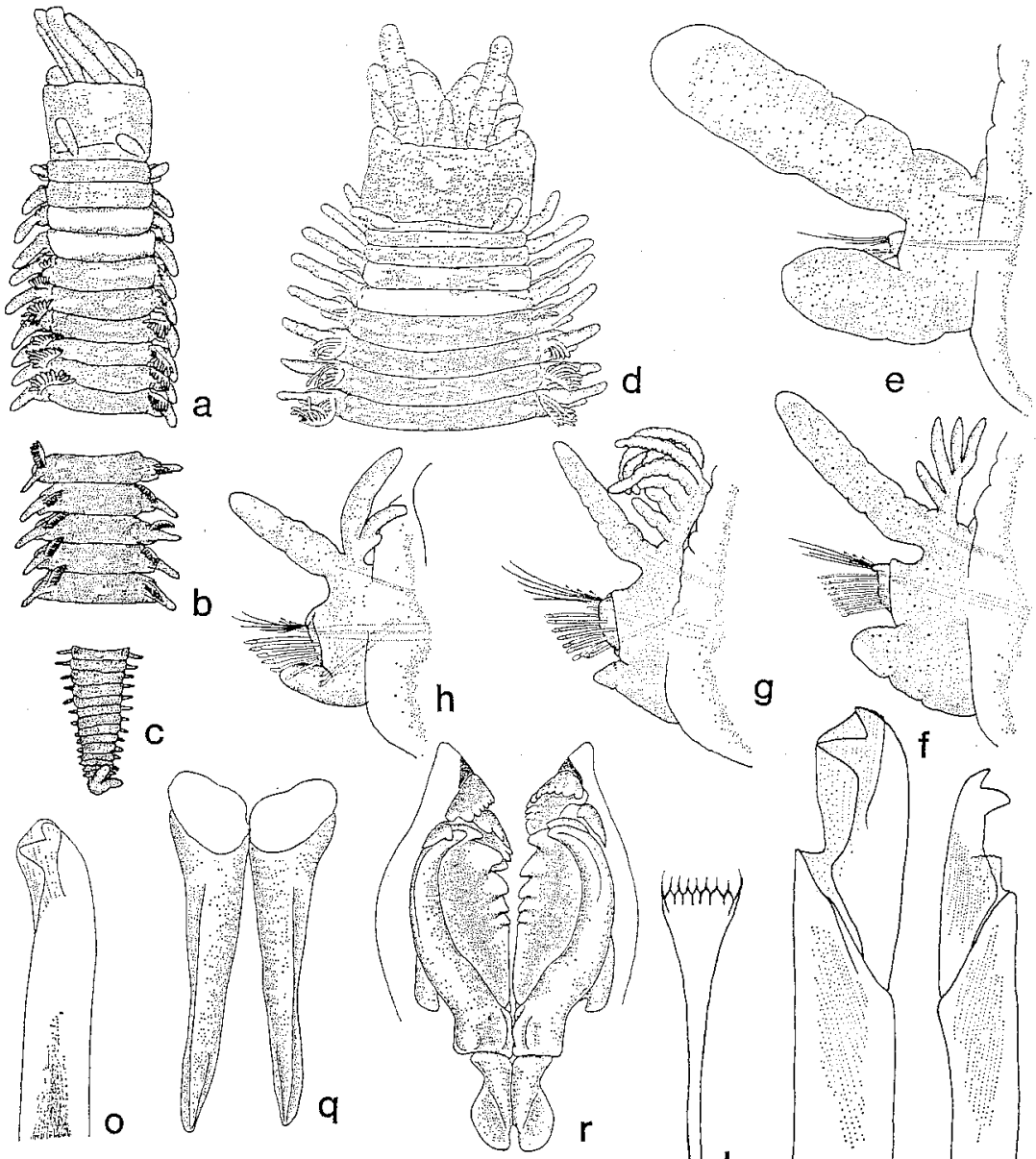

g
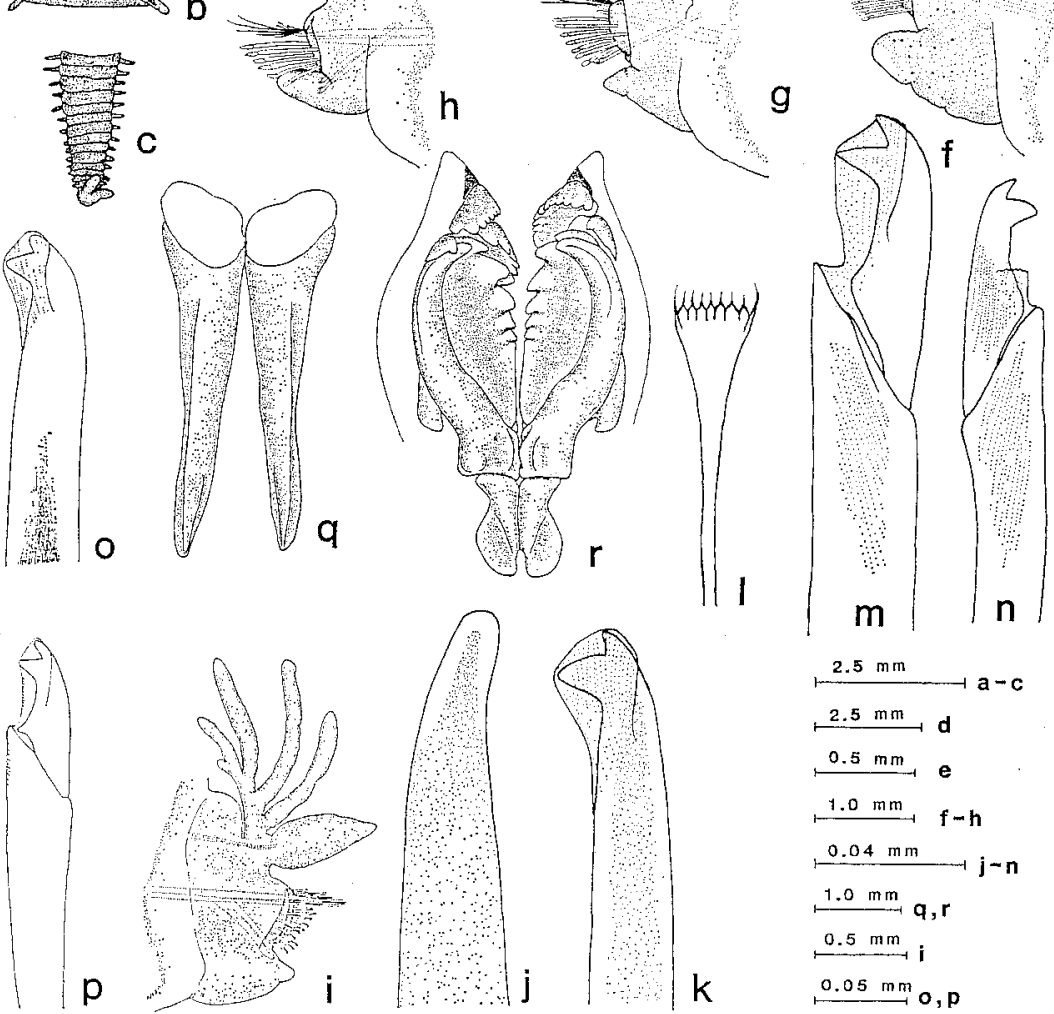

Fig. 1. Juvenile stage of Eunice aphroditois (Pallas, 1788). a. Anterior end of a specimen from Misaki measuring $7.3 \mathrm{~mm}$ wide with 125 setigers, dorsal view; b. Median segments of the same, dorsal view; c. Posterior end of the same, dorsal view; d. Anterior end of a specimen from Misaki measuring $8.7 \mathrm{~mm}$ wide with 140 setigers, dorsal view; e. First parapodium of the same, anterior view; f. Parapodium 5; g. Parapodium 35; h. Parapodium 115; i. A parapodium of Eunice ovalifera Fauvel, 1936 (UCOA Slide No. S-57); j. Aciculum; k. Subacicular hook; l. Pectinate seta; m. Compound falciger; n. Damaged falciger; o. Subacicular hook of $E$. ovalifera; $p$. Compound falciger from the same; $q$. Mandibles; r. Maxillae. 


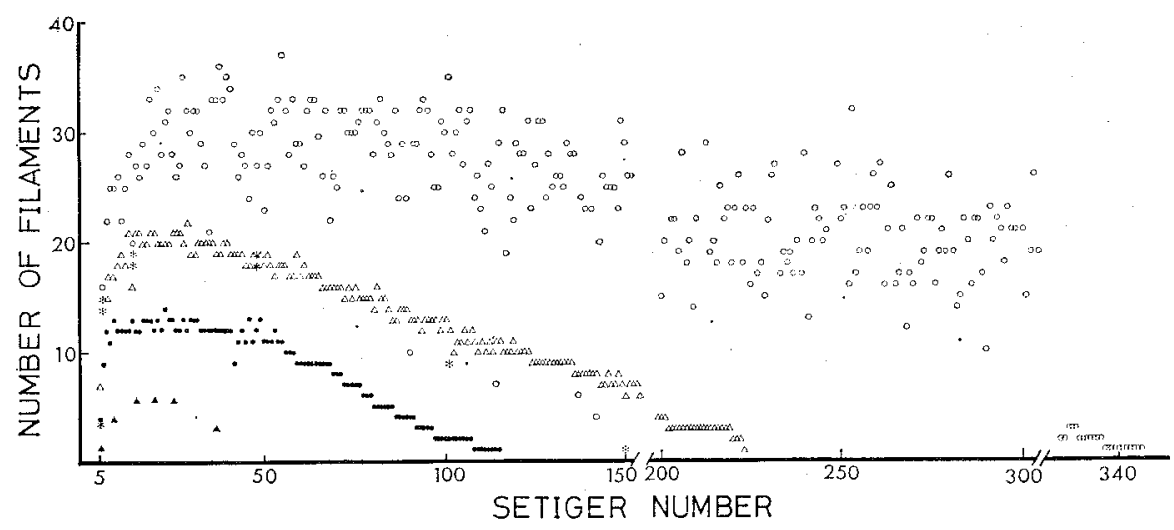

Fig. 2. Branchial distribution in Eunice aphroditois (Pallas, 1788). Number of branchial filaments per parapodia is plotted for each setiger; open circle, adult specimen from Kominato measuring $24.0 \mathrm{~mm}$ wide; open triangle, juvenile specimen from Amakusa measuring $12.0 \mathrm{~mm}$ wide; closed circle, juvenile specimen from Aburatsubo measuring $7.3 \mathrm{~mm}$ wide; asterisk, Eunice flavopicta Izuka, 1912; closed triangle, Eunice ovalifera Fauvel, 1936.

Subacicular hooks are black, bidentate and hooded (Fig. 1, k). They appear at first from setigers $26-30$ in the specimens from Misaki. They occur singly on each anterior parapodium while two to three are present on each posterior parapodium. Acicula are black and distally recurved (Fig. 1, j). Notoacicular setae are embedded at the base of the dorsal cirrus. Each pectinate seta has six to seven inner teeth and almost symmetrical lateral extentions (Fig. 1, 1). Compound falcigers are bidentate and hooded (Fig. 1, m).

The mandibles are calcified on the cutting edge (Fig. 1, q). The maxillary formula is $\mathrm{Mx} . \mathrm{I}=1+1, \mathrm{Mx} . \mathrm{II}=5+6, \mathrm{Mx} . \mathrm{III}=5+0, \mathrm{Mx} . \mathrm{IV}=4+11, \mathrm{Mx} . \mathrm{V}=$ $1+1$ in a specimen from Misaki (Fig. 1, r).

The pygidium. (Fig. 1, c) has two short and stout anal cirri, that is known to be a unique character for this species (Miura, 1977a).

Remarks. The color pattern of the juvenile stage of Eunice aphroditois fits also with descriptions of E. flavopicta Izuka, 1912 and E. ovalifera Fauvel, 1936.

The shape of dorsal cirri in E. ovalifera has been emphasized as "renfles en court boudin ovoide" by Fauvel (1936). The dorsal cirri of Fauvel's specimen (Fig. 1, i) are shorter and wider than those from Misaki. It may be due to the poor preparation of slide mounting and the small size of his specimen. The smallest specimen from Sakura-jima has relatively stout dorsal cirri in comparison with the specimens from Misaki and Amakusa.

The branchial distributions of adult and juvenile of the present specimens, $E$. ovalifera Fauvel, 1936 and E. flavopicta reported by Imajima \& Hartman (1964) are shown in Fig. 2. In E. flavopicta, the first branchia appear on setiger 5 with five filaments (Izuka, 1912) or on setiger 6 with four (Imajima \& Hartman, 1964). According to Fauvel (1936), E. ovalifera has the first branchia of single filament on 
setiger 5. The beginning sites of branchiae in these species are included in the variable range, setigers 5-6, of the adult specimens of E. aphroditois as reported in my previous study (Miura, 1977a). Considering the different body width, $1 \mathrm{~mm}$ in $E$. ovalifera Fauvel, 1936, $2.5 \mathrm{~mm}$ in E. flavopicta Izuka, 1912, $10 \mathrm{~mm}$ in the specimens reported by Imajima \& Hartman (1964) as E. flavopicta and $1.0-15.0 \mathrm{~mm}$ in the juveniles described above, the numbers of branchial filaments reported in these species or specimens do not seem to have significant difference, because the difference in numbers of filaments between specimens is due to the difference of their size as shown in Fig. 2.

The bidentate and hooded compound falciger of E. ovalifera (Fig. 1, p) is very similar to that of E. aphroditois. Some damaged falcigers of E. aphroditois (Fig. 1, n) are also observed and their hoods sometimes look like subdentations between two teeth of the blade as drawn by Izuka (1912, pl. 14, fig. 4). These ultrastructures of chaetae have no taxonomic value if not compared with the same observation accuracy, such as at the scanning electron microscopy level, for all objective species. Morphology of setae in all species above mentioned corresponds well to that of the adult $E$. aphroditois reported by Miura (1977a).

Eunice flavopicta Izuka, 1912 and E. ovalifera Fauvel, 1936 are thus identified with the juvenile states of $E$. aphroditois (Pallas, 1788) in various body sizes.

Distribution. Indo-Pacific, shallow water; South Pacific coast of Japan, intertidal to subtidal depth.

\section{Eunice alata Miura, 1977}

(Fig. 3)

Eunice alata Miura, 1977a, pp. 2-6, figs 1, a-h \& 2, i-o.

New Records. ORI, one juvenile, off Shikoku, middle of Kuroshio Current, boring in the pith of a drifting land grass chip, "Hakuho-Maru" Cruise, KH-77-2 Station 23, 30 37.7' N 134 $59.5^{\circ} \mathrm{E}-$ $30^{\circ} 47.8^{\prime} \mathrm{N} 134^{\circ} 58.5^{\prime} \mathrm{E}, 12$ July 1977 , ORI neuston net-33, Dr. Yutaka Matsuo (YM). ORI, one juvenile, off Shionomisaki, middle of Kuroshio Current, boring in the pith of a drifting land grass chip, KH-77-2 Station $45,27^{\circ} 58.3^{\prime} \mathrm{N} 136^{\circ} 15.1^{\prime} \mathrm{E}-27^{\circ} 57.5^{\prime} \mathrm{N} 136^{\circ} 14.2^{\prime} \mathrm{E}$, 17 July 1977 , ORI neuston net-33, YM.

Remarks. The precise branchial distributions of the type and newly collected specimens are shown in Fig. 3. This species was erected previously on the basis of three specimens which bored into the land grass drifting in coastal water at Kominato. Other two specimens were newly collected using a neuston-net from the middle area of the Kuroshio Gurrent, at least $200 \mathrm{~km}$ apart from the nearest coast. As this species has never been caught directly from the bottom of Japanese coast, these specimens may be transported from the upper reaches of the Kuroshio Current such as Philippine and Indonesian islands, or the species may have a pelagic life history and uses drifting material as their habitat.

Distribution. West Pacific, only neustonic specimens were recorded. 


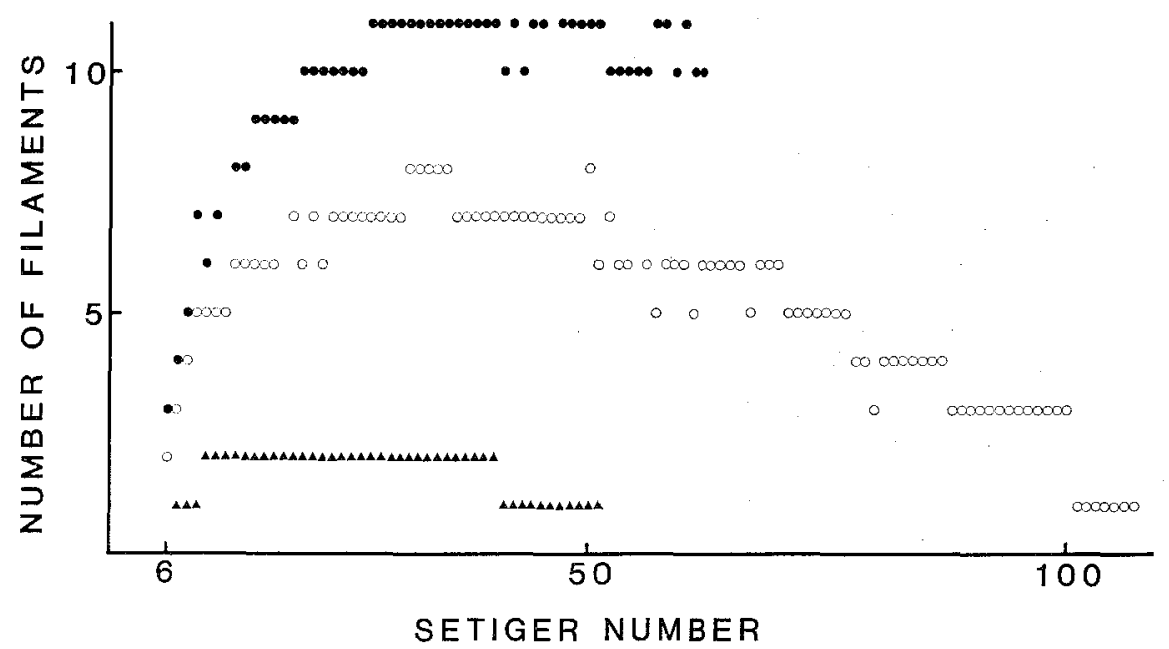

Fig. 3. Branchial distribution in Eunice alata Miura, 1977. Open circle, holotype NSMTPol. H-124, body width (BW) $5.5 \mathrm{~mm}$; closed circle, paratype NSMT-Pol. P-125, BW $7.7 \mathrm{~mm}$; triangle, juvenile (present specimen), BW $1.4 \mathrm{~mm}$.

\section{Eunice afra punctata Peters, 1854}

(Fig. 4)

Eunice punctata Peters, 1854, p. 611.

Eunice afra punctata: Day, 1957, pp. 89 90.

Eunice afra: Okuda, 1937, pp. 276-278, figs 18-19; Okuda, 1940, p. 97; Miura, 1979, pp. 33-35, fig. 1 , a-n.

Remarks. Eunice afra reported from the Ryukyu Islands by Okuda (1940) and Miura (1979) agrees well with the description of $E$. afra punctata by Day (1957) in which Peter's types of $E$. afra and $E$. punctata were comparatively examined. Here the branchial distribution of the specimen reported by Miura (1979) from Ishigaki Island was shown in Fig. 4. The first branchia occurs on setiger 16. The maximal number of filaments is five. More than thirty posterior parapodia lack branchiae.

Distribution. Ryukyu Islands, Japan, intertidal coral reef; maybe widely distributed in the western Pacific.

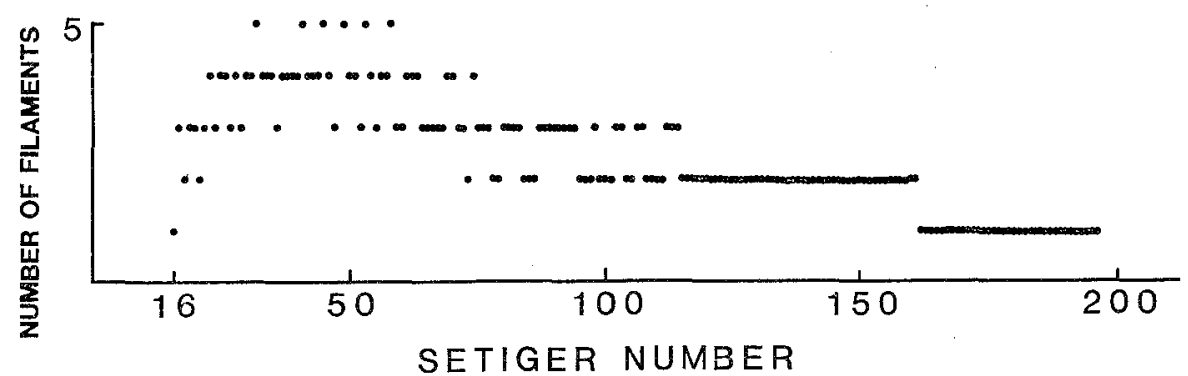

Fig. 4. Branchial distribution in Eunice afra punctata Peters, 1854. Specimen E 180 (Miura, 1979) measuring $6.0 \mathrm{~mm}$ wide with 233 setigers. 


\section{Eunice masudai sp. nov.}

(Figs $5 \& 6$ )

Eunice investigatoris sensu Miura, 1979, pp. 37-39, figs 3 \& 4, a-o (not Fauvel, 1932).

Holotype: NSMT-Pol. H-217, complete female with a parchiment-like tube, off Kushimoto, Kii Channel, 293-335 m, muddy sand, "Tansei-Maru" Cruise KT-84-12 Station 6, 33'24.5' $\mathrm{N} 135^{\circ}$ $42.5^{\prime} \mathrm{E}-33^{\circ} 24.4^{\prime} \mathrm{N} 135^{\circ} 43.6^{\prime} \mathrm{E}, 30$ Aug. 1984, $2 \mathrm{~m}$ beam trawl, Mr. Ryuta Yamamoto (RY). Paratypes: USNM, three incomplete, collected from the same station as the holotype. NSMT-Pol. P-218, incomplete, north off Oone, entrance of Otsuschi Bay, northern Pacific coast of Japan, $90 \mathrm{~m}$, coarse sand, 22 May 1984, ORI dredge, RY. ORI, complete immature with a parchment-like tube, Sado

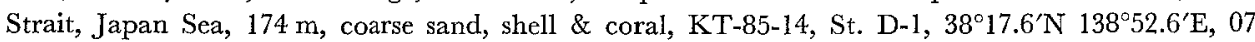
Sep. 1985, Smith-McIntyre grab, TM. Type locality: Kii Channel, 293-335 m.

The holotype measures $93 \mathrm{~mm}$ long by $6.6 \mathrm{~mm}$ wide with 130 setigers. The color of dorsum is light reddish brown. The prostomium is bilobed. Two black eyes are situated at the base of outer lateral antennae. All occipital antennae are irregularly articulated. The central longest antenna with twelve to fourteen annulations extends to the anterior margin of setiger 4-6, the inner pair with nine to eleven annulations to the anterior margin of setigers 3-4, and the outer pair with five to eight annulations to the anterior margin of the second apodous ring (Fig. 5, a \& b). The first apodous ring is about four times as long as the second. The peristomial cirri have three to six annulations. The pygidium has a pair of short flattened anal cirri (Fig. 5, c).

The first parapodium has a cylindrical dorsal cirrus and a digitiform ventral one (Fig. 5, d). The dorsal cirri become slender at the branchial region (Fig. 5, e-i). The ventral cirri have basal swellings on the anterior parapodia. (Fig. 5, e-h) and become simple and digitiform posteriorly (Fig. 5, i). The setal lobes are swollen at the supracicular position.

Branchiae start from setigers 7-8 with one to three filaments. The branchial distribution is bimodal (Fig. 6). The first peak in the number of filament appears on the parapodia between setigers 20-30 and the second after setiger 100. In the posterior peak, the branchiae are more filamentous than in the anterior peak. The maximal number of filaments depends on the size of the specimen. In the holotype, the numbers in the anterior and posterior peaks are six and eight, respectively. The specimens previously studied are larger than the holotype and consequently the numbers are larger, namely in their anterior peak nine to twelve and in the posterior twenty to twenty-three.

Acicula are dark and recurved at the terminal end (Fig. 5, j). Bidentate subacicular hooks are also dark (Fig. 5, k). Each pectinate seta has seven to nine inner teeth and almost symmetrical outer extentions (Fig. 5, 1). Compound falcigers are bidentate and hooded. The blade of each falciger is three quaters as large as the stem (Fig. 5, m).

Mandibles are well calcified at the anterior flared end (Fig. 5, n). The maxillary formula of the holotype is: $\mathrm{Mx} . \mathrm{I}=1+1$ (forceps), $\mathrm{Mx}$. II $=5+5, \mathrm{Mx}$. III $=$ $6+0, \mathrm{Mx} . \mathrm{IV}=4+7, \mathrm{Mx} . \mathrm{V}=\mathrm{l}+\mathrm{l}$ (Fig. 5, o). The number of teeth of each 

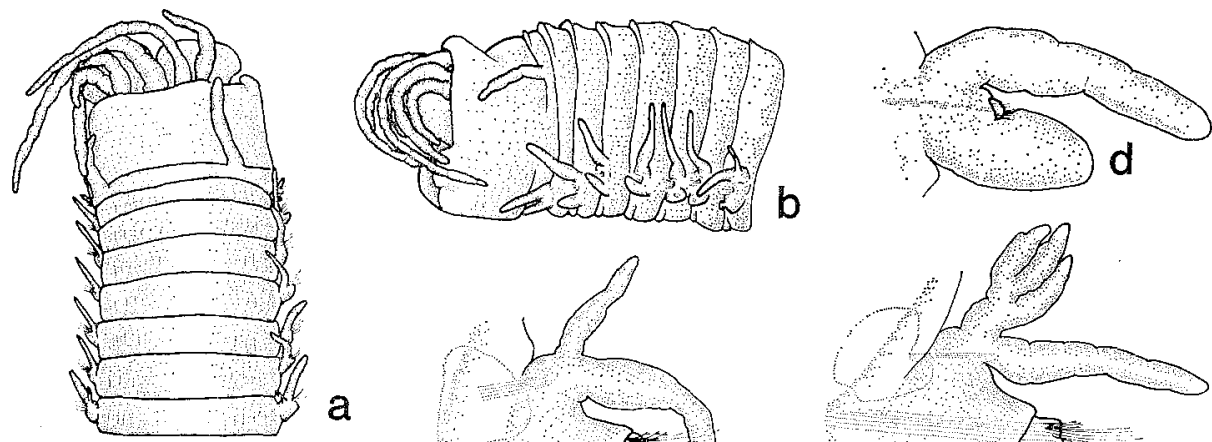

a
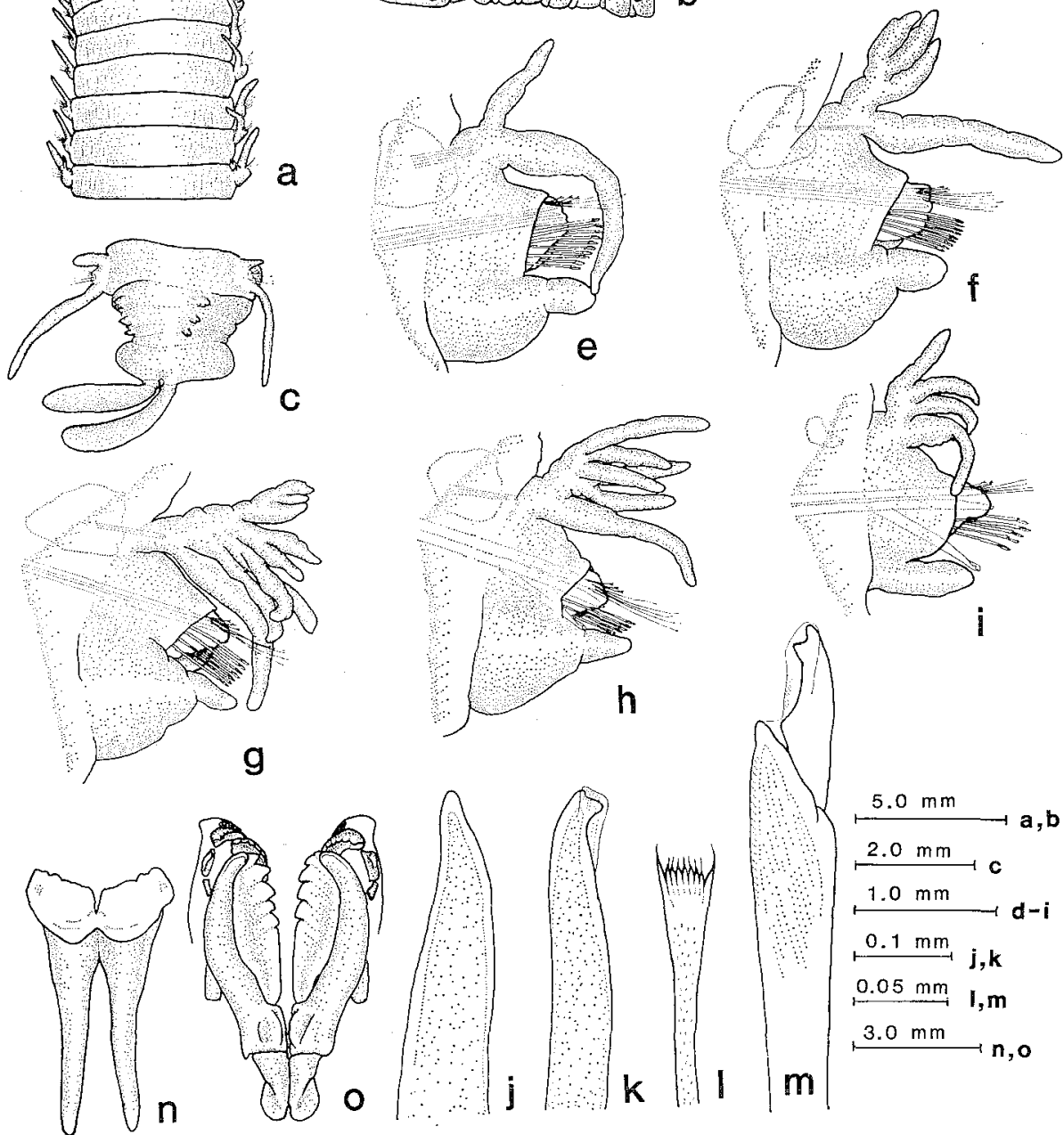

Fig. 5. Eunice masudai sp. nov. a. Anterior end, dorsal view (Paratype from Otsuchi Bay); b. Anterior end, lateral view of the same; c. Posterior end, ventral view (Holotype); d. First parapodium, anterior view (Paratype from Otsuchi Bay); e. Parapodium 7, the same; f. Parapodium 10, the same; g. Parapodium 16, the same; h. Parapodium 40, the same; i. Parapodium 50, the same; j. Aciculum; k. Subacicular hook; 1. Pectinate seta; m. Compound falciger; n. Mandibles; o. Maxillae.

maxillary plate depends on the body size, e.g., the previously reported specimens have more teeth on plates II, III and IV.

Remarks. Eunice masudai sp. nov. is closely related to E. investigatoris Fauvel, 1932 in showing bimodal branchial distribution in the fuscus-bidentate group of the 


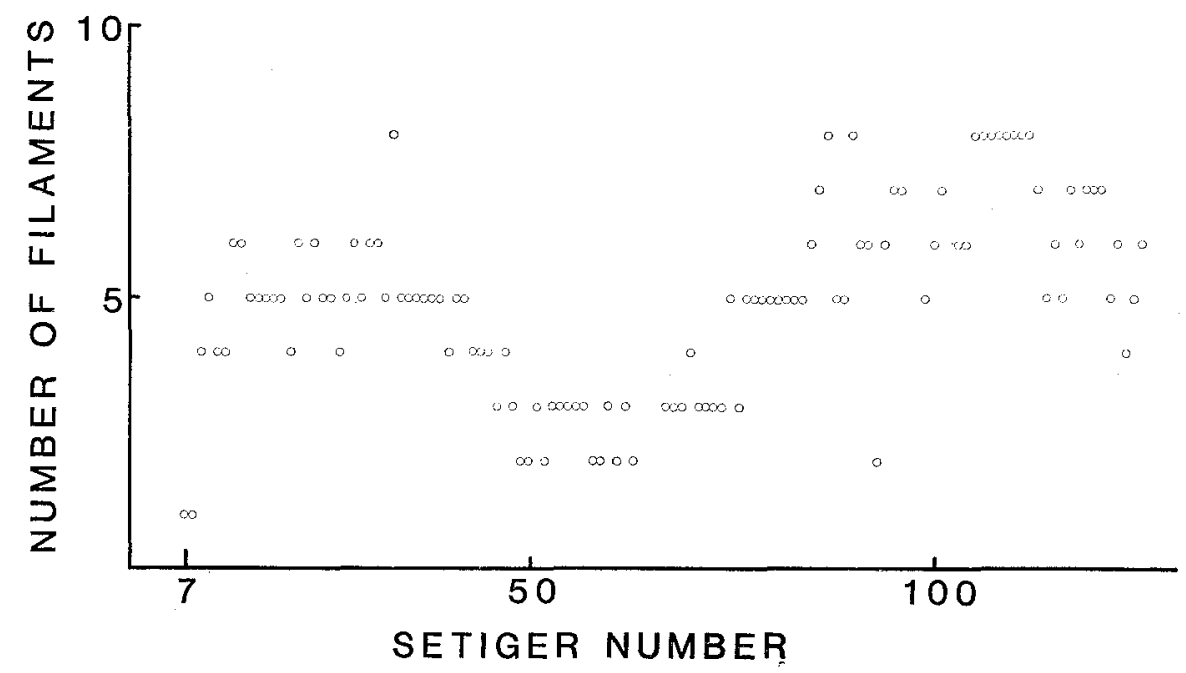

Fig. 6. Branchial distribution in the holotype of Eunice masudai sp. nov., measuring $6.6 \mathrm{~mm}$ wide with 130 setigers.

genus. The former has short and flattened anal cirri and differs from the latter that has long and smooth ones. The occipital antennae and the branchial distribution are also different between these two species. In E. investigatoris, antennae are smooth and branchiae start from setiger 6 with 18-20 filaments in the anterior peak. In contrast, E. masudai sp. nov. has articulated antennae and branchiae from setigers 7-8 with 6-12 filaments in the anterior peak.

Etymology. The new species is named in honor of the late professor of Tokyo University of Fisheries, Dr. Tatsuyoshi Masuda who adviced me to study the Japanese eunicid polychaetes.

Distribution. Pacific coast of Japan, deep waters and Japan Sea, shallow waters.

\section{Eunice microprion Marenzeller, 1879}

(Figs 7 \& 8)

Eunice microprion Marenzeller, 1879, pp. 135-136, pl. 5, fig. 1.

Eunice northioidea Miura, 1977a, pp. 17-19, figs 8, a-k \& 9 (not Moore, 1903, see also Eunice northioidea northioidea in the text).

Nere records. USNM, complete female, Kominato, $8 \mathrm{~m}$, under boulders, 18 Oct. 1983, TM. BM, complete immature, Misaki, Sagami Bay, $5 \mathrm{~m}$, Ecklonia cava forest, rocky bottom, 10 Aug. 1984, TM. ORI, complete immature, Tsuji-shima, Amakusa, intertidal rocky shore, under boulders, 3 June 1984, TM. NSMT, one complete \& one incomplete, immature, south of Tsuma, off Oki Is., Japan Sea, 37-40 m, gravelly bottom, 23 July 1984, dredge, Miss Masumi Yamamuro (MY).

Remarks. The species is characterized by moniliform antennae, black bidentate subacicular hooks, the first occurrence of branchiae from setiger 4 and the maximal 


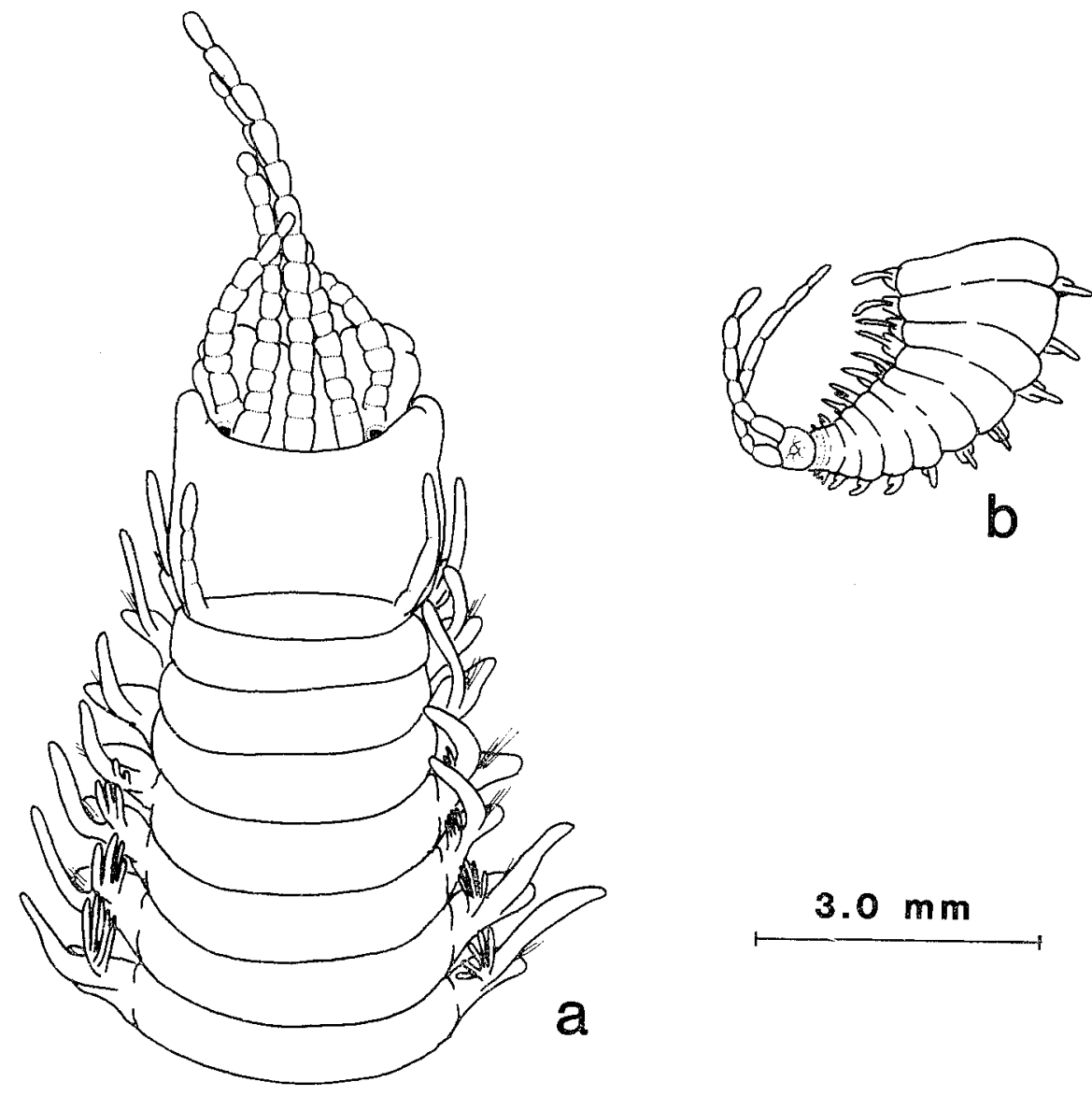

Fig. 7. Eunice microprion Marenzeller, 1879. a. Anteroior end, dorsal view of a female from Kominato; b. Posterior end of the same.

number of branchial filaments more than five. The specimen from Kominato, containing some oocytes in the posterior coelum, measures $88 \mathrm{~mm}$ long by $5.6 \mathrm{~mm}$ wide with 137 setigers (Fig. 7, a \& b). The species inhabits hard substrates, such as under boulders and in clefts of rocky bottom and occurs commonly on the Japanese coast.

The type of Eunice northioidea Moore, 1903 is redescribed in the present paper and found to differ from E. northioidea sensu Miura, 1977a by the branchial distribution. The latter is referred to E. microprion Marenzeller, 1879 in having well developed branchiae from setiger 4 (Fig. 8 ), instead of poorly branching ones from setiger 3 in the type of $E$. northioidea.

Distribution. Sagami Bay, Suruga Bay, Kyushu, Japan Sea, intertidal to shallow rocky bottoms. 


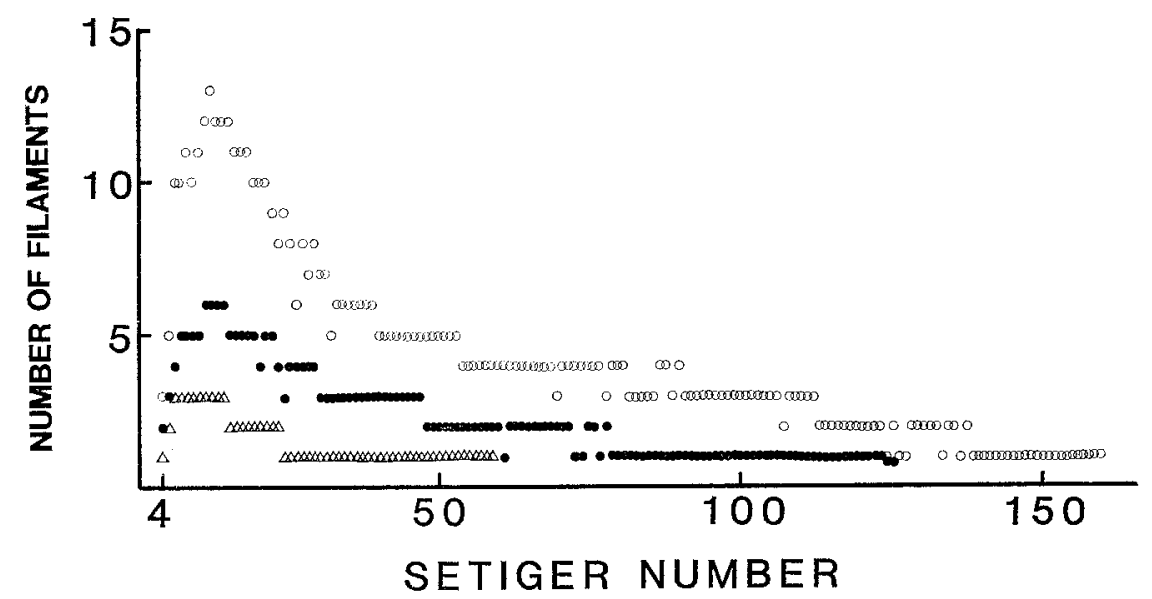

Fig. 8. Branchial distribution in Eunice microprion Marenzeller, 1879. Open circle, specimen from Misaki measuring $6.0 \mathrm{~mm}$ wide with 166 setigers; closed circle, female from Kominato measuring $5.6 \mathrm{~mm}$ wide with 137 setigers; triangle, juvenile from Tsujishima measuring $2.3 \mathrm{~mm}$ wide with 98 setigers.

\section{Eunice northioidea northioidea Moore, 1903}

(Figs $9 \& 10)$

Eunice northioidea Moore, 1903, pp. 433-435, pl. 25, figs 36-38. (not Miura, 1977, see also the text of Eunice microprion Marenzeller, 1879).

Holotype: USNM 15728, incomplete immature, collected from off Ose-zaki, Suruga Bay, 65 fms (119 m), volcanic sand, shells and rocks, 11 May, 1900, "Albatross" Station 3718.

The holotype is an anterior fragment separated into two parts with 45 and 39 setigers, measures 29 and $26 \mathrm{~mm}$ long respectively and $4.0 \mathrm{~mm}$ wide including parapodia at setiger 10 . The prostomium is strongly retracted within the peristomial fold. Eyes are present. Central three antennae are roughly equivalent in length, reaching setiger 5 and have six articulations. Outer lateral antennae with three to four articulations extend to setiger 1. Peristomial tentacles are smooth and reach setiger 2 (Fig. 9, a \& b).

Parapodia have long, slender and smooth dorsal cirri, sometimes articulated. The ventral cirri are short and conical on the anterior parapodia and digitiform posteriorly (Fig. 9, c). Branchiae begin from setiger 3 as a single filament. The number of branchial filaments increases to become four as a maximum between setigers 13-19, then gradually decreases between setigers 20-30 (Fig. 9, d), and becomes again one from setiger 32 to the posterior end of the fragmentary holotype (Fig. 10).

Subacicular hooks are black, bidentate and hooded (Fig. 9, f). They always occur singly per parapodium from setiger 27 to the posterior end. Acicula are black (Fig. 9, e). Notoacicular setae are embedded in the basal part of the dorsal cirrus. Each pectinate seta has six to eight inner spines and asymmetrical outer extentions (Fig. 9, h). Compound falcigers are bidentate and hooded. The 


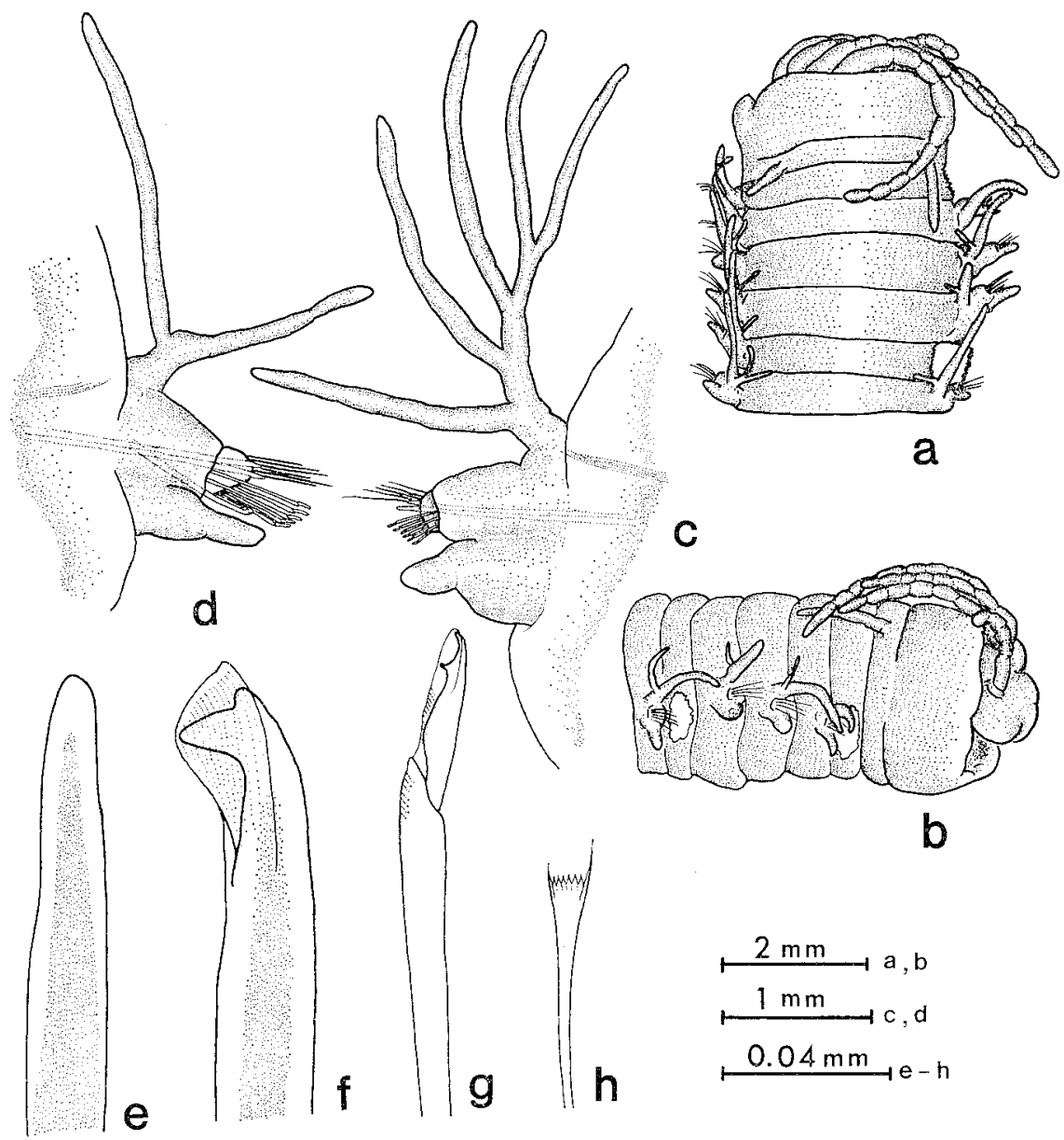

Fig. 9. Eunice northioidea northioidea Moore, 1903. a. Anterior end, dorsal view of the holotype; b. Anterior end, lateral view of the same; c. Parapodium 18, anterior view; d. Parapodium 30; e. Aciculum; f. Subacicular hook; g. Compound falciger; h. Pectinate seta.

blade is long and slender. Two small teeth are separated distantly each other (Fig. $9, g)$.

Remarks. Eunice northioidea sensu Miura (1977a) differs from E. northioidea northioidea Moore, 1903 in having branchiae from setiger 4 with more than ten filaments as a maximum and large teeth and blade of compound falcigers, instead of branchiae from setiger 3 with four filaments as a maximum and small teeth separated each other and slender blade of compound falcigers.

Distribution. Suruga Bay, $119 \mathrm{~m}$ depth, Japan. 


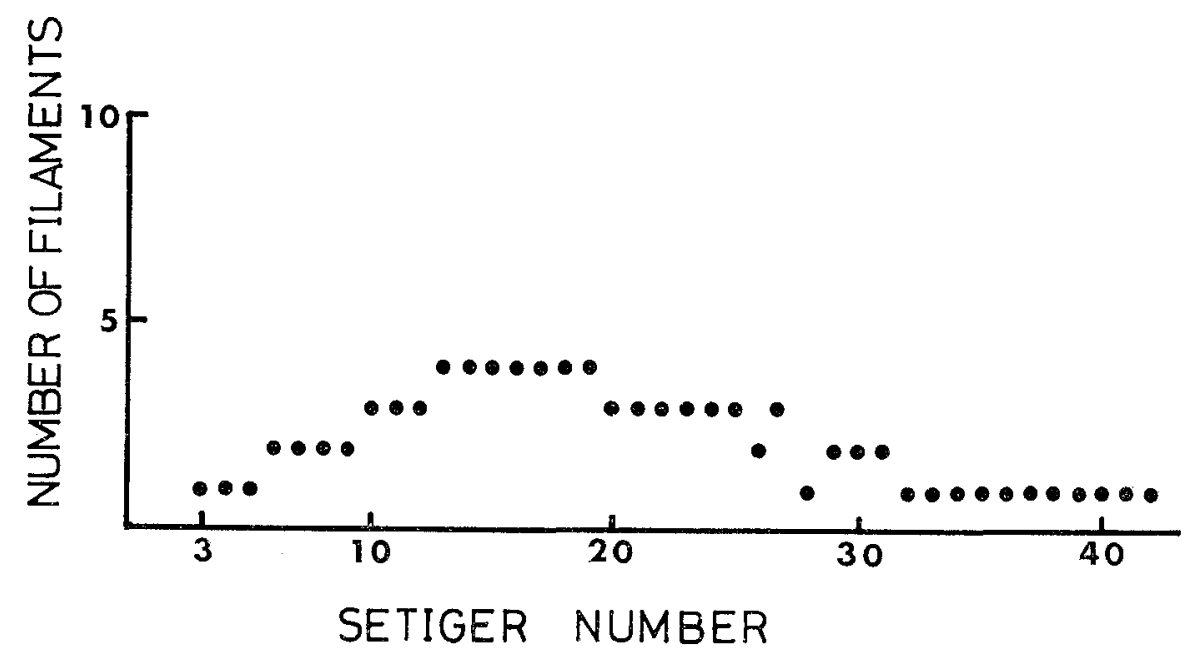

Fig. 10. Branchial distribution in the holotype (USHNM 15728) of Eunice northioidea northioidea Moore, 1903, measuring $4.0 \mathrm{~mm}$ wide with 145 setigers.

\section{Eunice northioidea brevibranchiata subsp. nov.}

(Figs 11 \& 12)

Holotype: NSMT-Pol. H-219, complete female, off Ose-zaki, Suruga Bay, 138-151 m, sand, shells and rocks, collected with many stalked crinoids, "Tansei-Maru" Cruise KT-86-1 Station A-1, $35^{\circ} 03.3^{\prime} \mathrm{N} 138^{\circ} 48.8^{\prime} \mathrm{E}-35^{\circ} 03.0^{\prime} \mathrm{N} 138^{\circ} 47.7^{\prime} \mathrm{E}, 23 \mathrm{Feb} .1896,2 \mathrm{~m}$ beam trawl, RY. Paratypes: USNM incomplete female, complete immature \& incomplete immature, same station as the holotype. Type locality: Suruga Bay, $150 \mathrm{~m}$.

The living animal is pale or colorless except for red branchiae. The holotype is an ovigerous specimen and measures $70 \mathrm{~mm}$ long by $5.0 \mathrm{~mm}$ wide with 71 setigers. The prostomium is incised in the middle and strongly retracted in the peristomial fold. Two black and rounded eyes are situated at the base of inner lateral antennae behind outer antennae. All occipital antennae are long, slender and irregularly annulated. The central three antennae extend to setiger 1 and the outer pair to the first peristomial ring. One of paratypes has longer antennae (Fig. 11, a \& b). The first apodous ring is four times as long as the second. The peristomial cirri are annulated irregularly and reach the middle of prostomium. The pygidium has a pair of long and slender anal cirri (Fig. 11, c).

The first parapodium has an irregularly annulated, very long and slender dorsal cirrus and a cylindrical ventral one (Fig. 11, d). The dorsal cirri become longer on the anterior branchial parapodia (Fig. 11, e), and again become shorter posteriorly (Fig. 11, f \& g). The ventral cirri have basal swellings on the branchial parapodia (Fig. 11, e \& f), and become simple and conical posteriorly (Fig. 11, g). Branchiae are short, stout and poorly developed. They start from setiger 4 in the holotype, while from setigers 4 to 6 in the paratypes. They are simple or bifurcate, and occasionally have as many as three or four filaments per parapodium (Fig. 12). 


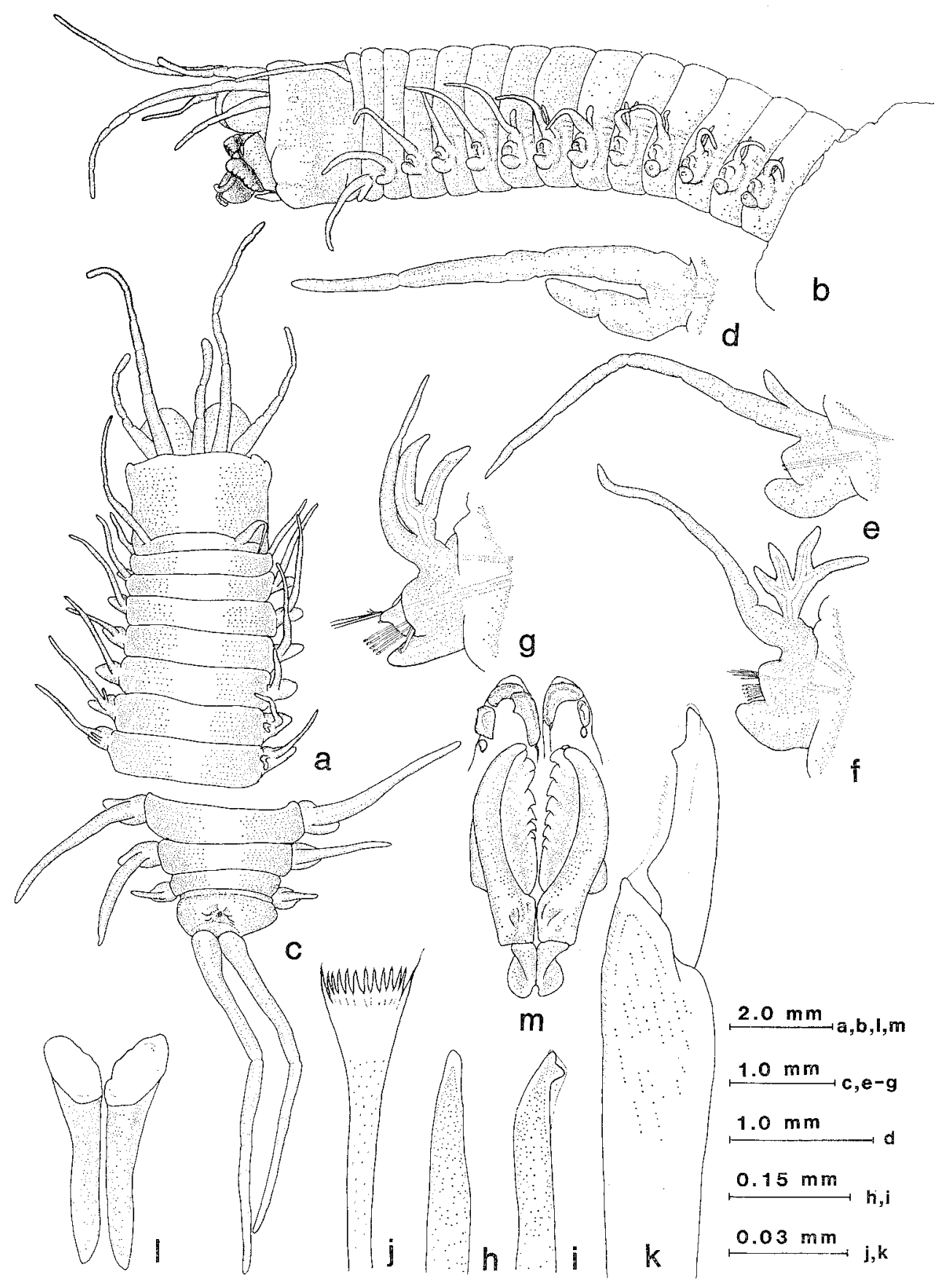

Fig. 11. Eunice northioidea brevibranchiata subsp. nov. a. Anterior end, dorsal view of paratype; b. Lateral view of the same projecting from a bryozoa; c. Posterior end of the holotype; d. First parapodium of the holotype, anterior view; e. Parapodium 4; f. Parapodium 10; g. Parapodium 24; h. Aciculum; i. Subacicular hook; j. Pectinate seta; k. Compound falciger; l. Mandibles; m. Maxillae. 


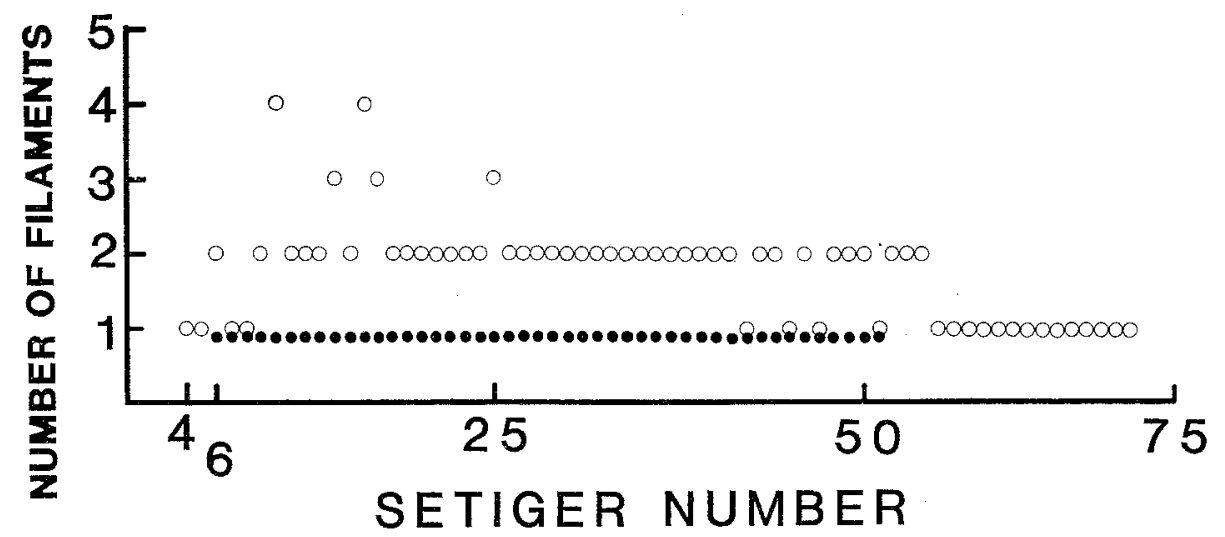

Fig. 12. Branchial distribution in Eunice northioidea brevibranchiata subsp. nov. Open circle, holotype measuring $5.0 \mathrm{~mm}$ wide with 71 setigers; closed circle, immature paratype measuring $4.3 \mathrm{~mm}$ wide with 57 setigers.

Acicula are dark and slightly recurved in the terminal portion (Fig. 11, h). Subacicular hooks are bidentate and hooded (Fig. 11, i). They start from setiger 24 on right and setiger 25 on left in the holotype, and setigers 16-20 in the paratypes. Each pectinate seta has ten to eleven inner teeth and almost symmetrical outer extentions (Fig. 11, j). Compound falcigers are bidentate and hooded. The blade is about a half as wide as the stem, and the two teeth are blunt (Fig. 11, k).

The mandibles are calcified on the cutting edge (Fig. 11, 1). The maxillary formula is: $\mathrm{Mx} . \mathrm{I}=1+1, \mathrm{Mx} . \mathrm{II}=7+8, \mathrm{Mx} . \mathrm{III}=7+0, \mathrm{Mx} . \mathrm{IV}=5+9, \mathrm{Mx} . \mathrm{V}=$ $1+1$ (Fig. 11, m). Posterior to the maxillae $V$, a pair of calcified suports is situated.

Remarks. Eunice northioidea brevibranchiata subsp. nov. is closely related to $E$. northioidea northioidea Moore, 1903 in having long and slender dorsal cirri and poorly developed branchiae. The former differs from the latter in having short and stout branchiae, ten to eleven inner teeth of pectinate setae and short and stout blades of compound falcigers, instead of long and slender branchiae, six to eight inner teeth of pectinate setae and long blades of compound setae. All specimens were anesthetized using 5\% magnesium chloride solution in seawater when collected and the soft body was well retained except for some damaged antennae and parapodia. The short branchiae are thus thought not to be the result of reduction at the time of the fixation. E. northioidea northioidea was erected from a single specimen found off Osezaki, the same locality as in the new subspecies. Although the newly collected specimens are morphologically distinguishable from $E$. northioidea northioidea, a new taxon of species level is not erected and they are included in the same species because of unknown variability of the latter.

Etymology. The subspecific name is derived from the short and stout branchial filament of the new subspecies.

Distribution. Continental shelf in the Pacific coast of Japan, sometimes inhabiting bryozoan colonies. 


\section{Eunice yamamotoi sp. nov.}

(Figs $13 \& 14$ )

Holotype: NSMT-Pol. H-220, female autotomised in three parts, off Kushimoto, Kii Channel, 92-102 m, spoges \& gravels, “Tansei-Maru” Cruise KT-84-12 Station 3-2, 33 $25.9^{\prime} \mathrm{N} 135^{\circ} 43.3^{\prime} \mathrm{E}-$ $33^{\circ} 25.7^{\prime} \mathrm{N}$ 13544.4'E, 30 Aug. 1984, Mikawa dredge, RY. Paratypes: USNM, one incomplete female \& one complete immature, the same station as the holotype. NSMT-Pol. P-221, two immature \& some median fragments, off Kushimoto, Kii Channel, 97-103 m, sponges, coral \& gravels,

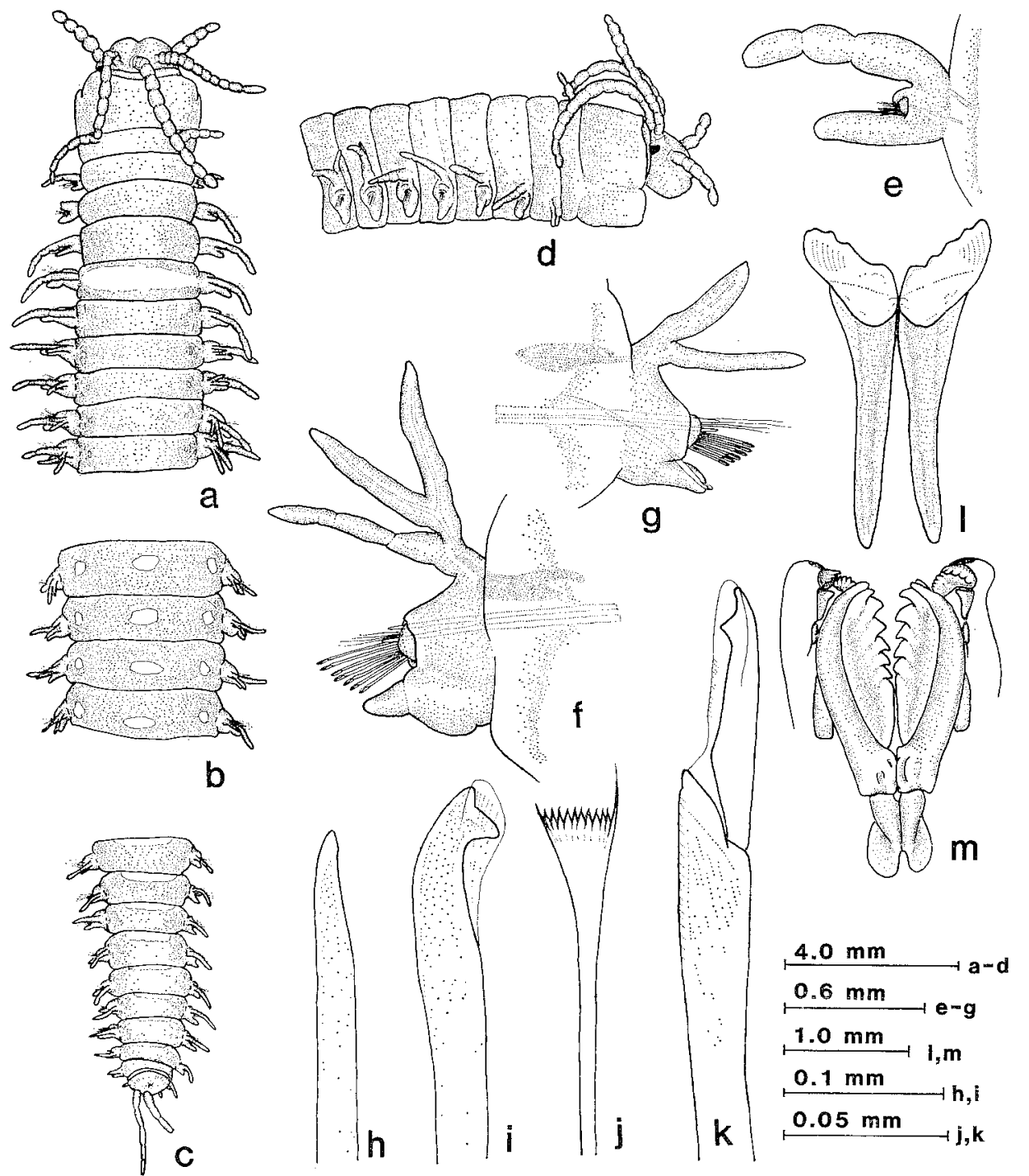

Fig. 13. Eunice yamamotoi sp. nov. a. Anterior end of the holotype, dorsal view; b. Median segments of the same; c. Posterior end of the same; d. Anterior end of the same, lateral view; e. First parapodium, anterior view; f. Parapodium 19; g. Parapodium 56; h. Aciculum; i. Subacicular hook; j. Pectinate seta; k. Compound falciger; 1. Mandibles; m. Maxillae. 
KT-84-12 Station $3-1,33^{\circ} 26.0^{\prime} \mathrm{N} 135^{\circ} 43.0^{\prime} \mathrm{E}-33^{\circ} 25.8^{\prime} \mathrm{N} 135^{\circ} 44.1^{\prime} \mathrm{E}$, 30 Aug. 1984, Mikawa dredge, RY. ORI, three incomplete, off Misaki, $100-120 \mathrm{~m}$, sand and many polychaetae tubes, 10 July 1985, Mikawa dredge, TM. BM, five incomplete containing one female, off Ose-zaki, Suruga Bay, 138-151 m, sand, shells \& rocks, collected with many stalked crinoids, KT-86-1 Station A-1, 35 03.3' $\mathrm{N} 138^{\circ} 48.8^{\prime} \mathrm{E}-35^{\circ} 03.0^{\prime} \mathrm{N} 138^{\circ} 47.7^{\prime} \mathrm{E}, 23 \mathrm{Feb} .1986,2 \mathrm{~m}$ beam trawl, $\mathrm{RY}$.

Type locality: Kii Channel, 92-102 m, Japan.

The holotype is an ovigerous specimen autotomized in three parts at the time of fixation. It measures $67.9 \mathrm{~mm}$ long by $3.7 \mathrm{~mm}$ wide including parapodia, with 97 setigers. The dorsum is pale brown. Setiger 4 has a white band on the dorsum (Fig. 13, a). A lateral pair of white spots appears on each dorsum posterior to setiger 5, and becomes larger in the following setigers (Fig. 13, a \& b). In the middle of the body, another white spot is added on the central of the dorsum in each segment (Fig. 13, b). These three spots are replaced by a short white bar on the posterior segments (Fig. c). The prostomium is two thirds as wide as the peristomium. Two black eyes are situated outside the inner lateral antennae (Fig. 13, d). Occipital antennae are all moniliform, the central one with eleven annulations, the inner lateral pair with seven to eleven and the outer lateral with four to five. The first apodous ring is twice as long as the second. The peristomial cirri have four to five annulations.

The first parapodium has a cylindrical dorsal cirrus and a digitiform ventral one (Fig. 13, e). The dorsal cirri are articulated with one to three annulations on the anterior parapodia (Fig. 13, e \& f). The ventral cirri have basal swellings on the anterior parapodia (Fig. 13,f) and become slender, simple and conical posteriorly (Fig. 13, g).

Branchiae are poorly developed. They always first occur on setiger 6 with a single filament. The maximal number of filaments is two. The bifurcate branchiae arise on the parapodia just posterior to the first simple branchia and continue to setiger 24, then, between setigers 25 and 72 branchiae with single filament occur again (Fig. 14). About thirty posterior parapodia lack branchiae.

Subacicular hooks are black, bidentate and hooded (Fig. 13, i). They occur

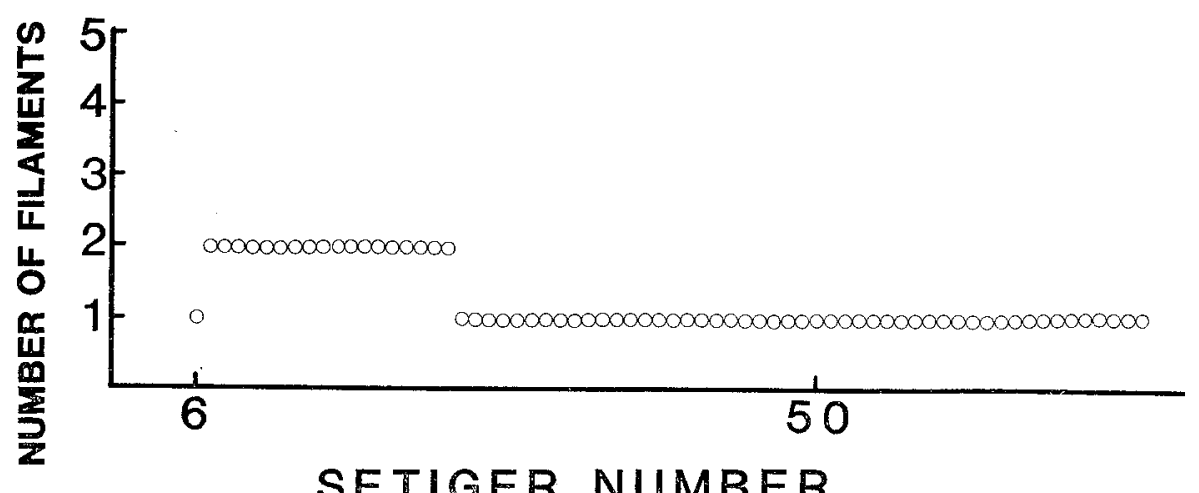

\section{SETIGER NUMBER}

Fig. 14. Branchial distribution in the holotype of Eunice yamamotoi sp. nov, measuring 3.7 $\mathrm{mm}$ wide with 97 setigers. 
singly per parapodium and start on the right parapodium of setiger 23 and on the left of setiger 25 in the holotype. They are first present on setigers $21-24$ in the paratypes. Acicula are also black with recurved tapered ends (Fig. 13, h). Notoacicular setae are embedded in the basal part of the dorsal cirri. At the supracicular position, there are simple capillaries and pectinate setae with about ten inner teeth and asymmetrical outer extentions (Fig. 13, j). Compound falcigers are bidentate and hooded. The blade is long, slender and about a half as wide as the stem. The two small teeth are separated distantly each other (Fig. 13, k).

The maxillary formula is: $\mathrm{Mx} . \mathrm{I}=1+1, \mathrm{Mx} . \mathrm{II}=6+6, \mathrm{Mx}$. III $=8+0, \mathrm{Mx}$. IV $=5+8, \mathrm{Mx} . \mathrm{V}=1+1$ (Fig. 13, m). White small supporting plates are situated posterior to the maxillary plate V. Mandibles have seven striations on the distal cutting edge under the calcareous plates in the holotype (Fig. 13, 1). The pygidium has two very short ventral anal cirri and long, articulated dorsal ones (Fig. 13, c).

Remarks. The new species is similar to Leodice armillata Treadwell, 1922 in having moniliform antennae and poorly developed branchiae starting from setiger 6 , but differs from the latter in having white setiger 4 and black acicula instead of white setiger 2 and yellow acicula. E. yamamotoi sp. nov. is closely related to $E$. parauensis Okuda, 1937 in having poorly developed branchiae from setiger 6-8 and dark bidentate subacicular hooks. However, the former has moniliform antennae and asymmetrical maxillae, differing from the latter that has smooth or faintly articulated antennae and symmetrical maxillae.

Etymology. The new species is affectionately named for Mr. Ryuta Yamamoto who supplied me many materials examined in this study.

Distribution. Shallow depth on continental shelf of Pacific coast of Japan.

\section{Eunice quinquifida Moore, 1903}

(Figs $15 \& 16$ )

Eunice quinquifida Moore, 1903, pp. 435-437, pl. 25, figs 39-41.

Holotype: USNM 15714, incomplete, immature, Sagami Bay, $153 \mathrm{fms}(280 \mathrm{~m})$, green mud, volcanic ashes and sand, 5 May 1900, "Albatross" Station 3698.

New record. NSMT, incomplete, immature, off Misaki, Sagami Bay, 70 m, oyster shells, 1 Apr. 1981, Mikawa dredge, TM.

The holotype is an anterior fragment with 54 setigers and measures $44 \mathrm{~mm}$ long by $4.0 \mathrm{~mm}$ wide. The specimen from off Misaki is larger than the holotype and measures $65 \mathrm{~mm}$ long by $9.0 \mathrm{~mm}$ wide with 69 setigers lacking considerable segments of the posterior end. The prostomium is divided into two lobes in the holotype and into four in the larger specimen. Two eyes are present, but obscure. Central three antennae are roughly equivalent in length and extend to setigers 3-4. Each of the central anntennae has five to seven articulations in the holotype (Fig. $15, \mathrm{~b})$. The new specimen has rather long antennae in which the central one has 


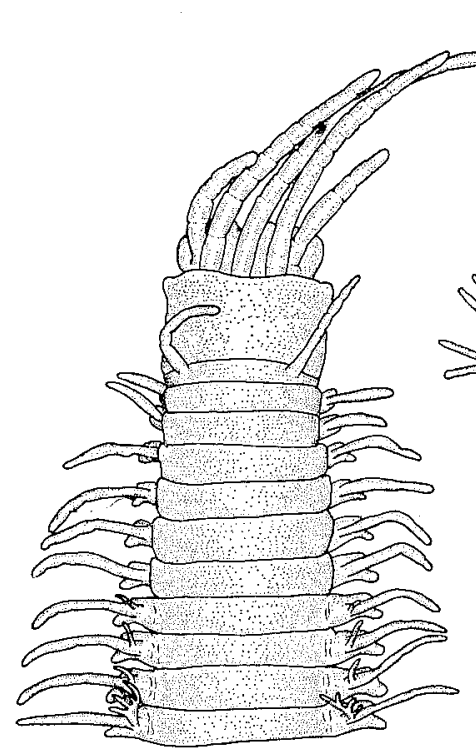

a

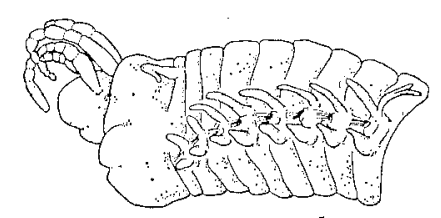

b
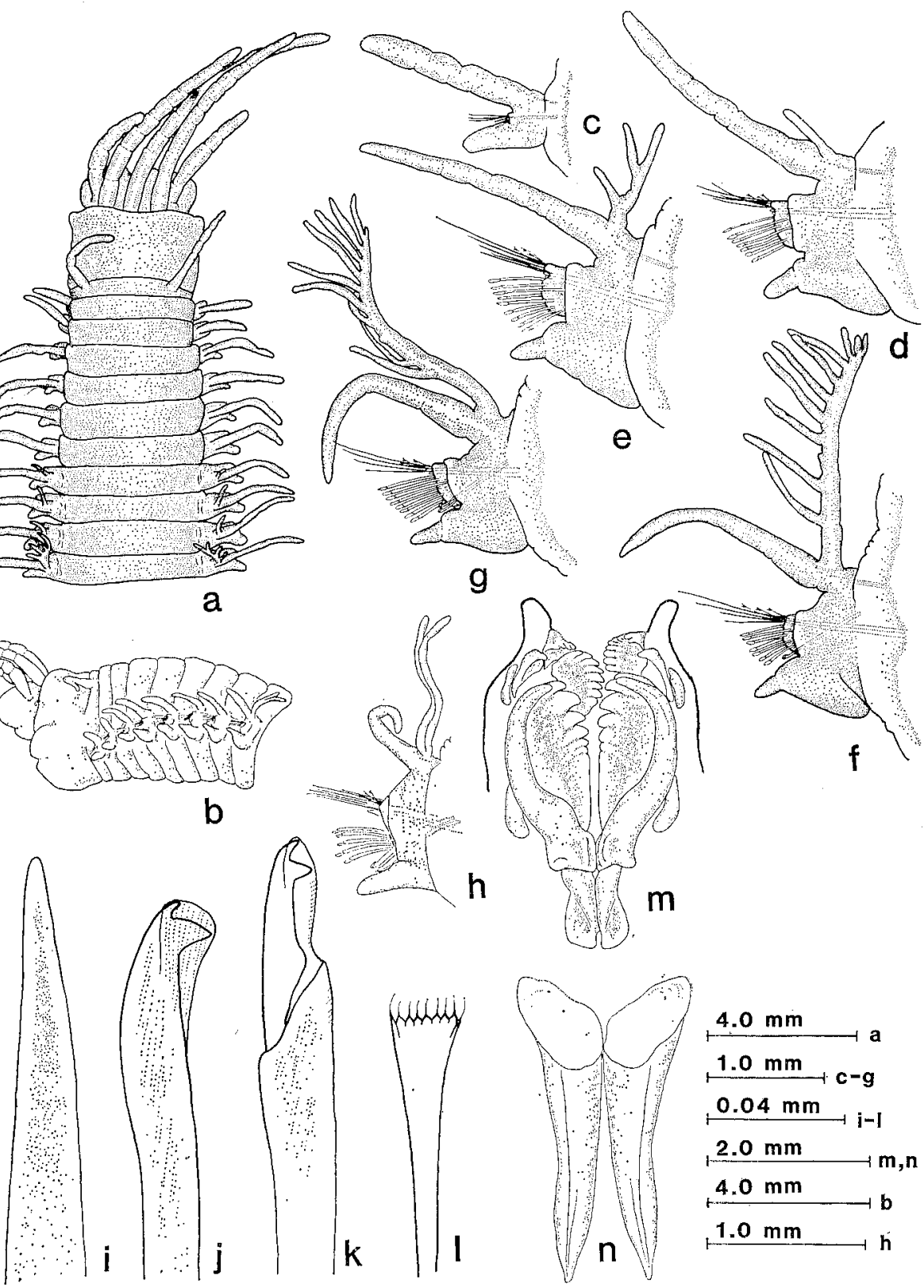

$\mathrm{m}$
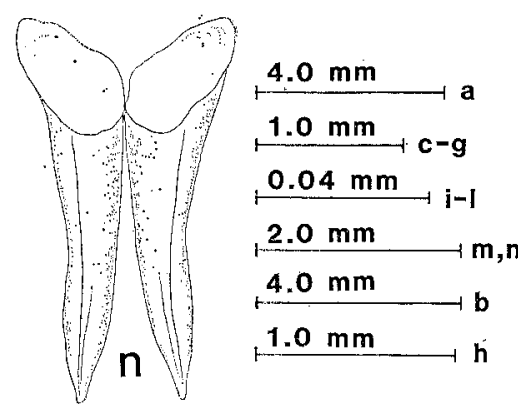

Fig. 15. Eunice quinquifida Moore, 1903. a. Anterior end of the specimen from off Misaki; b. Anterior end of the holotype; c. First parapodium of the specimen from off Misaki, anterior view; d. Parapodium 7; e. Parapodium 10; f. Parapodium 30; g. Parapodium 40; h. Parapodium 48 of the holotype; i. Aciculum; j. Subacicular hook; k. Compound falciger; 1 . Pectinate seta; $m$. Maxillae of the speciment from off Misaki; n. Mandibles of the same. 
eleven articulations and reaches setiger 7 (Fig. 15, a). Outer lateral antennae with three to five articulations extend to setigers 1-2. Peristomial cirri are smooth and reach setiger 2.

Parapodia has long dorsal and conical ventral cirri. The dorsal cirri are crumpled on the anterior setigers (Fig. 15, c-e) and smooth posteriorly (Fig. 15, f \& g). The ventral cirri have basal swellings at the branchial region (Fig. 15, d-g). They become simple and digitiform on the far posterior parapodia (Fig. $15 \mathrm{~h}$ ).

The first branchia occurs on setiger 7 with two filaments in the holotype or with a single filament in the other specimen. The number of branchial filaments increases on the anterior parapodia, exceeds five between setigers 12 and 23, and then gradually decrease to the posterior end of the fragmentary holotype. In the larger specimen, the branchiae are more developed and have maximally eleven filaments per parapodium (Fig. 16).

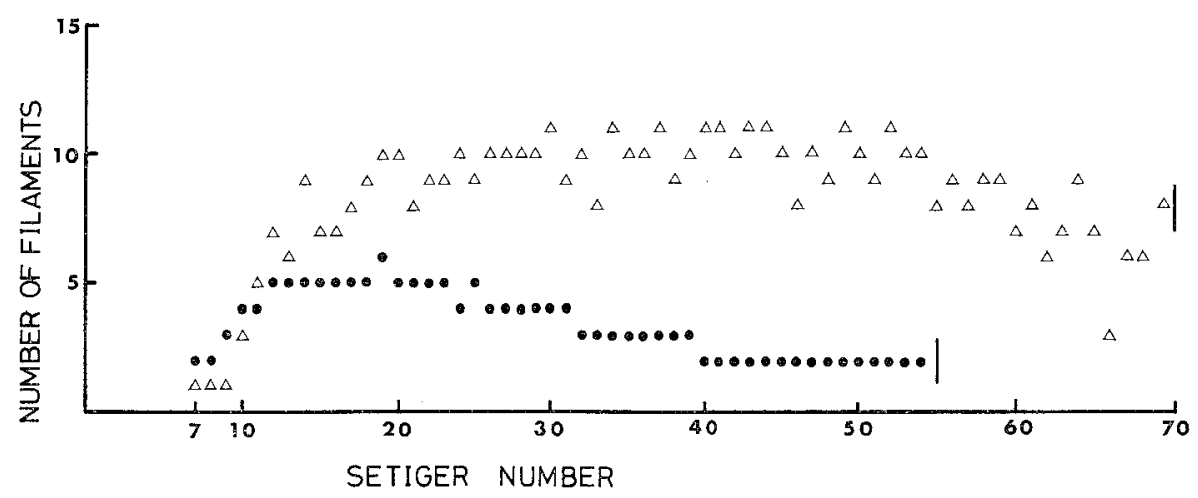

Fig. 16. Branchial distribution in Eunice quinquifida Moore, 1903. Closed circle, the holotype measuring $44 \mathrm{~mm}$ long by $4.0 \mathrm{~mm}$ wide, anterior fragment with 54 setigers; open triangle, specimen from off Misaki. $65 \mathrm{~mm}$ long by $9.0 \mathrm{~mm}$ wide, anterior fragment with 69 setigers.

Subacicular hooks are black, bidentate and hooded (Fig. 15, j). The first hook occurs on parapodium 30 in the left and on parapodium 31 in the right in the holotype. The number of hooks is one per parapodium at the beginning of occurrence and sometimes two on the posterior setigers such as setigers 44, 46-48 and 51 in the holotype. Acicula are black (Fig. 15, i). Each pectinate seta has nine inner teeth and almost symmetrical outer extentions (Fig. 15, 1). Compound falcigers are bidentate and hooded (Fig. 15, k).

Maxillary formula is $\mathrm{Mx} . \mathrm{I}=1+1, \& 1+1, \mathrm{Mx}$. II $=6+5 \& 6+6, \mathrm{Mx}$. III $=$ $8+0 \& 8+0, \mathrm{Mx} . \mathrm{IV}=5+11 \& 4+13, \mathbf{M x} . \mathrm{V}=1+1 \& 1+1$, in the holotype and in the new specimen, respectively (Fig. 15, m). Mandibles are broad and well calcified at the cutting edge (Fig. 15, n).

Remarks. Eunice quinquifida is closely related to E. contigens (Chamberlin, 1919) and E. multipectinata Moore, 1911 in having black and bidentate subacicular hooks and branchiae from setiger 7 . The first species differs from the second in having 
articulated occipital antennae instead of smooth ones and from the third in bearing the simple or bifurcate first branchia instead of the pectinate one.

Ditstribution. Sagami Bay, 70-280 m, Japan.

\section{Eunice (Nicidion) cariboea Grube, 1856}

(Fig. 17)

Eunice cariboea Grube, 1856, p. 57.

Eunice (Nicidion) cariboea: Hartman, 1944, pp. 123-124, pl. 7, figs 157-163, pl. 8, fig. 8; Miura, 1977b, pp. 67-69. fig. 3, a-n.

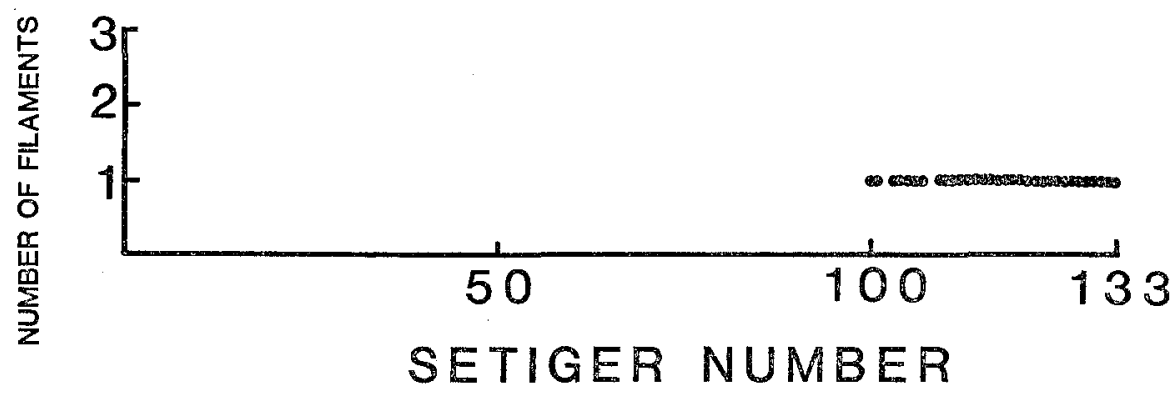

Fig. 17. Branchial distribution in specimen numbered E-136 from Kominato (Miura, $1977 \mathrm{~b}$ ) of Eunice (Nicidion) cariboea Grube, 1856, measuring $1.5 \mathrm{~mm}$ wide with 133 setigers.

Remarks. This species was recorded from Kominato (Miura, 1977b). Here only the branchial distribution is represented in Fig. 17. In the species, branchiae appear only on far posterior parapodia and they are always simple.

Distribution. West Indies, Gulf of California, Japan, in shallow depth.

\section{Eunice kobiensis McIntosh, 1885}

(Figs $18 \& 19$ )

Eunice kobiensis McIntosh, 1885, pp. 278-280, figs 37-38, pls 38, figs 12-13 \& 20A, figs 1-3; Fauchald, 1969, pp. 4-6, fig. 2. a-g; Miura, 1977a, pp. 15-17, fig. 7.

Eunice gracilis Moore, 1903, pp. 440-441, pl. 25, figs 46-48.

New records. USNM, seven incomplete containing one female, in a drainage way, Otsuchi Marine Laboratory, ORI, Iwate, 4 Oct. 1984, RY. USNM, complete female, Nanamodori, Otsuchi Bay, $7 \mathrm{~m}$, under a boulder, 23 Aug. 1980, TM. ZUMT, two complete \& one incomplete, the third coast battery, Tokyo Bay, July 1979, TM. ZUMT, complete, off Misaki, Sagami Bay, 70 m, oyster shells, 1 Apr. 1981, Mikawa dredge, TM. BM, complete, Aburatsubo, intertidal, under boulder, 18 Jan. 1980, TM. BM, two females, three males \& five immature, all incomplete, off Tsukumi, Bungo Channel, 72-76 m, coarse sand with pebbles, "Tansei-Maru" Cruise KT-84-12 Station 31, 33'02.2’ N $132^{\circ} 05.5^{\prime} \mathrm{E}-33^{\circ} 02.2^{\prime} \mathrm{N} 132^{\circ} 05.4^{\prime} \mathrm{E}$, 4 Sep. 1984 , ORI dreedge, RY. ORI, complete, off Tomioka, 42-45 m, gravels, 1 June 1984, dredge, TM. ORI, incomplete, off Oki Is., Japan Sea, 63-70 m, sand, 23 July 1984, dredge, MY.

Holotype of Eunice gracilis Moore, 1903, USNM 15724, complete, immature, off Omae-zaki, Japan, 34-37 fathoms (62-68 m), mud, gravels and rocks, "Albatross" Station 3730 . 


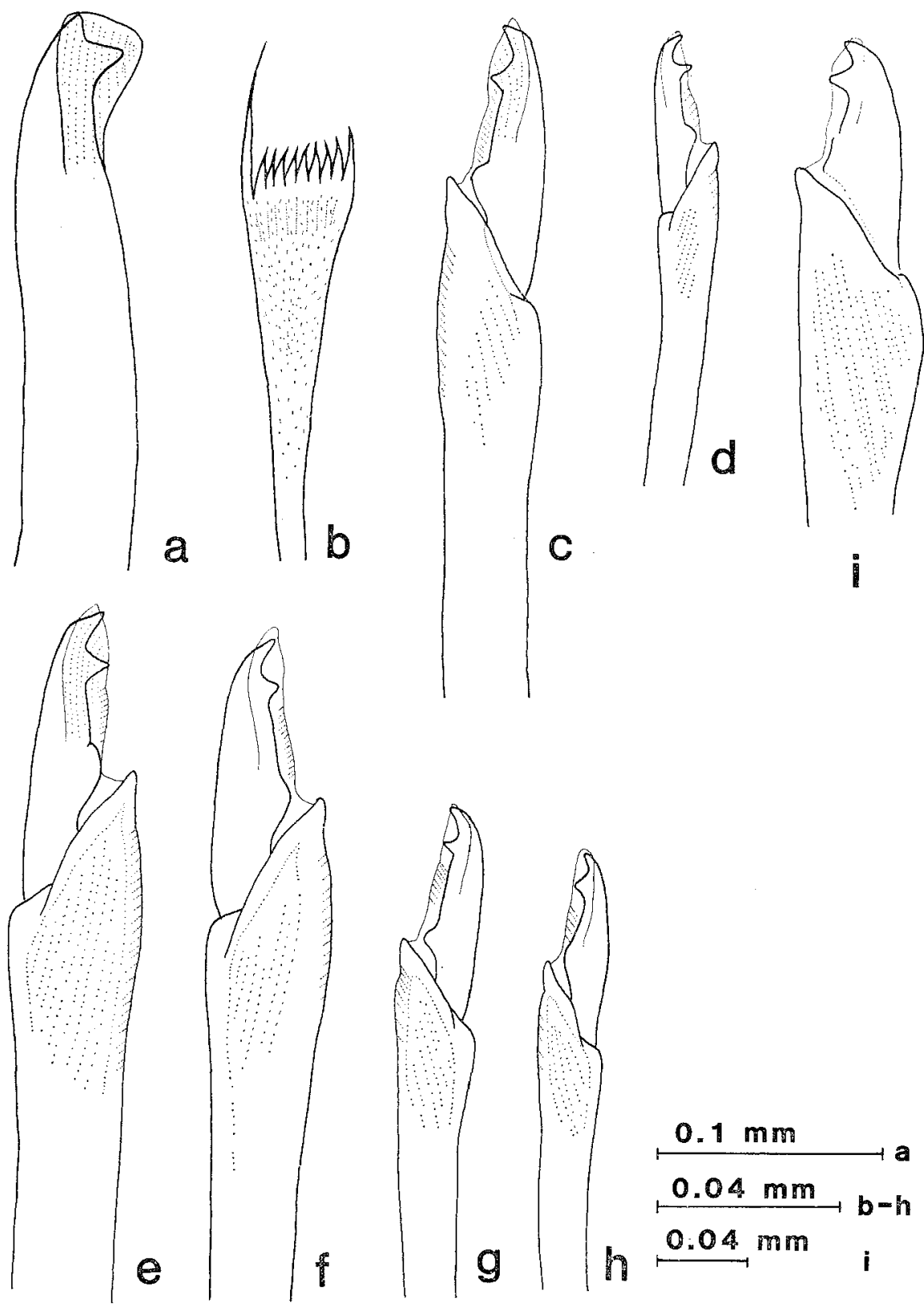

Fig. 18. Eunice kobiensis McIntosh, 1885. a. Subacicular hook in a large specimen from Otsuchi; b. Pectinate seta in the same; c. Compound falciger in the same; d. Compound falciger in a small specimen from Otsuch;; e. Compound falciger on an anterior parapodium in a large specimen from Aburatsubo; f. Compound falciger on a posterior parapodium in the same; $g$. Compound falciger on an anterior parapodium in a small specimen from Aburatsubo; $h$. Compound falciger on a posterior parapodium in the same; i. Compound falciger designed after the photograph in Gustus (1972, fig. 2, c). 
More than twenty specimens are newly recorded from Japanese coastal waters. The branchiae start always from setiger 3 and disappear after about setiger 60 . The maximal number of filaments varies from seven to thirteen depending on the size of specimen (Fig. 19). Bidentate subacicular hooks start on setigers 30-40 (Fig. 18, a). Each pectinate seta has eight inner teeth and asymmetrical lateral extentions (Fig. 18, b). Compound falcigers are bidentate and hooded (Fig. 18, c-h).

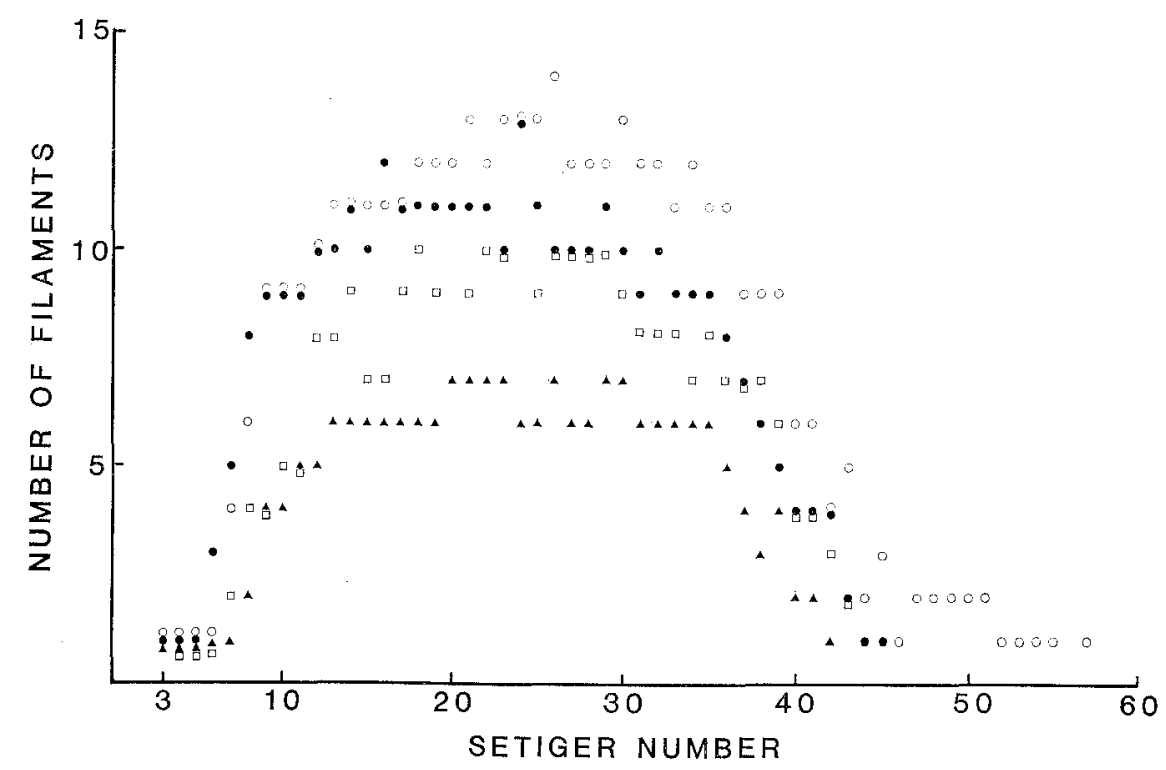

Fig. 19. Branchial distribution in Eunice kobiensis McIntosh, 1885. Open circle, specimen E-59 in Miura (1977a), measuring $4.5 \mathrm{~mm}$ wide with 142 setigers; closed circle, specimen E-128 in Miura (1977a), $4.9 \mathrm{~mm}$ wide with 135 setigers; triangle, specimen from off Misaki, $3.0 \mathrm{~mm}$ wide with 86 setigers; open square, the holotype of Eunice gracilis Moore, 1903 (USNM 15724).

Remarks. Eunice kobiensis was erected by McIntosh (1885) using an incomplete small specimen collected from off Kobe in Seto Inland Sea. The taxonomic discussion of this species has been made by Berkeley \& Berkeley (1948), Uschakov (1955), Fauchald (1969; 1970), Fauchald \& Hancock (1981) and Gustus (1972) without using adequate specimens from the type locality or adjacent areas except for the holotype.

The blades in the specimens collected from Japanese coasts are always longer than that of the specimens from the Gulf of Alaska (Fig. 18, i). The specimens reported by Berkeley \& Berkeley (1948) and Gustus (1972) are thus considered to differ from E. kobiensis.

Although Imajima \& Hartman (1964) have suggested E. kobiensis as synonymous with E. longicirrata Webster (1884), the former differs from the latter in having faintly annulated dorsal cirri on the anterior parapodia instead of well articulated ones as mentioned by Fauchald (1969).

The type of $E$. gracilis Moore, 1903 is a complete specimen measuring about 50 $\mathrm{mm}$ long by $4 \mathrm{~mm}$ wide with 104 setigers. All morphological characters of this 
species are well fit to that of $E$. kobiensis except for the first occurrence of branchiae. The first branchia occurs on setiger 4 in E. gracilis instead of setiger 3 in E. kobiensis, but the distribution patterns of branchiae are quite similar in these species (Fig. 19). In addition, the first three to four branchiae are always less developed or rudimentary in both species. According to Fauchald (1970), larger specimens apparently lose these first simple or rudimentary branchiae in many species. The difference between $E$. kobiensis and E. gracilis are very slight and as a result, the two species are considered synonymous.

Distribution. Seto Inland Sea, Pacific coast of Japan, Japan Sea, intertidal to shallow waters.

\section{Eunice gracilicirrata (Treadwell, 1922)}

(Fig. 20)

Leodice gracilicirrata Treadwell, 1922, pp. 149-150, figs 36-38, pl. 5, figs 1-8.

Eunice gracilicirrata: Miura, 1979, pp. 35-37, fig. 2, a-r.

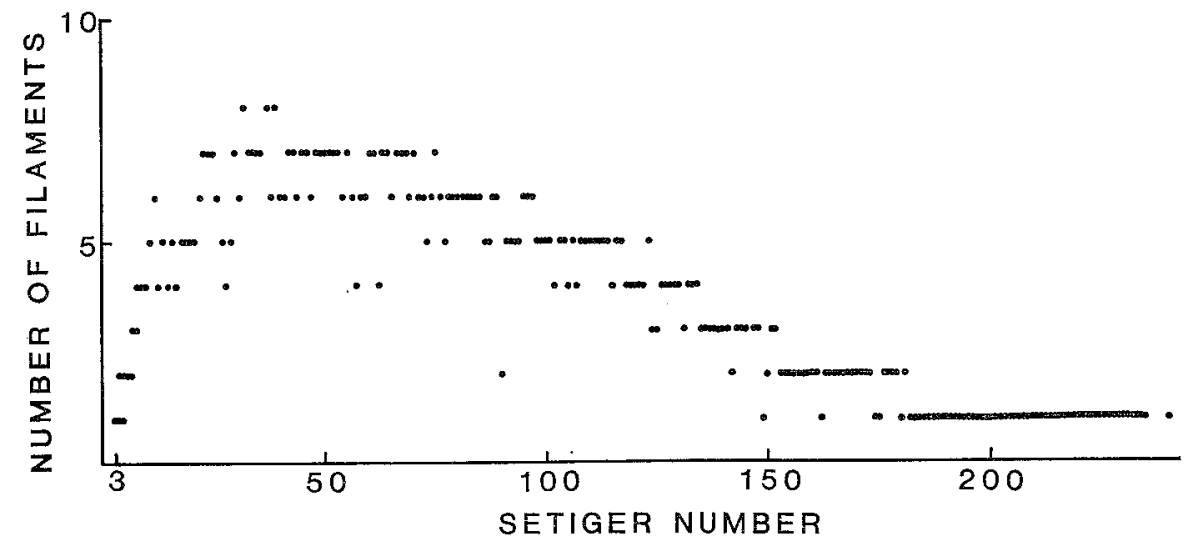

Fig. 20. Branchial distribution in specimen E-193 (Miura, 1979) of Eunice gracilicirrata (Treadwell, 1922), measeuring $6.0 \mathrm{~mm}$ wide with 343 setigers.

Remarks. The species has been reported previously from Ishigaki Island (Miura, 1979). Here the branchial distribution is represented in Fig. 20. Branchiae occur from setiger 3 to setiger 239 in the specimen with 343 setigers. The maximal number of filaments is eight.

Distribution. Fiji, southern Japan, coral reef, intertidal to shallow water.

\section{Eunice antennata (Savigny, 1818)}

(Fig. 21)

Leodice antennata Savigny, 1818, p. 322. 
Eunice antennata: Okuda, 1938, p. 96; Imajima, 1967, pp. 433-435, fig. 10, a-n; Miura, 1977a, pp. $7-9$, fig. 3, a-l (in partim).

New records. USNM, complete female, from an abalone rearing tank, Kominato, Chiba, 15 Aug. 1984, IH. USNM, complete, immature, Kominato, 3 m, under boulder, 17 Oct. 1983, TM. USNM, complete, immature, off Aburatsubo, rocky bottom, $5 \mathrm{~m}$, in Ecklonia forest, 10 Aug. 1984, TM. USNM, incomplete, Akase, Nomo-zaki, Nagasaki, intertidal rocky shore, 01 July 1984, TM. BM, one complete \& five incomplete, Shishiki-jima, Oki Is., Japan Sea, intertidal rocky shore, 22 July 1984, MY.

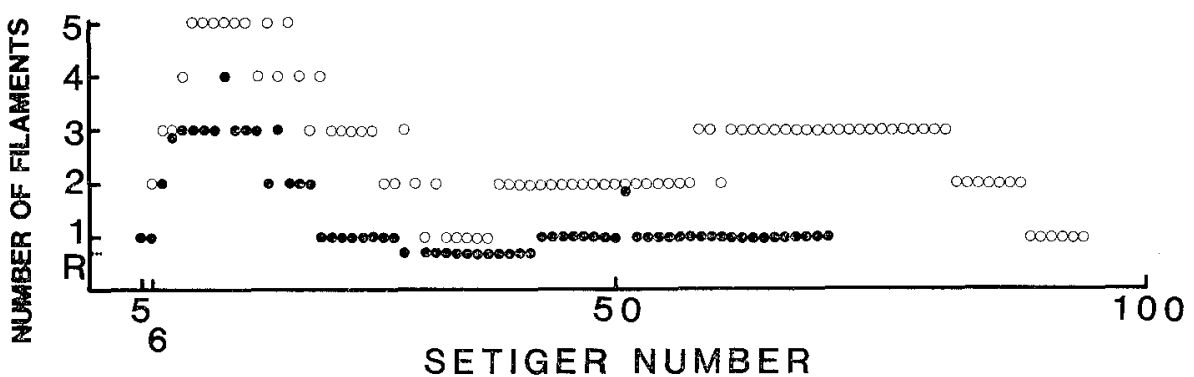

Fig. 21. Branchial distribution in Eunice antennata (Savigny, 1818). Open circle, specimen E-49 in Miura (1977a), measuring $4.2 \mathrm{~mm}$ wide with 94 setigres; closed circle, specimen E-2 in Miura (1977a), $2.7 \mathrm{~mm}$ wide with 77 setigers.

Remarks. Eunice antennata (Savigny, 1818) is characterized by the bimodal distribution of branchiae (Fig. 21), though the first occurrence of branchiae varies between setigers 5 to 7 . The hammer-shaped acicula of this species is a unique character in Japanese species of the genus. This point was confused in my previous paper (Miura, 1977a) and the specimens numbered E-130 to E-133 and E-172 to E-179 should be excluded from the species. Eunice antennata are common among seaweed roots from intertidal to subtidal hard bottoms in Japan. This species does not make a tube.

Distribution. Gulf of Suez, Indo-Pacific area; southern Pacific coast of Japan, Japan Sea, intertidal to sallow waters.

\section{Eunice annulicirrata sp. nov.}

(Figs $22 \& 23$ )

Eunice australis: Miura, 1977a, p. 13, fig. 5, a-j. (not Quatrefages, 1865)

Eunice antennata: Miura, 1977a, pp. 7-9, fig. 3, a-1. (in partim, not Savigny, 1818)

Holotype: NSMT-Pol. H-222, complete, immature, with the tube, Tsuji-shima, Amakusa, intertidal rocky shore, under a boulder, 3 June 1984, TM. Paratypes: USNM, one female \& one immature, both incomplete, south off Tsuma, Oki Is., Japan Sea, 37-40 m, gravels, 23 July 1984, dredge, MY.

Type locality: Amakusa, intertidal rocky shore, Japan.

The holotype is a complete but sexually immature specimen with 104 setigers and measures $58 \mathrm{~mm}$ long by $4.5 \mathrm{~mm}$ wide. One of the paratypes is ovigerous. 
The paratypes are incomplete and smaller than the holotype. The prostomium has a bifid, narrow and round anterior end which looks truncate in lateral view (Fig. 22, a \& b). Two eyes are situated outside the inner lateral antennae. Occipital antennae are moniliform. The central three antennae with 27-29 annulations extend

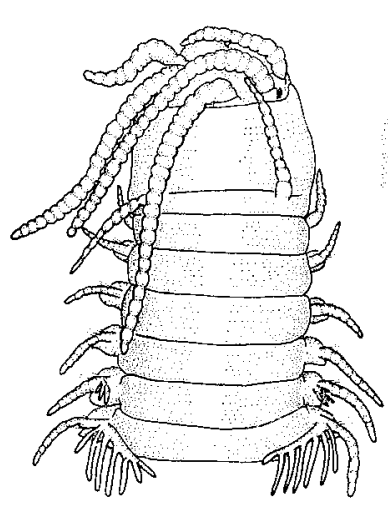

a
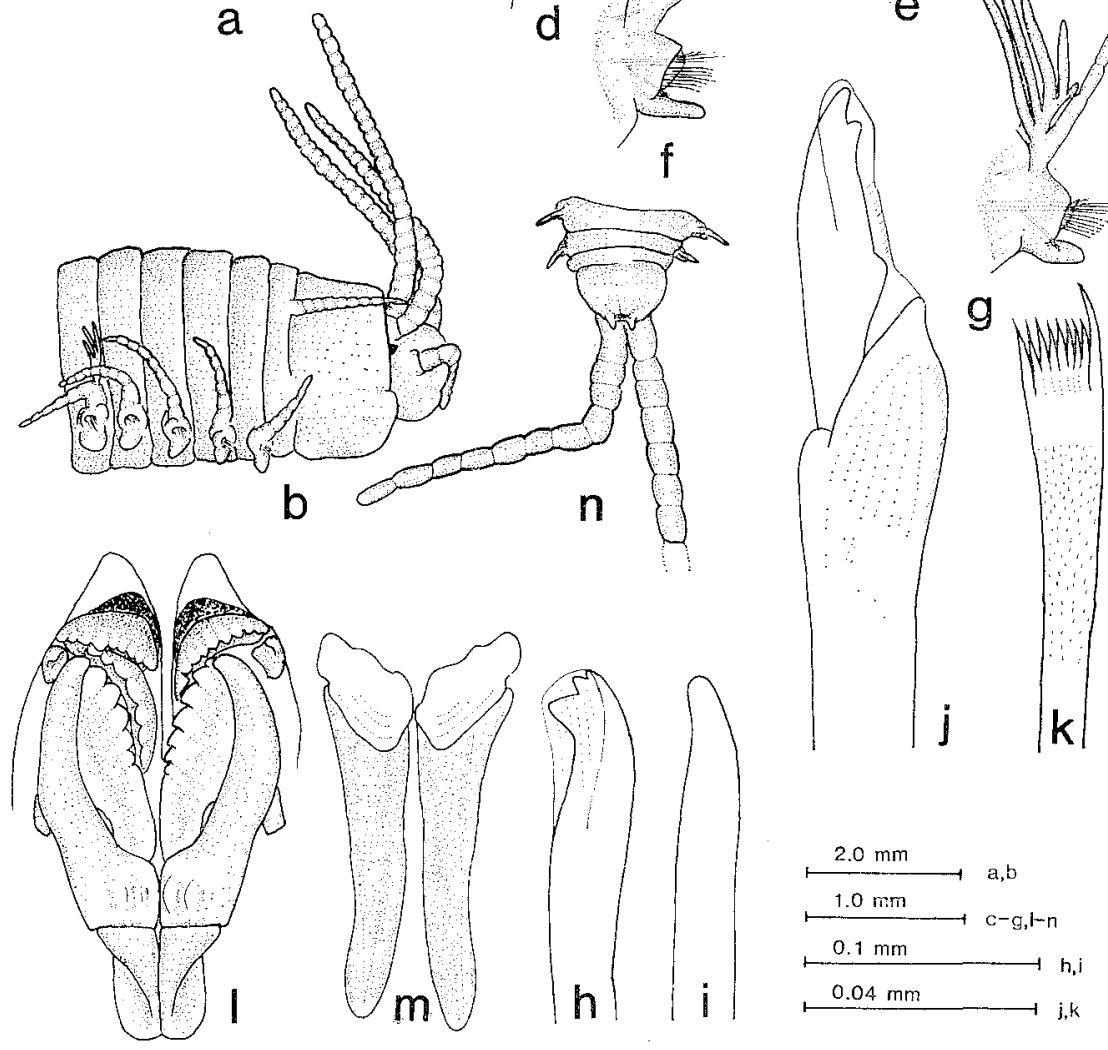

Fig. 22. Eunice annulicirrata sp. nov. a. Anterior end, dorsal view; b. The same, laferal view; c. First parapodium; d. Parapodium 5; e. Parapodium 11; f. Parapodium 39; g. Parapodium 88; h. Subacicular hook; i. Aciculum; j. Pectinate seta; k. Compound falciger; l. Maxillae; m. Mandibles; n. Pygidium. 
to setiger 4, while the outer lateral pair with 13-14 annulations reach the first peristomial ring. The first peristomial ring is three times as long as the second. Peristomial tentacles are also moniliform with 11 annulations and extend to setiger 3.

The first parapodium (Fig. 22, c) has a cylindrical and articulated dorsal cirrus and a digitiform ventral one. The dorsal cirri become slender on the posterior parapodia. They are always articulated and the number of joints is six to eight at the anterior branchial region, while only three posteriorly (Fig. 22, c-g). The ventral cirri have basal swellings at the anterior branchial region (Fig. 22, d \& e), and become simple posteriorly (Fig. 22, f \& g).

Branchiae are first present from setiger 5 in having three filaments (Fig. 22, c). The branchial distribution is bimodal (Fig. 23). The maximal number of filaments is eleven to twelve in setigers 10-12. Branchiae are less developed with three filaments at the middle body region between setigers 35 and 63 and well developed again with five to seven filaments at the region between setigers 70 and 90 .

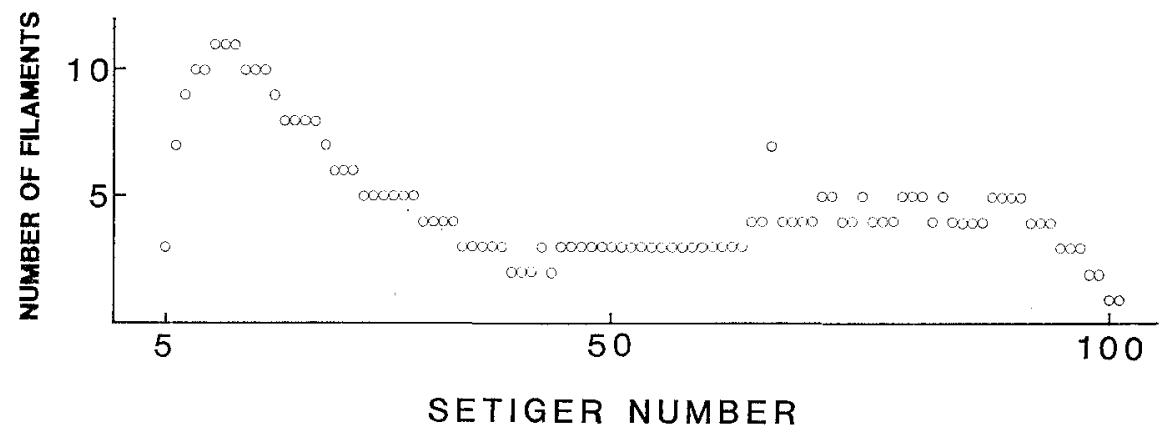

Fig. 23. Branchial distribution in the holotype of Eunice annulicirrata sp. nov., measuring $4.5 \mathrm{~mm}$ wide with 104 setigers.

Subacicular hooks are yellow, tridentate and hooded (Fig. 22, h). They start on setiger 23 and occur singly per parapodium though occasionally two were seen on the posterior parapodia. Acicula are also yellow. Their distal ends are tapered and rounded (Fig. 22, i). Notoacicular setae are embedded in the basal part of the dorsal cirri. At the supracicular position, there are simple capillaries and pectinate setae with seven to eight inner teeth and asymmetrical outer extentions (Fig. 22, j). Compound falcigers are bidentate and hooded (Fig. 22, k), but occasionally the proximal tooth was subdivided into two teeth which form a tridentate state in the blades of falcigers as described by Miura (1977a, p. 13, Fig. 5, i-2).

The maxillary formula is: $\mathrm{Mx} . \mathrm{I}=1+1, \mathrm{Mx} . \mathrm{II}=5+7, \mathrm{Mx} . \mathrm{III}=7+0, \mathrm{Mx}$. $I V=8+10, \mathrm{Mx} . \mathrm{V}=1+1$ (Fig. 22, 1). Mandibles are well calcified on the anterior edge (Fig. 22, m). The pygidium has a pair of moniliform anal cirri with about ten articulations (Fig. 22, n). The tube consists of large sand grains, shells and pebbles.

Remarks. Eunice annulicirrata sp. nov. is closely related to E. antennata (Savigny, 1818 ) in having moniliform antennae and bimodal distribution of branchiae. The 
new species differs from the latter in having articulated dorsal cirri instead of smooth ones and also tapered and rounded ends of acicula instead of hammer-shaped ones. The new species is tubicolous and in this point, can be also distinguished from $E$. antennata. In my previous paper (Miura, 1977a), some specimens of this new species from Suruga Bay numbered E130-E133 were confused with $E$. antennata.

Etymology. The specific name is derived from the well articulated dorsal cirri of the new species.

Distribution. Pacific coast of southern Japan, Japan Sea, intertidal to shallow water, under boulders on the rocky shore and on the bottom of gravels.

\section{Eunice fauchaldi sp. nov.}

(Figs 24-27)

Holotype: NSMT-Pol. H-223, complete female, off Tanabe, Kii Channel, 134-135 m, grayish fine muddy sand, "Tansei-Maru” Cruise KT-84-12 Station 25, 3339.6'N $135^{\circ} 12.2^{\prime} \mathrm{E}-33^{\circ} 39.7^{\prime} \mathrm{N}$ $135^{\circ} 11.6^{\prime} \mathrm{E}, 02$ Sep. 1984, $2 \mathrm{~m}$ beam trawl, RY. Paratypes: USNM, ten males and ten females, the same station as the holotype. NSMT-Pol. P-224, seven males, ten females, twenty-five immature, the same station as the holotype. ORI, male, off Kushimoto, Kii Channel, 97-103 m, sponge, coral and gravels, Station $3-1,33^{\circ} 26.0^{\prime} \mathrm{N} 135^{\circ} 43.0^{\prime} \mathrm{E}-33^{\circ} 25.8^{\prime} \mathrm{N} 135^{\circ} 44.1^{\prime} \mathrm{E}, 30$ Aug. 1984, Mikawa dredge, RY. ORI, immature, off Kushimoto, $92-102 \mathrm{~m}$, sponge and gravels, Station $3-2,33^{\circ} 25.9^{\prime} \mathrm{N} 135^{\circ}$ $43.3^{\prime} \mathrm{E}-33^{\circ} 25.7^{\prime} \mathrm{N} 135^{\circ} 44.4^{\prime} \mathrm{E}$, 30 Aug. 1984, Mikawa dredge, RY. ZMG, female, off Susami, Kii Channel, 100-101 $\mathrm{m}$, shell and sandy mud, Station $12-1,33^{\circ} 29.9^{\prime} \mathrm{N} 135^{\circ} 30.9^{\prime} \mathrm{E}-33^{\circ} 30.0^{\prime} \mathrm{N} 135^{\circ} 30.7^{\prime} \mathrm{E}$, 31 Aug. 1984, ORI Dredge, RY. BM, two females, one male and three immature, off Susami, 144$146 \mathrm{~m}$, shell and gravels, Station $13-2,33^{\circ} 29.2^{\prime} \mathrm{N} 135^{\circ} 30.5^{\prime} \mathrm{E}-33^{\circ} 29.5^{\prime} \mathrm{N} 135^{\circ} 29.3^{\prime} \mathrm{E}, 31$ Aug. 1984, Mikawa dredge, RY. ZMO, thirteen males, seven ferrales, nineteen immature, off Tanabe, Kii Channel, 119-120 m, grayish fine muddy sand, Station $24,33 .^{\circ} 40.4^{\prime} \mathrm{N} 135^{\circ} 12.8^{\prime} \mathrm{E}-33^{\circ} 04.8^{\prime} \mathrm{N} 135^{\circ}$ $12.3^{\prime} \mathrm{E}, 2$ Sep. 1984, $2 \mathrm{~m}$ beam trawl, RY. ORI, two females, ten immature, all incomplete, off Tsukumi, Bungo Channel, $72-76 \mathrm{~m}$, coarse sand with pebbles, Stations $31,33^{\circ} 02.2^{\prime} \mathrm{N} 132^{\circ} 05.5^{\prime} \mathrm{E}-$ $33^{\circ} 02.2^{\prime} \mathrm{N} 132^{\circ} 05.4^{\prime} \mathrm{E}, 4$ Sep. 1984, ORI dredge, RY. ZMG, three complete and twenty incomplete, all immature, off Ose-zaki, Suruga Bay, 138-151 m, sand, shell \& rocks, KT-86-1, Station A-1, $35^{\circ} 03.3^{\prime} \mathrm{N} 138^{\circ} 48.8^{\prime} \mathrm{E}-35^{\circ} 03.0^{\prime} \mathrm{N} 138^{\circ} 47.7^{\prime} \mathrm{E}, 23 \mathrm{Feb} .1986,2 \mathrm{~m}$ beam trawl, RY.

Type locality: Kii Channel, 90-150 m deep, Japan.

The holotype is a complete ovigerous female and measures $30 \mathrm{~mm}$ long by 1.1 $\mathrm{mm}$ wide with 108 setigers. The prostomium is anteriorly bifid. Two eyes are situated outside the inner lateral antennae. Occipital antennae are cylindrically articulated. The central longest one has eight annulations extending to setigers 89, while the inner pair six and the outer pair three. The first apodous ring is one and half times as long as the second. Peristomial tentacles are long, slender and articulated (Fig. 24, a).

The first parapodium has a cylindrical and articulated dorsal cirrus and a digitiform ventral one (Fig. 24, b). The dorsal cirri become slender on the posterior parapodia (Fig. 24, c-e). The ventral cirri bear basal swellings in the anterior branchial region (Fig. 24, c), and become simple and conical in the posterior branchial and abranchial regions (Fig. 24, d \& e). 


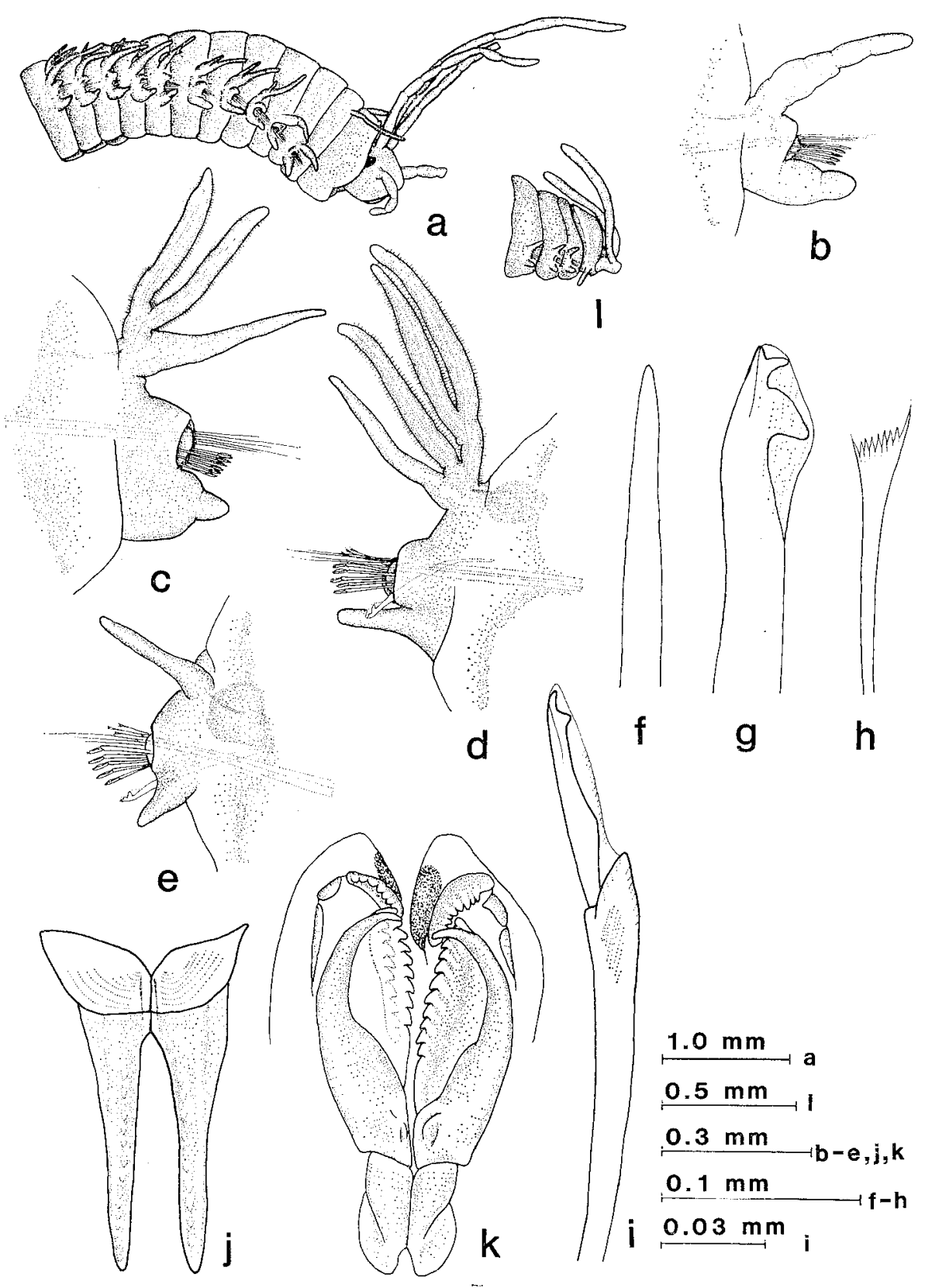

Fig. 24. Eunice fauchaldi sp. nov. a. Anterior end, lateral view; b. First parapodium; c. Parapodium 10; d. Parapodium 30; e. Parapodium 70, f. Acicula; g. Subacicular hook; h. Pectinate seta; i. Compound falciger; j. Mandibles; k. Maxillae; 1. Posterior end, lateral view. 


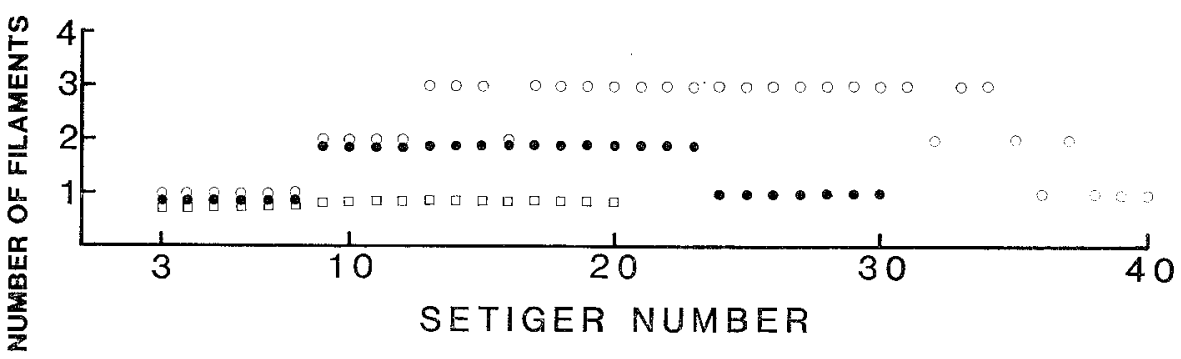

Fig. 25. Branchial distribution in Eunice fauchaldi sp. nov. Open circle, the holotype measuring $1.1 \mathrm{~mm}$ wide with 108 setigers; closed circle, juvenile of $0.7 \mathrm{~mm}$ wide; open rectangular, juvenile of $0.5 \mathrm{~mm}$ wide.

Branchiae are first present from setiger 3. There is no variation in the first occurrence of branchiae for more than a hundred specimens. Branchial distributions in the holotype and two juveniles are shown in Fig. 25. The first branchia on setiger 3 always appears as a single filament. The simple branchiae continue to setiger 8 in the holotype. The number of filaments becomes two on setigers 9-12, three on setigers 13-34 except for setigers 16 and 32, then again two on setigers 3537 , and one on setigers 36 and 38-40 in the holotype. The maximal number of filaments is three in the holotype and four in some paratypes larger than the holotype. In all adult specimens, the branchiae are limited to the anterior body region, from setiger 3 to about setiger 40 . Each branchial filament is well ciliated and vascular (Fig. 24, c \& d). The smallest specimen measuring $0.5 \mathrm{~mm}$ wide have only eighteen pairs of simple branchiae. Another juvenile of $0.7 \mathrm{~mm}$ wide has six pairs of simple branchiae anteriorly, fifteen pairs of bifurcate branchiae at the middle branchial region and seven pairs of simple branchiae posteriorly. The ontogenetic change of branchial distribution patterns is given in Fig. 26. The total number of branchial filaments per individual and the setiger number of the parapdoium on which the last branchia appears are due to the body size (body width). The relationships are statistically evaluated using twenty-five specimens consisting of eleven females, ten males and four juveniles. The correlation coefficient of the total number of branchial filaments per individual and the last branchial setiger number to the body width are 0.88 and 0.90 , respectively $(p<0.01, n=25)$.

Subacicular hooks are yellow, tridentate and hooded (Fig. 24, g). They occur singly per parapodium and start on the right parapodium of setiger 22 and on the left one of setiger 24 in the holotype. The first occurrence of subacicular hooks depends on the size of specimen, varying between setigers 19-23 in adults and more anteriorly, between setigers 15-19, in juvniles (Fig. 27). Acicula are also yellow (Fig. 24, f). Notoacicular setae are embedded in the basal part of the dorsal cirri. At the supracicular position, there are simple capillaries and pectinate setae with seven to eight inner teeth and asymmetrical outer extentions (Fig. 24, h). Compound falcigers are bidentate and hooded. The blade of each falciger is long and slender and the two small teeth are separated distantly each other (Fig. 24, i).

The maxillary formula is: $\mathrm{Mx} . \mathrm{I}=1+1, \mathrm{Mx} . \mathrm{II}=9+11$. $\mathrm{Mx}$. III $=9+0, \mathrm{Mx}$. 


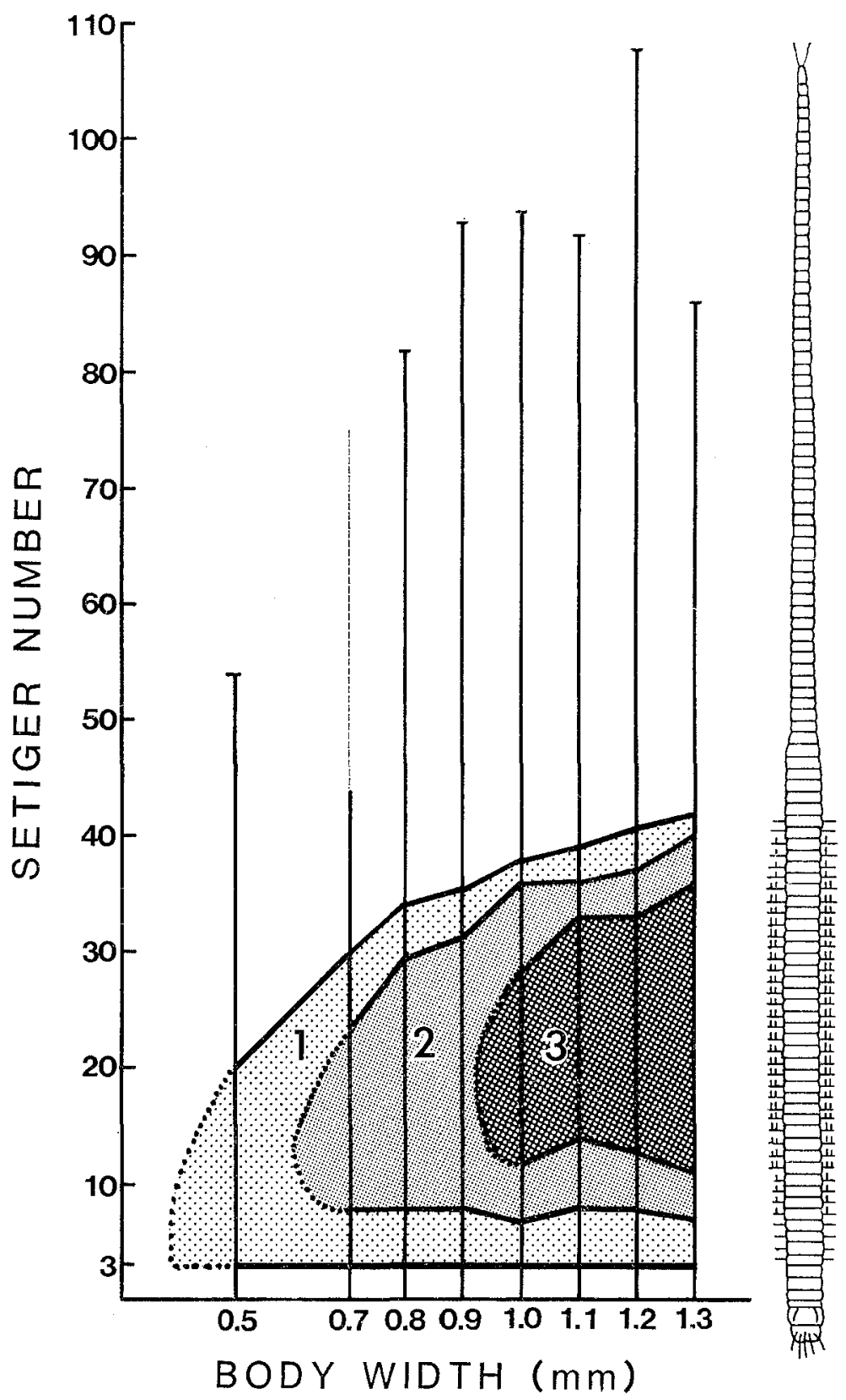

Fig. 26. Ontogenetic development of branchiae in Eunice fauchaldi sp. nov. Simple (1), bifurcate (2) and trifurcate (3) branchiae are shown in each specimens of various body width. 


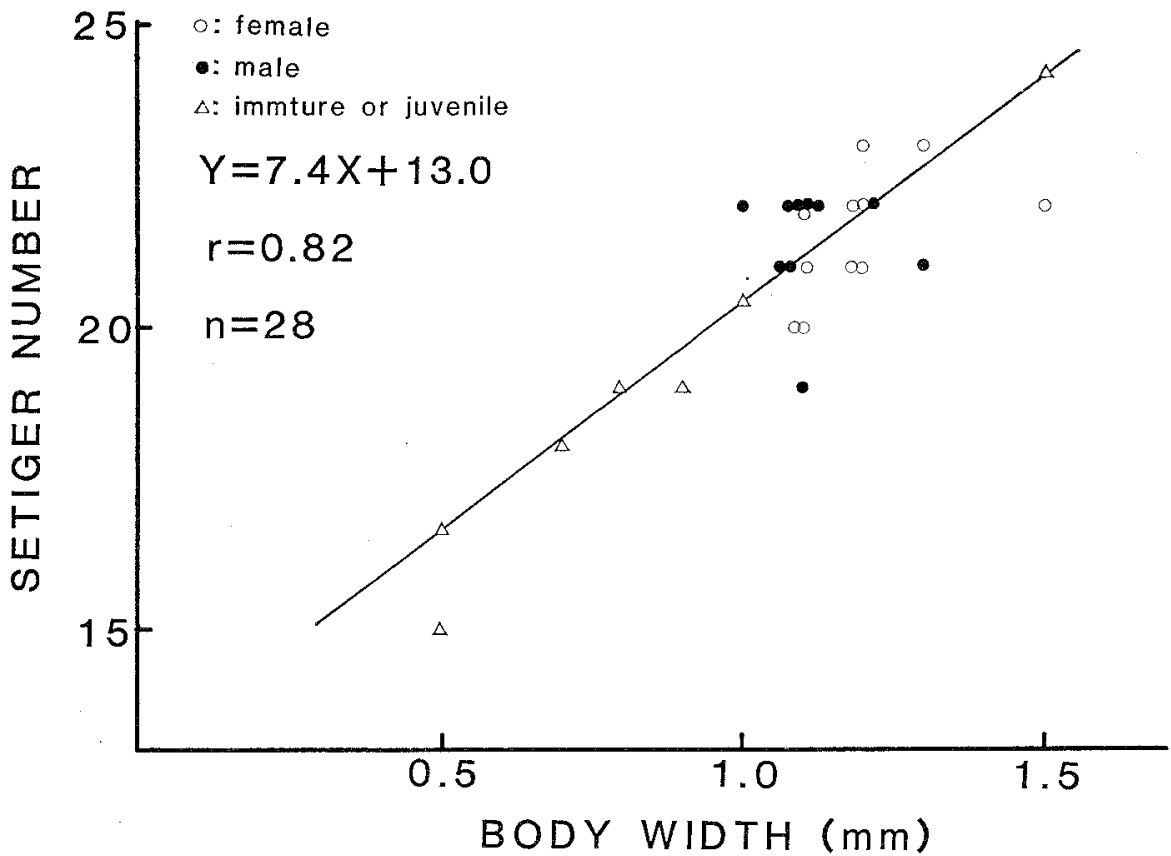

Fig. 27. Ontogenetic change in the first occurrence of subacicular hooks in Eunice fauchaldi sp. nov. The position on which the first subacicular hooks occur is represented in setiger number. Open circle, female; closed circle, male; triangule, immature or juvenile.

IV $=6+8, \mathrm{Mx} . \mathrm{V}=1+1$ (Fig. 24, $\mathrm{k}$ ). Mandibles are well calcified on the anterior edge (Fig. 24, j).

The pigidium has two long dorsal cirri and two very short ventral ones (Fig. $24,1)$.

The tube consists of shells and sand grains and is attached to large pebbles or shells.

Remarks. Loedice makemona Chamberlin, 1919, L. oliga Chamberlin, 1919, Eunice bicirrata Rullier, 1964 and E. multicylindri Shisko, 1981 are known to have poorly developed branchiae and yellow tridentate subacicular hooks. The first two species differ from $E$. fauchaldi sp. nov, in having branchiae from setigers 5-7 instead of setiger 3. E. bicirrata is similar to the new species in having branchiae from setiger 3 , but differs from the latter in lacking pectinate setae and mandibles. The new species differs from E. multicylindri in having branchiae on setigers 3 to 40 and seven inner teeth on pectinate setae, instead of branchiae on setigers 3 to 25 and five inner teeth on pectinate setae seen in the latter.

Etymology. The specific name is dedicated to the famous polychaete researcher, Dr. Kristian Fauchald for his valuable advice and encouragement to me since my work on eunicids was started.

Distribution. Continental shelf of Pacific coast of Japan. 


\section{Eunice indica Kinberg, 1865}

(Figs $28 \& 29$ and Table 1)

Eunice indica Kinberg, 1865, p. 562: Okuda, 1938, p. 95: Miura, 1977a, pp. 14-15, fig. 6, a-g. Eunice medicina Moore, 1903, pp. 441-444, p1. 25, figs 49-51.

New records. NSMT, complete, immatuer, off Jogashima, Sagami Bay, $70 \mathrm{~m}$, shells, 1 Apr. 1981, Mikawa dredge, TM. USNM, complete female with the tube, off Benten-jima, Kagoshima Bay, 145 m, 28 May 1984, dredge, TM. USNM, sixty-two specimens containing nine males, six females and forty-five immature, off Aburatsubo, Sagami Bay, $15 \mathrm{~m}$, sand, 9 Aug. 1984, ORI dredge, TM. BM, two incomplete, off Aburatsubo, $20 \mathrm{~m}$, sand, 9 Aug. 1984, ORI dredge, TM. BM, three females, one male and four immature, off Tomioka, Amakusa, $31 \mathrm{~m}$, sand, 01 June 1984, dredge, TM. ORI, one female and three immature, off Tomioka, 11-12 m, Zostera bed on sandy bottom, 1 June 1984, dredge, TM. ORI, complete female, off Tomioka, $9 \mathrm{~m}$, mud, 01 June 1984, dredge, TM. ZUMT, two immature, incomplete, off Kushimoto, Kii Channel, 79-81 m, sandy mud, "TanseiMaru” Cruise KT-84-12 Station 2, 33'26.4’ $\mathrm{N} 135^{\circ} 43.8^{\prime} \mathrm{E}-33^{\circ} 26.2^{\prime} \mathrm{N} 135^{\circ} 44.3^{\prime} \mathrm{E}, 30$ Aug. 1984, ORI dredge, RY. ORI, ten immature, incompete, off Tsukumi, Bungo Channel, 72-76 m, coarse sand with pebbles, Station $31,33^{\circ} 02.2^{\prime} \mathrm{E} 132^{\circ} 05.5^{\prime} \mathrm{E}-33^{\circ} 02.2^{\prime} \mathrm{N} 132^{\circ} 05.4^{\prime} \mathrm{E}, 4$ Sep. 1984, ORI dredge, RY. ORI, two immature, incomplete, off Tsukumi, $89-91 \mathrm{~m}$, coarse sand \& muddy sand, Station $32,33^{\circ}$ 06.8 ${ }^{\prime} \mathrm{N} 132^{\circ} 08.2^{\prime} \mathrm{E}-33^{\circ} 06.5^{\prime} \mathrm{N} 132^{\circ} 08.4^{\prime} \mathrm{E}$, 4 Sep. 1984, ORI dredge, RY. USNM, fifty-five immature, incomplete, off Tsukumi, $89-91 \mathrm{~m}$, coarse sand \& muddy sand, Station $33,33^{\circ} 06.9^{\prime} \mathrm{N} 132^{\circ}$ $08.0^{\prime} \mathrm{E}-33^{\circ} 06.7^{\prime} \mathrm{N} 132^{\circ} 07.9^{\prime} \mathrm{E}, 4$ Sep. 1984, ORI dredge, RY.

Holotype of Eunice medicina Moore, 1903, USNM 15852, incomplete, immature, Seno-umi, Suruga Bay, Japan, $63 \mathrm{fms}(115 \mathrm{~m})$, volcanic sand \& mud, "Albatross" Station 3700.

Many small and mature specimens were collected from shallow sandy or muddy bottoms off Aburatsubo in Sagami Bay at $15 \mathrm{~m}$ and off Tomioka in Hayasaki Straits at $19-31 \mathrm{~m}$. They measure $12-36 \mathrm{~mm}$ long by 1.0 to $2.3 \mathrm{~mm}$ wide with $70-90$ setigers. Also two large specimens were collected from deeper bottoms off Jogashima in Sagami Bay at $70 \mathrm{~m}$ deep and off Benten-jima in Kagoshima Bay at $145 \mathrm{~m}$, and measure 48 and $50 \mathrm{~mm}$ long by 3.5 and $3.5 \mathrm{~mm}$ wide with 93 and 96 setigers, respectively.

The color of the dorsum is reddish brown except for white setiger 4. Each dorsum of the segment in the middle body region consists of two color bands as reported by Miura (1977a). A living specimen collected from off Jogashima was moving their branchia parallel to the body axis.

The prostomium is short, truncate and divided into two lobes. Eyes are present. Prostomial antennae and peristomial tentacles are smooth or irregularly crumpled. The central three antennae extend to setigers $7-8$ and the outer pair to setiger 1 (Fig. 28, a). The first peristomial ring is laterally swollen and 2 to 2.5 times as long as the second.

The pygidium has two long dorsal and two short ventral anal cirri. The dorsal pair is ten times as long as the ventral (Fig. 28, b). In some specimens, short and conical papillae (maybe retractive) are projecting from the anus.

Dorsal cirri are rather short compared with the other species of the genus and sometimes crumpled (Fig. 28, d). Ventral cirri are short and conical, bearing basal swellings on the branchial parapodia (Fig. 28, c), while short and cylindrical posteriorly (Fig. 28, d). The first branchia with a single filament occurs always at setiger 3 . 


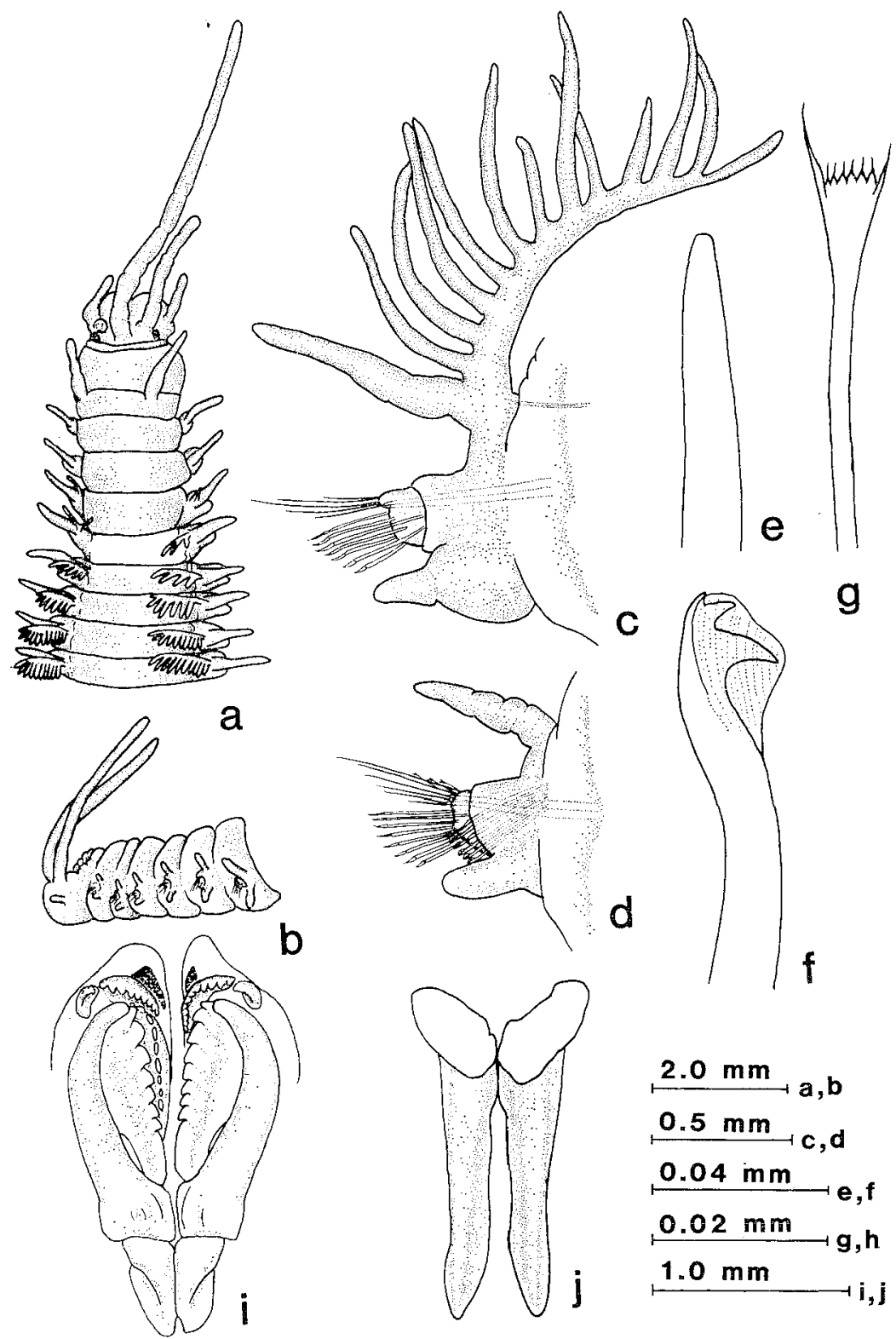

Fig. 28. Eunice indica Kinberg, 1865. a. Anterior end of the specimen from off Misaki, dorsal view; b. Posterior end, lateral view; c. Parapodium 15; d. Parapodium 50; e. Aciculum; f. Subacicular hook; g. Pectinate seta; h. Compound falciger; i. Maxillae; j. Mandibles.

The branchiae are limited to the anterior thirty setigers. The first and last several branchiae are less developed than the rest. The maximal number of branchial filaments depends on the body size and is twelve to fourteen in large specimens, but four to eight in small ones (Fig. 29). 


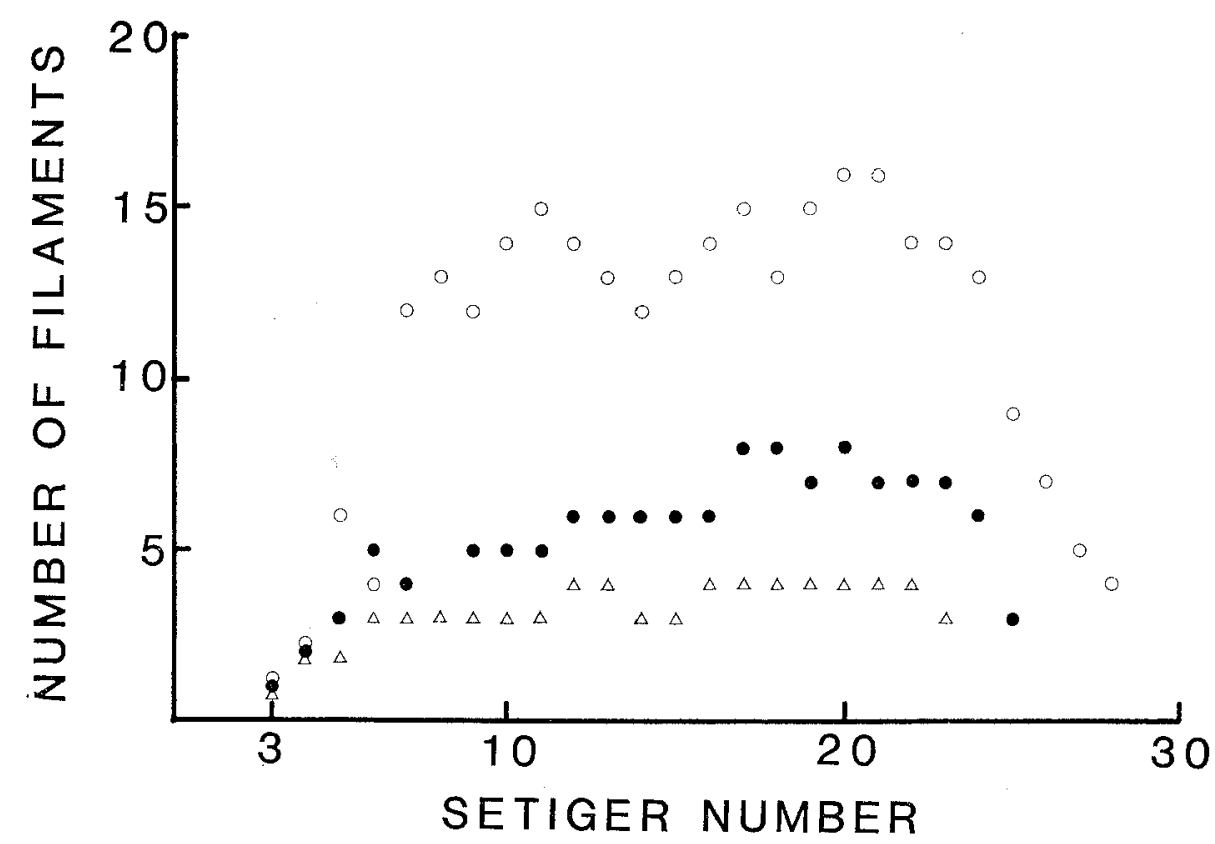

Fig. 29. Branchial distribution in Eunice indica Kinberg, 1865. Open circle, specimen from off Benten-jima, $145 \mathrm{~m}$ depth, measuring $3.5 \mathrm{~mm}$ wide with 93 setigers; closed circle, male from off Abratsubo, $15 \mathrm{~m}$ depth, $2.0 \mathrm{~mm}$ wide; triangle, male from the same, $1.0 \mathrm{~mm}$ wide with 71 setigers.

Mandibles are calcified on the anterior edge (Fig. 28, j). Maxillary formula is: $\mathrm{Mx} . \mathrm{I}=1+1, \mathrm{Mx} . \mathrm{II}=7+8, \mathrm{Mx} . \mathrm{III}=9+0, \mathrm{Mx} . \mathrm{IV}=9+12, \mathrm{Mx} . \mathrm{V}=1+1$ in a specimen from off Misaki (Fig. 28, i).

Subacicular hooks are yellow tridentate and hooded (Fig. 28, f). They appear at first on setigers 19-25. Acicula are yellow (Fig. 28, e). Each pectinate seta has five to six inner teeth and lateral asymmetrical extentions (Fig. 28, g). Compound falcigers are bidentate and have long pointed hoods (Fig. 28, h). The length of hood varies in relation to the specimen size as well as to the body region. Longer hoods are observed in larger specimens and in the anterior body region rather than in the posterior.

The variabilities regarding the first occurrence of subacicular hooks, the maximal number of hooks per parapodium, the first and last occurrence of branchiae and the maximal number of branchial filaments per parapodium in relation to the body width were examined using fifty specimens among which twenty-nine specimens are complete and twenty-one specimens are fragmental but long enough to estimate the occurrence of branchiae and subacicular hooks (Table 1). Only the first occurrence of branchiae is invariable. All other characters are positively dependent to the body width (correlation coefficients $=0.636-0.900, p<0.0001$ ). The first occurrence of subacicular hooks depends on the body width $(\mathrm{R}=0.709, \mathrm{p}<0.0001)$. The maximal number of hooks per parapodium depending on the size of specimen is three in small specimens and six to seven in large ones. The linear relationship between the body 
Table 1. Variability in some morphological characters in Japanese specimens of Eunice indica Kinberg, 1865

\begin{tabular}{lccccc}
\hline \hline & Mean & Range & S.D. & C.V. & Number \\
\cline { 2 - 6 } Body width & 1.70 & $0.6-3.6$ & 0.848 & 50.00 & 50 \\
$\begin{array}{l}\text { First occurrence of subacicular } \\
\text { hooks }\end{array}$ & 19.5 & $13-25$ & 2.25 & 11.54 & 50 \\
Maximal number of S.H. & 3.6 & $? 1-7$ & 1.25 & 34.83 & 50 \\
First occurrence of banchiae & 3.0 & 3 & 0.00 & 0.00 & 50 \\
Last occurrence of banchiae & 23.9 & $20-30$ & 1.89 & 7.90 & 50 \\
$\begin{array}{l}\text { Maximal number of banchial } \\
\text { fiaments }\end{array}$ & 6.2 & $2-16$ & 2.28 & 45.62 & 50 \\
\hline
\end{tabular}

width $(\mathrm{X})$ and the maximal number of hooks per parapodium $(\mathrm{Y})$ is: $\mathrm{Y}=1.135 \mathrm{X}+$ $1.656(\mathrm{R}=0.772, \mathrm{p}<0.0001)$. On the basis of this formula, the specimens of this species larger than $1.2 \mathrm{~mm}$ in body width can easily be distinguished from other Japanese species in having more than three yellow subacicular hooks. Even in the specimens larger than $0.5 \mathrm{~mm}$ and smaller than $1.2 \mathrm{~mm}$ in body width, if they have more than two subacicular hooks, they may differ from the relative species, such as $E$. fauchaldi and $E$. congesta.

Remarks. Although Eunice medicina Moore, 1903 has been thought to be synonymous with E. vittata (Delle Chiaje, 1828), the type of the former has two subacicular hooks per parapodium on some setigers and crumpled occipital antennae and differs from the latter that has single hook per parapodium and well articulated antennae. The branchiae of $E$. medicina occur from setiger 3 to setiger 25 with five to seven filaments as maximal number. This occurrence of branchiae and subacicular hooks are very similar to the juvenile stage of $E$. indica, and thus Moore's species is regarded to be synonymous with $E$. indica in this study.

Distribution. Pacific coast of Japan, subtidal to shallow depth, sandy or muddy bottoms; Pacific Ocean (originally described from Bangka Strait, Indonesia).

\section{Eunice mucronata Moore, 1903}

(Figs 30 \& 31)

Eunice mucronata Moore, 1903, pp. 437-440, pl. 25, figs 42-45.

Holotype, USNM 15851 and thirteen paratypes, USNM, 5341, off Manazuru-zaki, Sagami Bay, 153 fms $(280 \mathrm{~m})$, green mud, volcanic ashes and sand, 5 May 1900, "Albatross" Station 3698.

New records. NSMT, immature, off Hagachi-zaki, Suruga Bay, 367-375 m, silty mud, "TanseiMaru"' Cruise KT-83-18, Station H-4, 34 $40.8^{\prime} \mathrm{N} 138^{\circ} 41.5^{\prime} \mathrm{E}-34^{\circ} 40.0^{\prime} \mathrm{N} 138^{\circ} 42.9^{\prime} \mathrm{E}$, 11 Nov. 1983, $3 \mathrm{~m}$ beam trawl, TM. ORI, one complete female \& two incomplete, off Kominato, 335-260 m, "Umitaka-Maru" Station 79068, 34 57.5’ $\mathrm{N} 140^{\circ} 07.5^{\prime} \mathrm{E}-34^{\circ} 57.7^{\prime} \mathrm{N} 140^{\circ} 07.4^{\prime} \mathrm{E}, 7$ Aug. 1979, sleigh net, Prof. Masaaki Murano.

The holotype is a complete specimen and measures $110 \mathrm{~mm}$ long by $4 \mathrm{~mm}$ wide with 115 setigers. The prostomium is anteriorly divided into four lobes. Eyes 


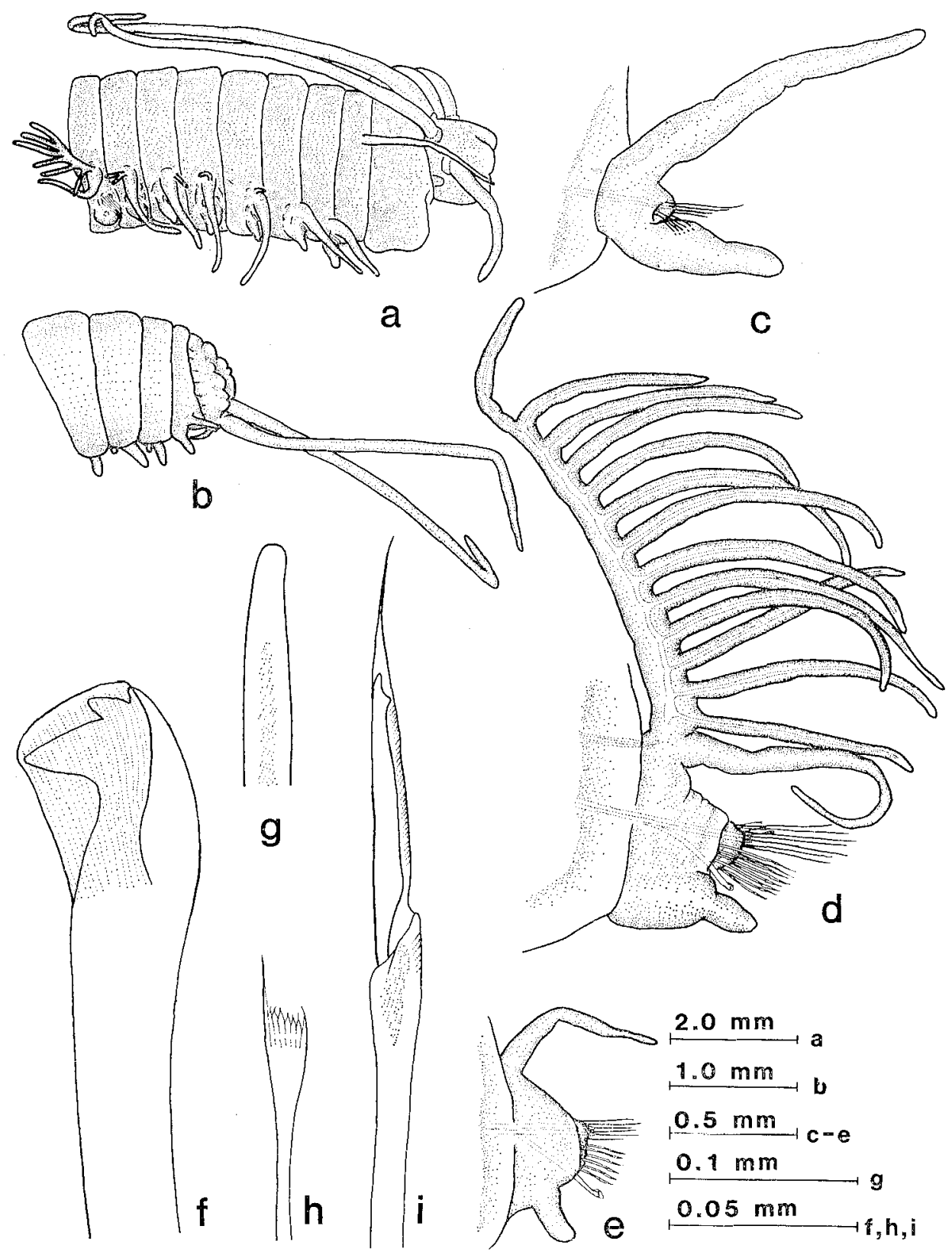

Fig. 30. Eunice mucronata Moore, 1903. a. Anterior end of the holotype, lateral view; b. Posterior end of the same; c. First parapodium of a paratype; d. Parapodium 20 of the same; e. Parapodium 49 of the same; f. Subacicular hook; g. Aciculum; h. Pectinate seta; i. Compound falciger. 
are present. All occipital antennae are smooth. The central antenna extends to the anterior margin of setiger 11 , the inner pair to setigers $6-9$, and the outer to setigers 1-2. The first apodous ring is twice as long as the second. A pair of smooth peristomial tentacles reaches setiger 4 (Fig. 30, a). The pygidium has two very long dorsal and two short ventral cirri (Fig. 30, b).

The first parapodium has a cylindrical dorsal cirrus and a digitiform ventral one (Fig. 30, c). The dorsal cirri become slender on the posterior parapodia. The ventral cirri bear basal swellings on the branchial parapodia (Fig. 30, d), and become simple digitiform posteriorly (Fig. 30, e).

Branchiae are first present from setiger 3 as a single filament. There is no variation on the first occurrence of branchiae at least for the eighteen specimens. The number of branchial filaments rapidly increases to become ten on setigers 9 and 10 , reaches thirteen as a maximum on setigers $23-25$, and then decreases to be only one on setiger 34 in the holotype. The branchial distribution in three specimens is shown in Fig. 31. The appearance of branchiae is similar in these specimens. The branchiae are present from setiger 3 to setigers 32-34 and bear ten to fourteen filaments as a maximal number between setigers 20-25.

Subacicular hooks are yellow, tridentate and hooded (Fig. 30, f). They are first present from left parapodium 20 and from right parapodium 21 in the holotype. The first occurrence of hooks varies on parapodia 19-21 in thirteen paratypes. They occur singly per parapodium and sometimes two, such as on right parapodia $40,44,46,48-50,70,71,110$ in the holotype. Acicula are yellow and distally rounded (Fig. 30, g). Notoacicular setae are embedded at the bases of dorsal cirri (Fig. 30, c-d). Simple capillary setae are long and slender. Each pectinate seta has lateral asymmetrical extensions and about six inner teeth (Fig. 30, h).

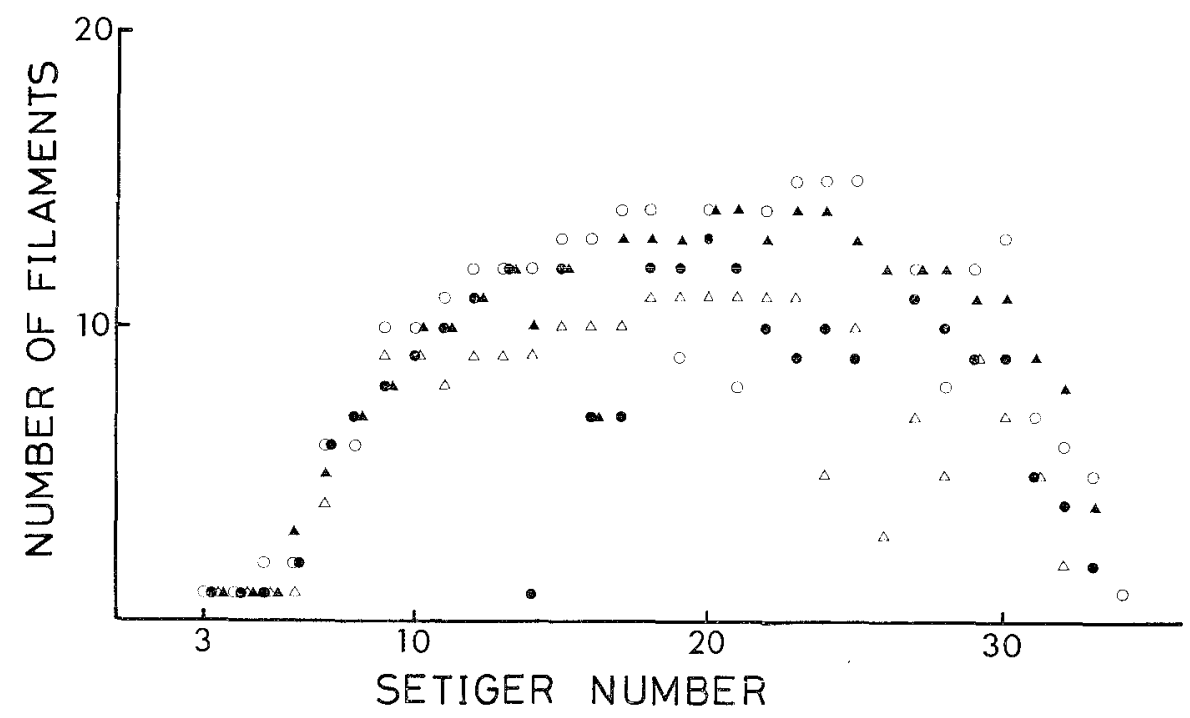

Fig. 31. Branchial distribution in Eunice mucronata Moore, 1903. Open circle, the holotype of $4.0 \mathrm{~mm}$ wide with 115 setigers; other symbols, paratypes. 
Compound falcigers are bidentate and hooded. The hood is very long and has a pointed end (Fig. 30, i).

The maxillary formula is $\mathrm{Mx} . \mathrm{I}=1+1, \mathrm{Mx} . \mathrm{II}=8+8, \mathrm{Mx} . \mathrm{III}=9+0, \mathrm{Mx}$. $\mathrm{IV}=6+10, \mathrm{Mx} . \mathrm{V}=1+1$ in the holotype.

Remarks. Eunice mucronata Moore, 1903 is closely related to E. americana Hartman, 1944 in having yellow tridentate subacicular hooks, bidentate compound falcigers with long pointed hoods and branchiae from setiger 3 . These two species differ from each other in the maximal number of branchial filaments and the first occurrence of subacicular hooks. The subacicular hooks of the former occur singly (occasionally two) per parapodium from setigers 19-21, but those of the latter three to four per parapodium from setiger 25. The maximal number of branchial filaments is fourteen in E. mucronata and twenty in E. americana.

Distribution. Sagami Bay, 280 m, Suruga Bay, 367-375 m, Pacific coast, Japan.

\section{Eunice tanseiae sp. nov.}

(Figs 32 \& 33)

Holotype: NSMT Pol. H-225, incomplete female, off Susami, Kii Channel, 100-101 m, shell \& sandy mud, "Tansei-Maru" Cruise KT-84-12 Station 12-1, 33'29.9'N 135'30.9'E-33'30.0'N $135^{\circ}$ 30.7’E, 31 Aug. 1984, ORI. dredge, RY.

Type locality: Kii Channel, about $100 \mathrm{~m}$ depth.

The holotype is an ovigerous specimen autotomised in two parts without posterior considerable setigers. The dorsum is monotonously light brown to pale in color. The type measures $31.8 \mathrm{~mm}$ long by $2.6 \mathrm{~mm}$ wide with 47 setigers. The prostomium is truncate anteriorly and incised in the center. Two black eyes are situated at the base of the outer lateral antennae (Fig. 32, b). All occipital antennae are moniliform. The central longest antenna with thirteen annulations extends to setiger 4, the inner pair with ten to twelve annulations to setiger 2, and the outer pair with six to seven annulations to the second peristomial ring (Fig. 32, a). The first peristomial ring is twice as long as the second. The peristomial cirri with four annulations reach setiger 2.

The first parapodium has a cylindrical and triarticulated, dorsal cirrus and a digitiform ventral one (Fig. 32, c). The ventral cirri become conical in the prebranchial region (Fig. 32, d), basally swollen in the branchial region (Fig. 32, e \& f) and again digitiform in the postbranchial region (Fig. 32, g). The dorsal cirri are articulated in the prebranchial and branchial regions (Fig. 32, d-f).

Branchiae start from setiger 10 with two filaments. The number of filaments increases rapidly to become six as a maximum at setigers $17-23$, and then the branchiae abruptly disappear posterior of setiger 27 . The branchial distribution is monomodal and restricted to the anterior part of the body (Fig. 33).

Acicula are yellow and recurved at the terminal end (Fig. 32, h). Yellow and 


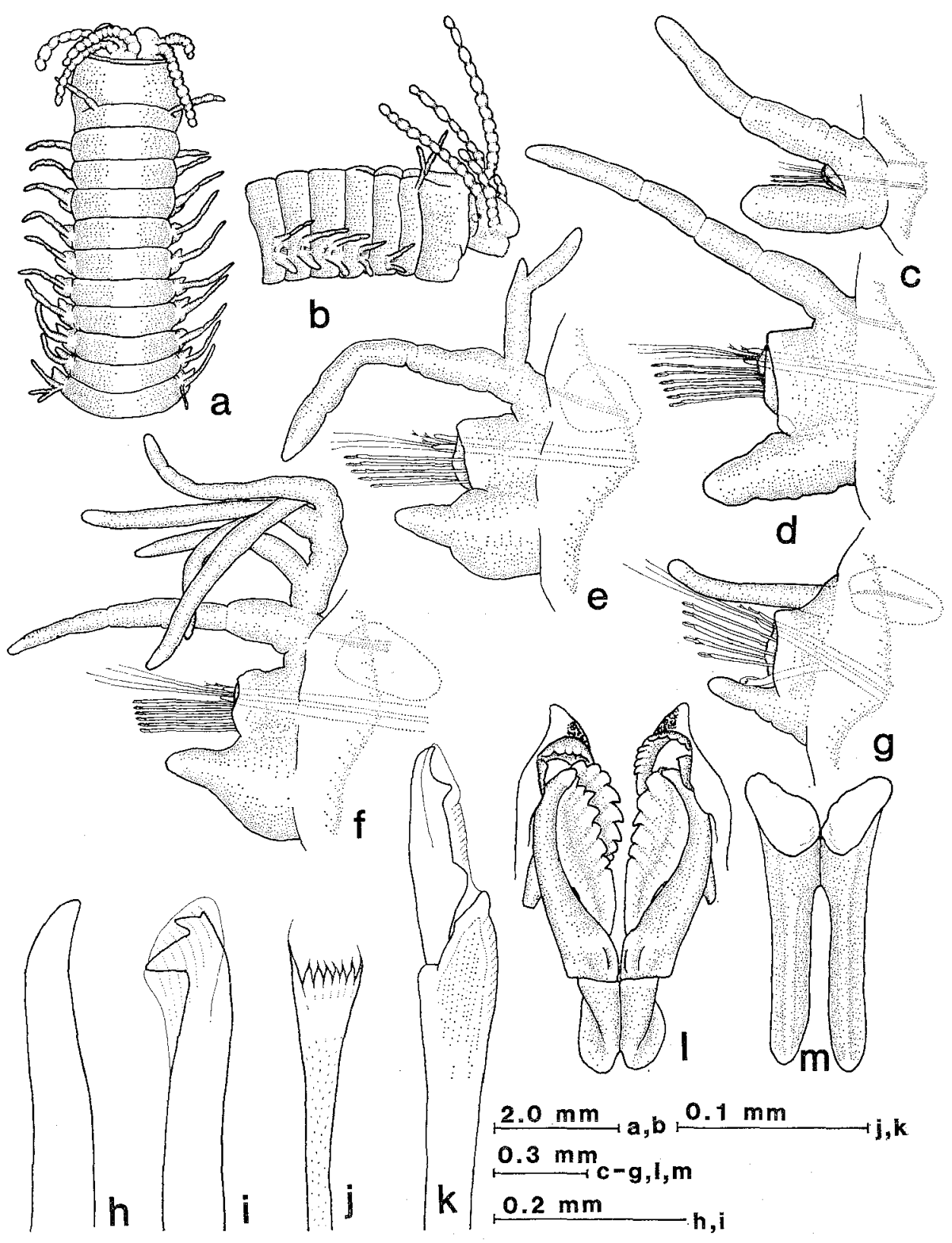

Fig. 32. Eunice tanseiae sp. nov. a. Anterior end, dorsal view; b. The same, lateral view; c. First parapodium; d. Parapodium 5; e. Parapodium 10; f. Parapodium 15; g. Parapodium 36; h. Aciculum; i. Subacicular hook; j. Pectinate seta; k. Compound falciger; 1. Maxillae; m. Mandibles. 


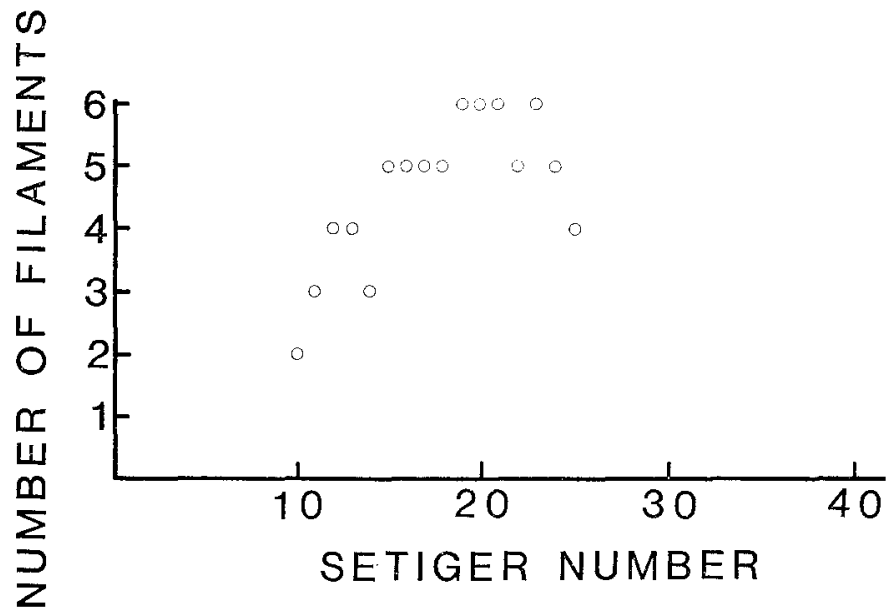

Fig. 33. Branchial distribution in the holotype of Eunice tanseiae sp. nov., measuring 2.6 $\mathrm{mm}$ wide with 47 anterior setigers.

tridentate subacicular hooks start on the left parapodium of setiger 28 and on the right of setiger 29 (Fig. 32, i). At the supracicular position, there are long slender capillaries and pectinate setae with six inner teeth and asymmetrical lateral extentions (Fig. 32, j). Compound falcigers are bidentate and hooded. The two teeth of each falciger are slightly apart from each other (Fig. 32, $\mathrm{k}$ ).

The maxillary formula is: $\mathrm{Mx} . \mathrm{I}=\mathbf{l}+1, \mathrm{Mx} . \mathrm{II}=7+6, \mathrm{Mx} . \mathrm{III}=8+0, \mathrm{Mx}$. $\mathrm{IV}=7+9, \mathrm{Mx} . \mathrm{V}=1+1$ (Fig. 32, l). Mandibles are well calcified at the anterior tips (Fig. 32, m).

Remarks. The new species is unique in the flavus-tridentate groups of the genus, in having branchiae from setiger 10 .

Etymology. The new species is named for the Research Vessel, "Tansei-Maru" of Ocean Research Institute.

Distribution. Pacific coast of Japan, in shallow waters.

\section{Eunice congesta Marenzeller, 1879}

(Fig. 34)

Eunice congesta Marenzeller, 1879, pp. 134-135, pl. 4, fig. 2.

Eunice vittata: Miura, 1977b, pp. 61-64, fig. 1, a-o. (not delle Chiaje, 1828)

New records. USNM, complete immature with its tube, Kominato, Chiba, $7 \mathrm{~m}$, under a boulder, 18 Oct. 1983, TM. USNM, one male and two immature, both complete, Kominato, $6 \mathrm{~m}$, under boulders, 18 Oct. 1983, TM. ORI, two complete immature, Kominato, $2 \mathrm{~m}$, under boulders, 18 Oct. 1983, TM. ORI, two complete immature, Kominato, $8 \mathrm{~m}$, under boulders, 18 Oct. 1983, TM. BM, one complete and one incomplete, immature, Kominato, $3 \mathrm{~m}$, under boulders, 17 Oct. 1983, TM. BM, complete immature in the tube, Kominato, 5 m, under a boulder, 17 Oct. 1983, TM. BM, complete male, in abalone rearing tank, Kominato, 15 Aug. 1984, IH. 


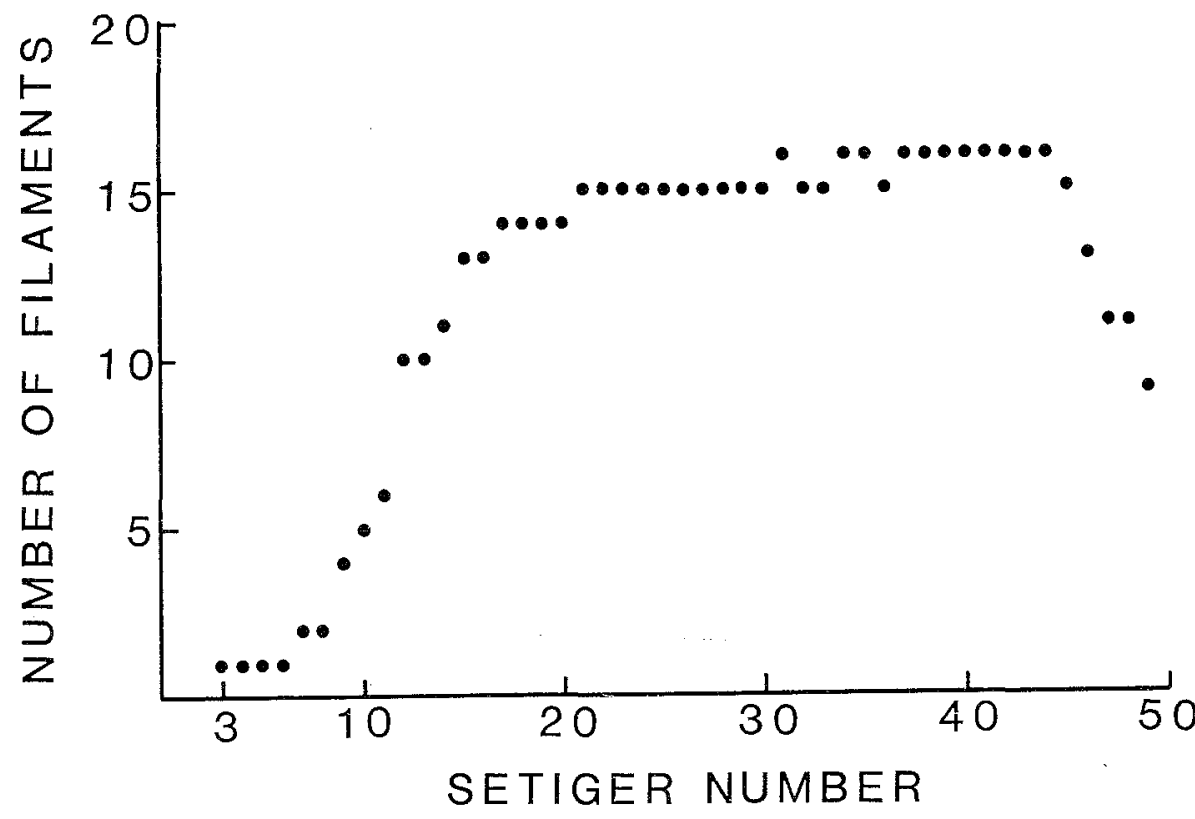

Fig. 34. Branchial distribution in Eunice congesta Marenzeller, 1879. Specimen E-50 in Miura (1977b) measuring $4.5 \mathrm{~mm}$ wide with about 200 setigers.

Remarks. Eunice congesta Marenzeller, 1879 has been thought synonymous with E. vittata (delle Chiaje, 1828), but differs from the latter in having smooth or faintly annulated occipital antennae instead of cylindrically articulated ones as mentioned in Fauchald (1970), Gathof (1984), etc. The beginning site of branchiae varies between setigers 7-8 (Marenzeller, 1879) or 3-6 (Miura, 1977b as E. vittata). The first branchiae are simple or rudimentary and tend to be lost in large specimens. Newly collected specimens fit well with the previous reports. The branchial distribution is represented in Fig. 34. The branchiae are well developed and restricted in the anterior body region. The maximal number of filaments exceeds fifteen.

Distribution. Southern Pacific coast of Japan, intertidal to subtidal depth, rocky shore.

Eunice tibiana sensu Izuka, 1912

Euncie tibiana sensu Izuka, 1912, pp. 119-120, pl. 2, fig. 3; Imajima \& Hartman, 1964, pp. 254-255 (not Poutales, 1863)

Remarks. Eunice tibiana sensu Izuka, 1912 has been recorded from Sagami Bay, but neither his collection nor any materials corresponding to his description were available for this study. The lack of the precise account on the setae in his description makes difficult for the identification of his species. The horny tube in regularly waving form of the species is similar to that of E. tibiana Poutales, 1863. However, if Iuzka's species has dark acicula as mentioned by Imajima \& Hartman 
(1964), it should be separated from Poutales' species, that has yellow acicula as redescribed by Ehler (1887).

Eunice longicirrata sensu Imajima, 1964

Eunice longicirrata sensu Imajima, 1964, p. 242, figs 19-20 (not Webster, 1884).

Remarks. The holotype of $E$. longicirrata Webster, 1884 was redescribed by Fauchald (1969, pp. 12-13, fig. 6, a-e) with a new name $E$. websteri because the original specific name had been preoccupied in the combination $E$. (Nicidion) longicirrata Kinberg 1865. E. longicirrata sensu Imajima, 1964 has smooth antennae, but those of $E$. websteri are articulated, and thus the former should be separated from the latter.

\section{Genus Euniphysa Wesenberg-Lund, 1949}

The genus Euniphysa was erected by Wesenberg-Lund (1949) as an aberrant eunicid worm characterized by having both peristomial cirri and compound spinigers, which means that it might be related to both the genera Eunice Cuvier, 1817 and Marphysa Quatrefages, 1865. The type-species, Euniphysa aculeata Wesenberg-Lund, 1949 from Persian Gulf has five occipital antennae, two peristomial cirri, poorly developed branchiae, well developed ventral glanduler pads on parapodia, a few long teeth on maxillae III, IV, V and compound spinigers. The genus well defined by these characters was revised by Pettibone (1970) and the status was supported by Fauchald (1977) and Gathof (1984). Some species of the genus Eunice sensu lato listed below show also those Euniphysa type features mentioned above and they should be replaced to the genus Euniphysa, in my opinion.

Euniphysa jeffreysii (McIntosh, 1904) comb. nov.

Eunice jeffreysii McIntosh, 1904, pp. 137-140, pl. 11, figs 15-20. Tanjiers Bay, Morocco.

Euniphysa tubifex (Crossland, 1904) comb. nov.

Eunice tubifex Crossland, 1904, pp. 303-310, pl. 21, figs 1-8, text-figs 52-55.

Kokotoni Harbor, Zanzibar.

Euniphysa tubicola (Treadwell, 1922) comb. nov.

Leodice tubicola Treadwell, 1922, pp. 139-142, pl. 3, figs 1-6, text-figs 17-23.

Pago Pago Harbor, Samoa.

Euniphysa spinea (Miura, 1977) comb. nov.

Eunice spinea Miura, 1977b, pp. 64-67, fig. 2, a-p. Kagoshima Bay, Japan.

In addition to these species, Gathof (1984) reported on a species of the genus Euniphysa from Gulf of Mexico and thus the total number of species belonging to this genus becomes six. The members of this genus are subdivided into two main groups by whether the compound falcigers are present or not. Euniphysa aculeata, Euniphysa 
jeffreyssii comb. nov. and Euniphysa sp. A. sensu Gathof, 1984 do not have any compound falcigers. They are very closely related to each other in having smooth and slender occipital antennae, dark brown or black subacicular hooks and poorly developed branchiae, but different in the first occurrence of subacicular hooks, namely on setiger 25 in the first species, on setiger 50 in the second and on setigers 35-40 in the third. They are also distinguishable in the first occurrence of branchiae on setigers 16-25, on setiger 28 and on setigers 30-38, respectively. In Euniphysa tubifex comb. nov., Euniphysa tubicola comb. nov. and Euniphysa spinea comb nov., compound spinigers are replaced by compound falcigers at least on some posterior parapodia. In this group, E. spinea differs from the other two in having black acicula instead of yellow ones. E. tubifex has articulated occipital antennae and branchiae starting from setiger 35 and differs from $E$. tubicola, that has smooth antennae and branchiae from setiger 12. Only one species, E. spinea, is recorded from Japanese waters.

\section{Euniphysa spinea (Miura, 1977)}

(Figs 35-37)

Euniphysa spinea Miura, 1977b, pp. 64 67, fig. 2, a-p.

Paratypes: NSMT-Pol. P-139, sixteen specmiens including one female, Kagoshima Bay, $110 \mathrm{~m}$, 01 Aug. 1974, dredge, Dr. Minoru Imajima.

New records. USNM, eight incomplete immature, off Tsukumi, Bungo Channel, 89-91 m, coarse sand \& muddy sand, "Tansei-Maru" Cruise KT-84-12 Station 33, 33 $06.9^{\prime} \mathrm{N} 132^{\circ} 08.0^{\prime} \mathrm{E}-33^{\circ} 06.7^{\prime} \mathrm{N}$ $132^{\circ} 07.9^{\prime} \mathrm{E}$, 4 Sep. 1984, ORI dredge, RY. ORI, incomplete immature, off Tsukumi, 72-76 m, coarse sand with pebbles, Station $31,33^{\circ} 02.2^{\prime} \mathrm{N} 132^{\circ} 05.5^{\prime} \mathrm{E}-33^{\circ} 02.2^{\prime} \mathrm{N} 132^{\circ} 05.4^{\prime} \mathrm{E}, 4$ Sep. 1984 , ORI dredge, RY.

Some specimens were newly collected from Bungo Channel and compared with the paratypes of Eunice spinea Miura, 1977. The characters of the chaetae are redescribed below, because the pseudocompound spinigers were confused with the compound spinigers in the original description.

Euniphysa spinea has seven kinds of chaetae, acicula (Fig. 35, a), subacicular hooks (Fig. 35, b), pectinate setae (Fig. 35, c), capillary setae, pseudocompound spinigers (Fig. 35, d), compound spinigers (Fig. 35, e) and compound falcigers (Fig. $35, \mathrm{f})$. The acicula are black with rounded tips. They are more numerous on the anterior parapodia than on the posterior. The subacicular hooks are black with bidentate and hooded distal ends. They occur singly per parapodium, and are first present on setigers 15-22 in small specimens and on setigers 25-30 in large ones (Fig. 36). The pectinate setae with five to eight inner spines and asymmetrical lateral extentions occur from the first parapodia. The pseudocompound spinigers are restricted to the anterior body region and replaced by the compound spinigers on setigers 12-25. The first occurrence of the compound spinigers depends on the body size as in the case of the subacicular hooks. The compound falcigers occur on the 0-7 segments posterior to the compound spinigers. Each compound falciger 

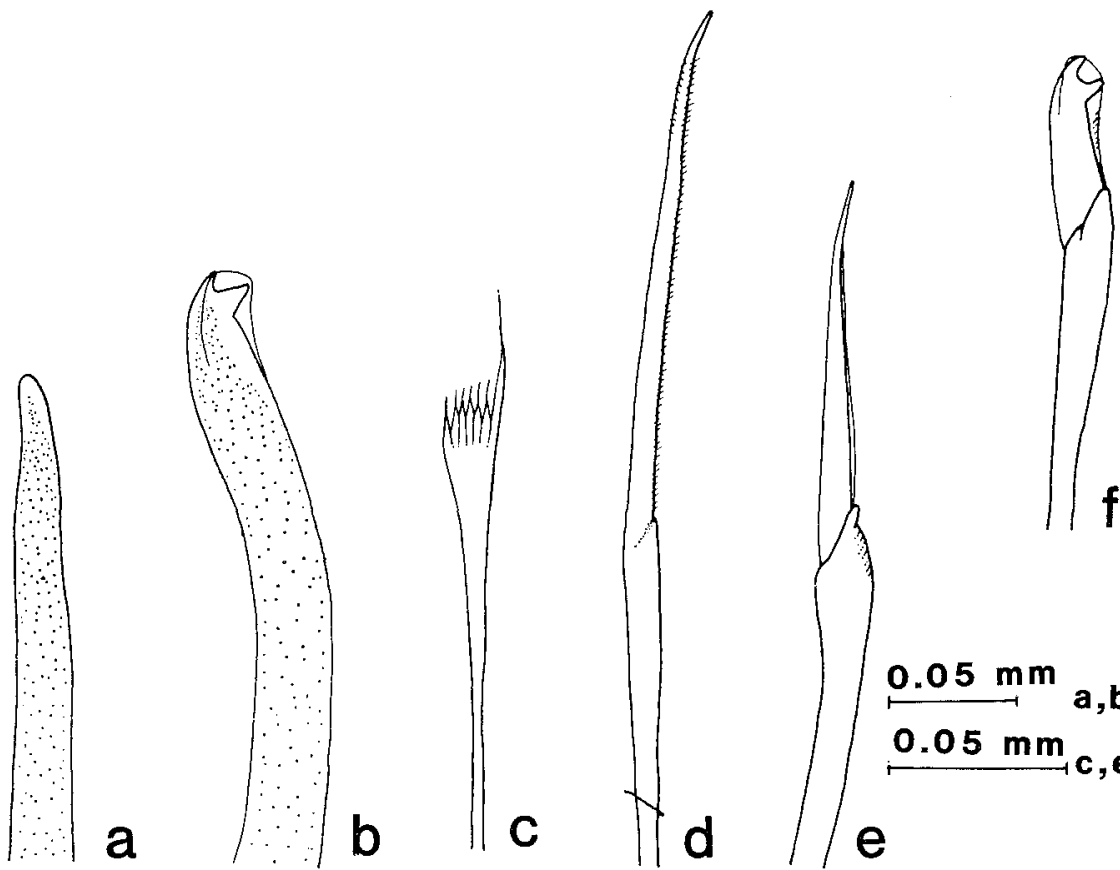

Fig. 35. Euniphysa spinea (Miura, 1977). a. Aciculum; b. Subacicular hook; c. Pectinate seta; d. Pseudocompound spiniger; e. Compound spineger; f. Compound falciger.

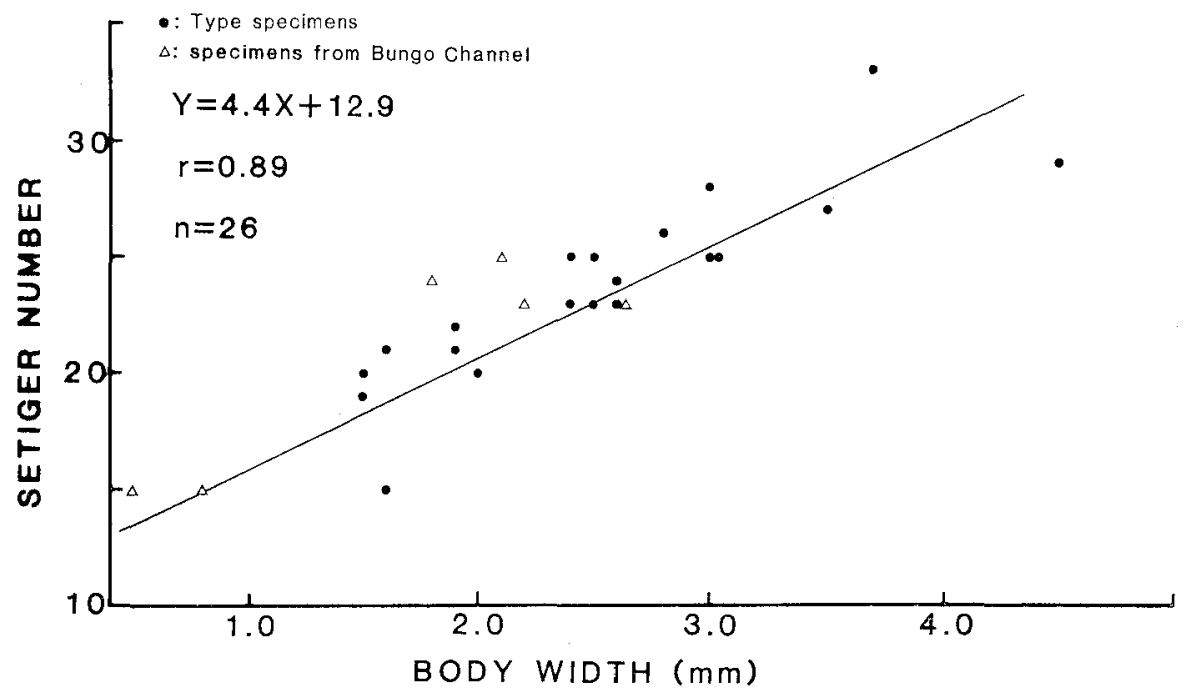

Fig. 36. Ontogenetic change in the first occurrence of subacicular hooks in Euniphysa spinea (Miura, 1977). The position on which the first subacicular hooks occur is represented in setiger number. 


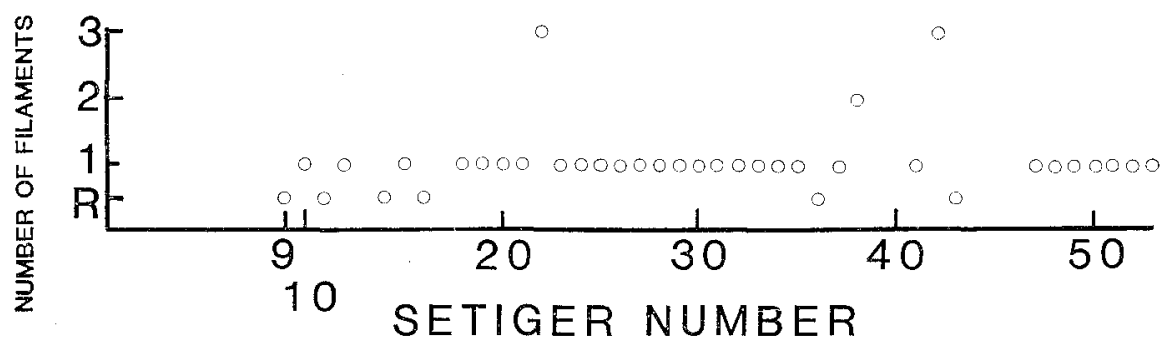

Fig. 37. Branchial distribution in Euniphysa spinea (Miura, 1977).

has a short stout blade with two separated teeth and a round hood. Branchiae are poorly developed in this species (Fig. 37).

Distribution. Kagoshima Bay, 20-200 m, Bungo Channel, 70-90 m, southern Pacific coast of Japan.

\section{Discussion}

Geographical and Bathymetrical Distribution.

In this study, twenty-one species or subspecies of the genus Eunice and a species of the genus Euniphysa were recognized from Japanese waters. Most of them (fifteen species) are endemic to Japanese waters, but two others were originally known from other Pacific areas, and the four remaining are widely spread throughout the world. For the last four species, E. afura punctata, E. (Nicidion) cariboea, E. aphroditois and $E$. antennata, further study is necessary to check whether they are truly cosmopolitan through comparison of the specimens collected from various localities of the world.

Each Japanese species of the genera Eunice shows well defined bathymetrical distribution range (Fig. 38). Half of all species were recorded from intertidal and subtidal ranges in depths less than 10 meters. Among them, Eunice annulicirrata and E. microprion were also collected in shallow depths less than 40 meters in the Japan Sea and $E$. kobiensis in less than 80 meters on the Pacific coasts. Other species appear sometimes at depths of more than 100 meters, of which six are distributed on bottoms less than 160 meters and only four species were recorded exceeding 200 meters.

Key to the Japanese species of the genus Eunice.

The key for the identification of the Japanese species of the genus Eunice is given below. In the key, both Eunice tibiana sensu Izuka, 1912 and E. longicirrata sensu Imajima \& Hartman, 1964 are excluded because of the lack of some morphological characters.

la. Subacicular hooks yellow............................................. 2

1b. Subacicular hooks black.............................................. 3

2a. Subacicular hooks bidentate........................................... 13

2b. Subacicular hooks tridentate........................................... 14 

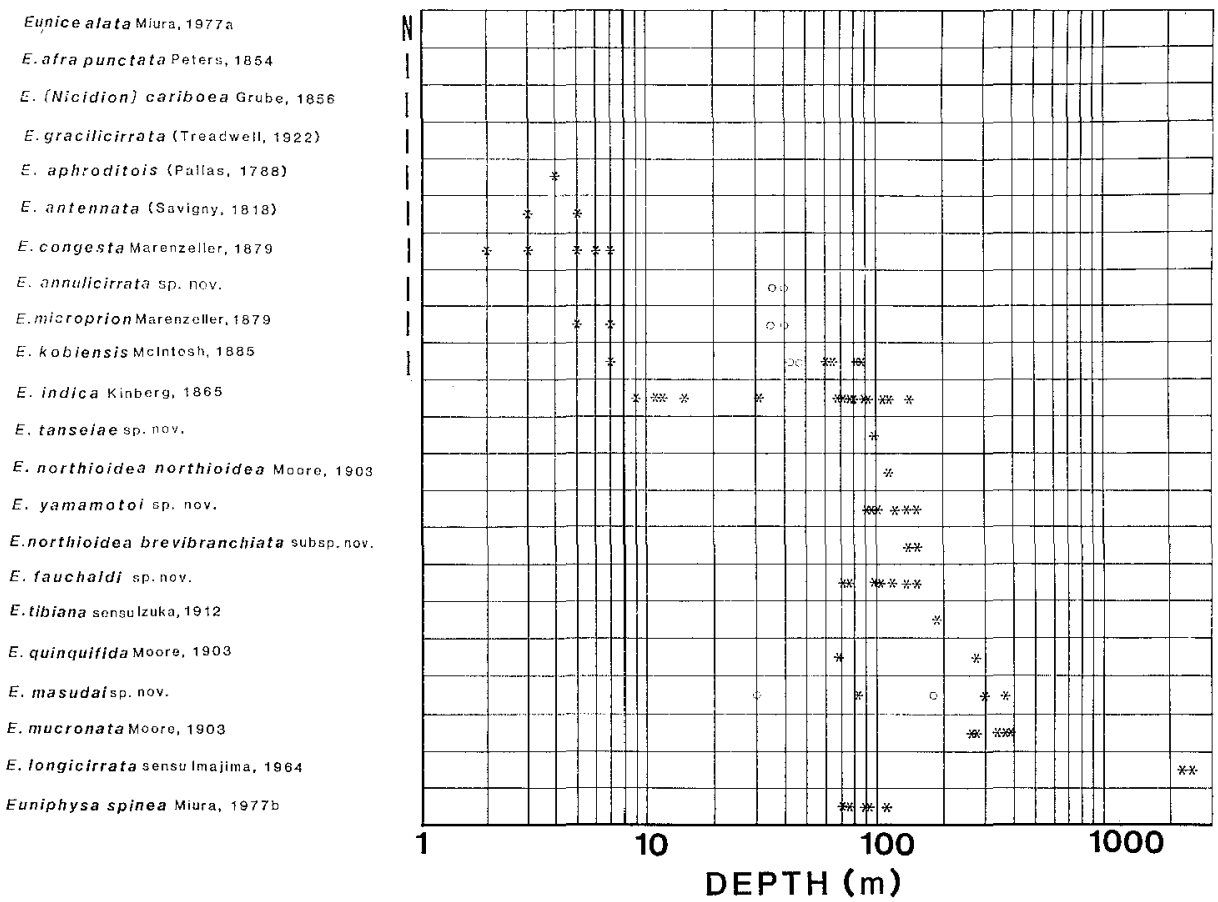

Fig. 38. Bathymetrical distribution in Japanese species of the genera Eunice and Euniphysa. N: Neustonic; I: Intertidal; open circle: Recorded from the Japan Sea; asterisk: Pacific coasts of Japan.

3a. Branchiae absent on the anterior parapodia

Eunice (Nicidion) cariboea Grube, 1856

3b. Branchiae present on the anterior parapodia.

4a. Branchiae well developed on the anterior and posterior parapodia, but less developed at the middle body region....

Eunice masudai sp. nov.

4b. Branchiae well developed on the anterior parapodia, but less developed on the posterior parapodia............................................... 5

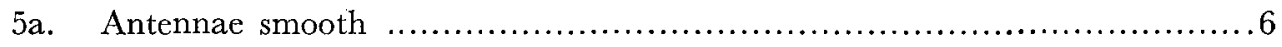

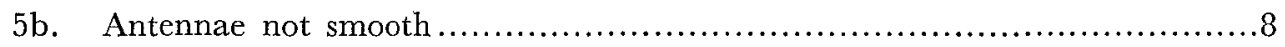

6a. Maximal number of branchial filaments more than 20.

Eunice aphroditois (Pallas, 1788) adult

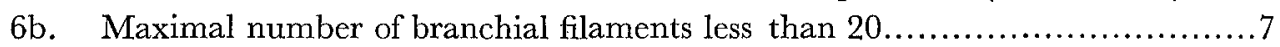

7a. Branchiae from setigers 4-5. Pectinate setae symmetrical..................

Eunice aphroditois (Pallas, 1788) juvenile

7b. Branchiae from setiger 6. Pectinate setae asymmetrical.....................

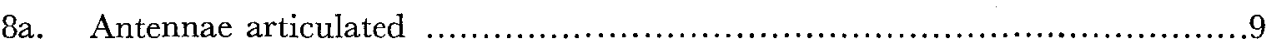

8b. Antennae moniliform ..................................................... 12

9a. Number of branchial filaments more than 10 .

Pectinate setae symmetrical.....................Eunice quinquifida Moore, 1903 
9b. Number of branchial filaments less than 5. Pectinate setae asymmetrical......10

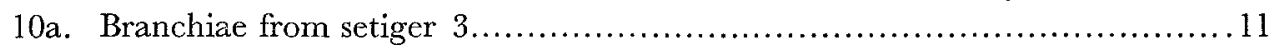

10b. Branchiae from setiger 16.................... Eunice afra punctata (Peters, 1854)

11a. Branchial filaments long and slender

Eunice northioidea northioidea Moore, 1903

11b. Branchial filaments short and stout.

Eunice northioidea brevibranchiata subsp. nov.

12a. Branchiae with more than 10 filaments, starting from setiger 4 .

Eunice microprion Marenzeller, 1879

12b. Branchiae with less than 3 filaments, starting from setigers $6-7$

Eunice yamamotoi sp. nov.

13a. Branchiae absent on the posterior parapodia

Eunice kobiensis McIntosh, 1885

13b. Branchiae present on the posterior parapodia

Eunice gracilicirrata (Treadwell, 1922)

14a. Branchiae absent on the posterior parapodia............................. 15

14b. Branchiae present on the posterior parapodia............................ 19

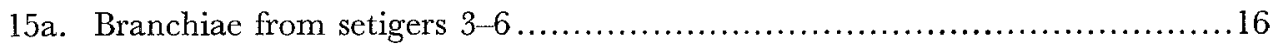

15b. Branchiae from setiger $10 \ldots \ldots \ldots \ldots \ldots \ldots \ldots \ldots \ldots \ldots \ldots \ldots \ldots \ldots \ldots \ldots$ Eunce tanseiae sp. nov.

16a. Maximal number of subacicular hooks per parapodium more than $3 \ldots \ldots \ldots$... Eunice indica Kinberg, 1865

16b. Maximal number of subacicular hooks per parapodium less than $3 \ldots \ldots \ldots \ldots 17$

17a. Antennae smooth ................................................... 18

17b. Antennae articulated .............................. Eunice fauchaldi $\mathrm{sp}$. nov.

18a. Compound falciger with a very long and slender blade. Dorsal cirri long and slender.

Eunice mucronata Moore, 1903

18b. Compound falciger with a tapered blade. Dorsal cirri short and stout...... Eunice congesta Marenzeller, 1879

19a. Aciculum with a hammer-shaped end. Without tube. Eunice antennata (Savigny, 1818)

19b. Aciculum with a tapered end. With a tube of shell and sand grains

Eunice annulicirrata sp. nov.

Subdivision of the Japanese Species of the Genus Eunice.

Morphological subdivision within the genus Eunice has been mentioned by Hartman (1944) and also by Fauchald (1970). According to these authors, the genus is subdivisible into five groups firstly by the dentation and color of subacicular hooks. They are FUSCUS-UNIDENTATUS group (with black unidentate subacicular hooks) as in E. sonorae Fauchald 1970, FUSCUS-BIDENTATUS (black bidentate) as in E. aphroditois (Pallas, 1788), FUSCUS-TRIDENTATUS (black tridentate) as in E. (Nicidion) curticirrus Knox, 1960, FLAVUS-BIDENTATUS (yellow bidentate) as in E. kobiensis McIntosh, 1885, and FLAVUS-TRIDENTATUS (yellow tridentate) as in E. mucronata Moore, 1903. The starting sites of hooks vary in correspondence with 
the growth as mentioned in the description of $E$. fauchaldi. However the dentam tion and color of hooks show little ontogenetic change except for the general wear and tear and accidental damage, according to some studies on the development of some species belonging to the genus or to the relative genera of the family Eunicidae (Aiyer, 1931; Akesson, 1967; Imai, 1975). The color and dentation of hooks are thus considered to be conservative enough to subdivide the genus Eunice at least into five groups, presumably corresponding to the generic or subgeneric level.

Fauchald (1970) also used the branchial distribution pattern for subdividing the members of the genus. The maximal number of branchial filaments and the

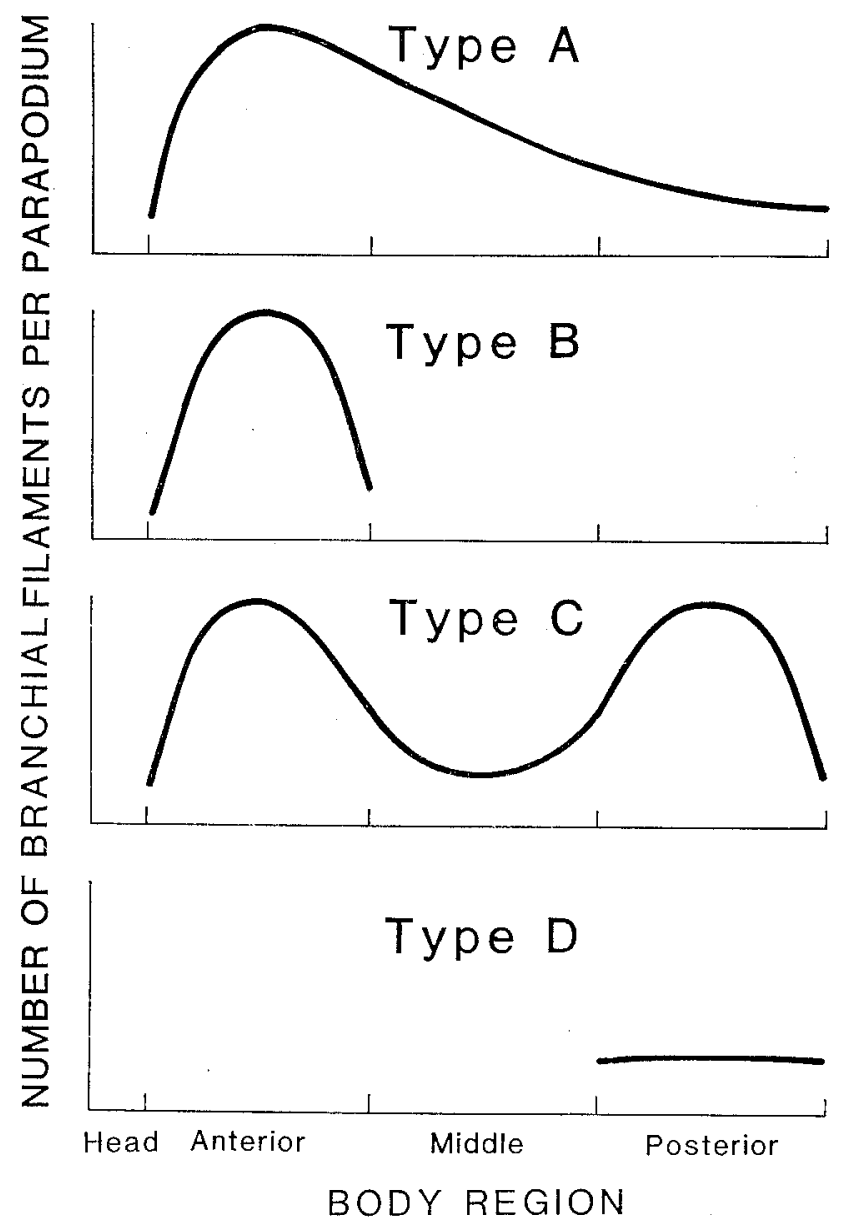

Fig. 39. Main types of branchial distribution in Japanese eunicid worms. Type A: Branchiae occur on most of parapodia, branchial distribution is monomodal, the mode is situated on the anterior parapodia; Type B: Branchiae are restricted on the anterior parapodia, branchial distribution is monomodal; Type C: Branchiae are well developed on the anterior and posterior parapodia, but less developed on the middle parapodia, branchial distribution is bimodal, anterior and posterior modes are recorded; Type D: Branchiae are restricted to the posterior parapodia, no mode, branchiae are simple or rudimentary. 
site of the last branchia, as shown by setiger number, become greater with growth in each species as mentioned in the descriptions of $E$. aphroditois and of E. fauchaldi. On the other hand, the beginning site of branchiae and their relative ditsribution pattern to body size are very stable irrespective of growth (as shown in the descriptions) or are predictable corresponding with growth except for some species. For these reasons, Fauchald's subdivision using the last site of branchiae represented by real setiger number is not directly applied in this study, but they are represented using their relative position to the total number of setigers.

On the basis of the descriptions of Japanese species, at least four main types of distribution patterns are well recognised. These four types are schematically represented in Fig. 39. In type A, branchiae are occurring on the anterior to posterior parapodia and the maximally developed branchiae are situated on the anterior setigers. In the Japanese fauna, seven species or subspecies, i.e., E. aphroditois, $E$. alata, E. microprion, E. northioidea brevibranchiata, E. yamamotoi, E. afra puncutata and E. gracilicirrata, belong to type A. Although no complete specimens of $E$. northioidea northioidea and $E$. quinquifida were available for this study, both species are presumably considered to belong to this type, because the decrease in number of their branchial

Table 2. Subdivision of Japanese species of the genus Eunice

\begin{tabular}{|c|c|c|c|}
\hline $\begin{array}{l}\text { Branchial Distri- } \\
\text { bution Type }\end{array}$ & A & B & $\mathrm{C}$ \\
\hline \multirow[t]{8}{*}{$\begin{array}{l}\text { FUSCUS- } \\
\text { BIDENTATUS }\end{array}$} & aphroditois (Pallas, 1788) & & $\begin{aligned} \text { masudai sp. nov. (Nicidion) cariboed } & \text { Grudbe, } 1856\end{aligned}$ \\
\hline & alata Miura, 1977a & & \\
\hline & $\begin{array}{l}\text { northioidea brevibranchiata } \\
\text { subsp. nov. }\end{array}$ & & \\
\hline & $\begin{array}{l}\text { microprion Marenzeller, } \\
1879\end{array}$ & & \\
\hline & yamamotoi sp. nov. & & \\
\hline & afra punctata Peters, 1854 & & \\
\hline & $\begin{array}{l}\text { northioidea northioidea } \\
\text { Moore, } 1903\end{array}$ & & \\
\hline & quinquifida Moore, 1903 & & \\
\hline \multirow[t]{2}{*}{$\begin{array}{l}\text { FLAVUS- } \\
\text { BIDENTATUS }\end{array}$} & $\begin{array}{l}\text { gracilicirrata (Treadwell, } \\
1922 \text { ) }\end{array}$ & $\begin{array}{l}\text { kobiensis McIntosh, } \\
1885\end{array}$ & \\
\hline & & $\begin{array}{l}\text { longicirrata sensu } \\
\text { Imajima, } 1964\end{array}$ & \\
\hline \multirow[t]{5}{*}{$\begin{array}{l}\text { FLAVUS- } \\
\text { TRIDENTATUS }\end{array}$} & & mucronata Moore, 1903 & $\begin{array}{l}\text { antennata } \\
\text { (Savigny, 1818) }\end{array}$ \\
\hline & & indica Kinberg, 1865 & $\begin{array}{l}\text { annulicirrata } \\
\text { sp. nov. }\end{array}$ \\
\hline & & $\begin{array}{l}\text { congesta Marenzeller, } \\
1879\end{array}$ & \\
\hline & & fauchaldi sp. nov. & \\
\hline & & tanseiae sp. nov. & \\
\hline$?$ & tibiana sensu Izuka, 1912 & & \\
\hline
\end{tabular}


filaments after the mode is moderate like in other species of type A. In type B, branchiae are restricted to the anterior parapodia that consist of $30-40 \%$ of the total setigers and are absent on the remaining parapodia. Eunice kobiensis, E. mucronata, E. indica, E. congesta, E. fauchaldi and E. tanseiae belong to this type among the Japanese eunicid species. All of them are the members of flavus-bidentate or tridentate group. In type $\mathrm{G}$, branchiae are well developed on anterior and posterior parapodia, but less on middle parapodia, and as a result, two modes are recognized in the branchial distribution for individual specimens. In E. masudai, E. annulicirrata and $E$. antennata, that show type $\mathrm{G}$ distribution, only a few anterior parapodia lack branchiae and the most posterior parapodia possess branchiae. In type $\mathrm{D}$, the anterior and middle parapodia are abranchiate, and simple or rudimentary branchiae are restricted to the posterior parapodia. E. (Nicidion) cariboea is the only species of this type in Japan. All Japanese species of the genus Eunice are subdivided using this criteria as shown in table 2.

Modification Pathways of Branchial Distribution Patterns.

Eunicid branchiae are expanded epithelial structures on dorsal cirri. The branchiae of the genus Eunice are pectinate and there are no species with spiral or brushy branchiae. Each branchia has a supply of parapodial blood vessels derived from either the right or left dorsal and midventral vessels. The function of parapodial branchiae is thought to be gas-exchange for respiration and/or ion-exchange for osmoregulation (Storch \& Alberti, 1978; Menendez et al., 1984; etc.). In the cladistic analysis, the branchiae beginning on anterior setigers with a moderate number of branchial filaments in a pectinate arrangement may be considered the plesiomorphic conidtion in each group of eunician polychaetes (Fauchald, 1982).

A theoretical archeotype or ancestor of the genus Eunice may have had poorly developed branchiae with a few filaments on most parapodia, namely they may have had homogenous body segments except for one to three first and last setigers which may correspond to larval setigerous segments and to precaudal growing setigers, respectively. Eunice northioidea brevibranchiata and presumably E. northioidea northioidea are considered to be very closely related to this archeotype of eunicid worms in having poorly developed branchiae over the whole body except for a few first and last setigers. All the modifications occurring on the archeotype can be a result of requirements for more effective gas- and ion-exchange with minimum effort in diverse environments or habitats. In E. longicirris Grube, 1870, E. torquata Quatrefages, 1865, E. afuerensis Hartman, 1944 and E. harassii Audoin \& Milne Edwards, 1834, branchiae have greater maximal number of filaments but are distributed on all parapodia except for the first two setigers. The fact that most of the parapodia are branchiate lead to the thought that the four species also show a branchial distribution closely related to the archeotype eunicid. The increase in the number of filaments compared with the hypothetical ancestor may be caused by the increase of body size which is thought to be an adaptation for producing more gametes and capturing larger food particles. 
In the species living in the crevices of intertidal rocky and coral shores or under boulders, such as $E$. aphroditois and $E$. microprion, the branchiae develop on all setigers except for some anterior and posterior setigers, and they can use the whole body for gas- and ion-exchange. In contrast, tubicolous species do not expose their whole body to fresh seawater. Those species with a totally branchial body are always found in non-polluted areas, and may not survive in a low oxygen environment. Storage of oxygen may also be important for maintaining the metabolism at lowtide conditions, when they can not obtain the seawater containing fresh gas, so they must effectively exchange gas and accumulate oxygen during the restricted period of high-tide. On the other hand, Eunice aphroditois is known as one of the largest species in the genus and sometimes exceeds more than $1000 \mathrm{~mm}$ in length. Some other species with a greater number of filaments, such as E. microprion, and E. gracilicirrata, are also larger than those with a small number of filaments.

The members subdivided as type A include species closely related to the archeotype eunicid with a moderate number of filaments and also larger species with an increased number of filaments. The branchial distribution of type $\mathrm{A}$ is thus considered to be derived directly from the archeotype pattern and the members are thought to be progressing towards an increase in the number of filaments in obtaining larger body size.

In some burrowers and tube-dwellers, when their burrow or tube has a single opening, only the anterior region of the body is available for gas exchange. In this case, it is apparently considered that the branchiae in both middle and posterior body regions do not function and tend to be lost, while the number of filaments in the anterior portion must increase to compensate. The branchial distribution of Type $\mathrm{B}$ is thought to be thus derived from type A. In some species, such as E. microprion, E. gracilicirrata, E. reducta Fauchald, 1970, and E. guildingi Baird, 1870, posteriorly $20-50 \%$ of the total setigers lack branchiae and these species show a transitional condition of the branchial distribution between types $\mathrm{A}$ and $\mathrm{B}$.

Another type of modification might occur in some tubicolous species with two tube openings. In E. masudai, the number of filaments is great in both anterior and posterior body regions and most of the parapodia are branchiate. This species dwells in a Y-shaped solid tube and the living animal may be supplied fresh seawater from both anterior and posterior openings of the tube. Thus the branchiae could be developed in both body regions near the openings of the tube. The distribution pattern of type $\mathrm{C}$ may be derived from type $\mathrm{A}$ or directly from the archeotype. The same pathway might occur on E. annulicirrata. On the other hand, when we compare $E$. antennata to its tubicolous subspecies $E$. antennata aedificatrix Monro, 1933, the parent species represents the bimodal distribution of branchiae, but the subspecies has branchiae less developed on the posterior parapodia. This modification in the posterior body region of tubicolous subspecies is thought to be caused by the structure of its tube, possibly by a blind end.

The modification seen in all species with very poorly developed branchiae in any distribution type mentioned above is accompanied with the reduction of body size. 
Since a small body shows an increase of the relative body surface against the volume, the gas- and ion-exchange through the epithelium shares a larger part of the total exchange in an individual and the role of branchiae becomes less important than in larger species. The type of branchial distribution in some species, such as E. yamamotoi, E. fauchaldi, E. rubella Knox, 1951, E. collini Augener, 1906, E. rosaurae Monro, 1939, and E. makemoana (Chabmerlin, 1919), can be explained by this reasoning. The distribution pattern of type $\mathrm{D}$ can also be derived from the archeotype through the diminution of branchial areas with the reduction of body size.

In the family Eunicidae, the genus Palola has been thought closely related to the genus Eunice in having five occipital antennae and has often been included in Eunice. In the genus Palola, the branchiae are always simple and restricted to the posterior region in contrast to their relatively large bodies. Their poorly developed branchiae can not be explained by the reduction of body size as mentioned above. Another possibility should be also mentioned in this discussion to explain the poorly developed branchiae. In the posterior body region of the species of Palola, high metabolic activity is neccessary for producing gametes and for separating and swimming out to the open seawater away from the anterior region still living in hard substrata. From these facts, the posterior parapodia are thought to have obtained simple branchiae as a result of the expansion of epithelium rather than the diminution of branchial areas and the simplification of pectinate branchiae. The genus Palola may be derived from a certain abranchiate eunicid ancestor in which gasand ion-exchange might be owed chiefly to the epithelium while the metabolic activity might be less than that in other eunicid species.

This discussion on the modification of the branchial distribution is only an approach to a phylogeny in the genus Eunice giving an attention to one character. However, as suggested by Ten Hove (1985), the phylogenetic approach may be very useful in indicating areas for further research even when applied to still imperfectly known groups. From my approach, it is suggested that further studies are necessary and at least one should be focused on the metabolic differences in oxygen consumption and ion exchange between body regions for claryfying these hypothetical pathways of the modifications in branchial distribution. A revision of all species of the genus Eunice should also be carried out because of incomplete original descriptions of many species.

\section{Acknowledgement}

My study on Japanese eunicid worms started under the guidance of the late professor Dr. Tatsuyoshi Masuda, Tokyo University of Fisheries as my master's thesis and taken up again with the support of a postdoctoral fellowship from the Japan Society for the Promotion of Science since 1982.

I express my thanks to Dr. Yoshihisa Shirayama and Dr. C.L. Besch, Ocean Research Institute, for their critical reading and language correction of my manuscript. Thanks are also due to the many scientists and research staffs listed below for communicating or supplying me with plenty of materials examined here containing type specimens. Dr. Kristian Fauchald of the Smithsonian Institution; the late professor Dr. Francois Rullier and Professor Dr. Louis Amoureux of l'Universite Catolique de l'Ouest, Anger; Mr. Ryuta Yamamoto, Dr. Ikuo Hayashi and Professor Dr. Takahisa 
Nemoto of Ocean Research Institute; Dr. Minoru. Imajima of National Science Museum, Tokyo; Professor Dr. Masaaki Murano of Tokyo University of Fisheries; Miss Masumi Yamamuro of the University of Tokyo; Dr. Hiroshi Suzuki of Kagoshima University; Dr. Yutaka Matsuo of Nansei Regional Fishery Research Station and also the chief scientists of "Tansei-Maru" cruises, Professor Dr. Masuoki Horikosi (KT-83-18) of the University of Chiba, Professor Dr. Itaru Hayami (KT-8412) of the University of Tokyo, Professor Dr. Muneo Okiyama (KT-85-14) and Dr. Suguru Ohta (KT-86-1) of Ocean Research Institute. When my own sampling was carried out, many staffs of various marine stations and crews of Research Vessels greatly assisted me. I wish to thank those of Misaki Marine Biological Station, University of Tokyo; Amakusa Marine Biological Station, University of Kyushu; Kominato Marine Station, Tokyo University of Fisheries; Nomo Marine Station, University of Nagasaki; and the Research Vessel "Tansei-Maru", Ocean Research Institute. My hearty thanks go to Mr. Ryuta Yamamoto, Mr. Eiji Tsuchida, Dr. Ikuo Hayashi of Ocean Research Institute; the late technician Mr. Toshio Takano at Kominato Marine Station and Dr. Hiroaki Tsutsumi of the University of Kyushu for their help and assistance in sea-shore sampling, diving and dredging.

\section{References}

Aiyer, R.G. 1931. An account of the development and breeding habits of a brackish water polychaete worm of the genus Marplysa. J. Linn. Soc. Lond., 37: 387-403.

Akesson, B. 1967. The embryology of the polychaete Eunice kobiensis. Acta zool., 48: 141-192.

Audouin, J.V., \& H. Milne Edwards. 1834. Recherches pour servir à l'histoire naturelle du littoral de la France, ou recueil de mémoires sur l'anatomie, la classification et les moeurs des animaux de nos côtes; ouvrage accompagné de planches faites d'après nature. Vol. 2. Annelides, 1 Pt. 290 pp., 8 pls. Crochard, Paris.

Berkeley, E., \& C. Berkeley. 1948. Annelida, Polychaeta Errantia. Can. Pacif. Fauna, 9b (1): 1-100.

Chamberlin, R.V. 1919. The Annelida Polychaeta. Mem. Mus. comp. Zool. Harv., 48: 1-514, 80 pls.

Crossland, C. 1904. The marine fauna of Zanzibar and British East Africa, from collections made by Cyril Crossland in the years 1901 and 1902. The Polychaeta, Part 3. With which is incorporated the account of Stanley Gardiner's collection made in the Maldive Archipelago in the year 1889. Proc. zool. Soc. Lond., 1904: 287-330, 3 pls.

Cuvier, G. 1817. La règne animale distribué d'après son organisation, pour servir de base à l'histoire naturelle des animaux et d'introduction à l'anatomie compareé. Vol. 2. xviii+532 pp. Deterville, Paris.

Day, J.H. 1957. The polychaet fauna of South Africa. Part 4. New species and records from Natal and Mozambique. Ann. Natal Mus., 14: 59-129.

Eblers, E. 1887. Report of the annelids of the dredging expedition of the U.S. Coast Survey Steamer BLAKE. Mem. Mus. comp. Zool. Harv., 15: 1-335, 60 pls.

Fauchald, K. 1969. A revision of six species of the flavus-bidentatus group of Eunice (Eunicidae: Polychaeta). Smithson. Contr. Zool., 6: 1-15.

- 1970. Polychaetous annelids of the families Eunicidac, Lumbrineridae, Iphitimidae, Arabellidae, Lysaretidae and Dorvileidae from Western Mexico. Allan Hancock Monogr. mar. Biol., 5: 1-335, 27 pls.

- 1977. The polychaete worms. Definitions and keys to the orders, families and genera. Nat. Hist. Mus. Los Angeles Citry, Sci. Ser., 28: 1-190.

-1982. Revision of Onuphis, Nothria, and Paradiopatra (Polychaeta: Onuphidae) based upon type material. Smithson. Contr. Zool., 356: 1-109.

-, \& D.R. Hancock. 1981. Deep-water polychaetes from a transect off central Oregon. Allan Hancock Monogr. mar. Biol., 11 : 1-73, 8 pls.

Fauvel, P. 1932. Annelida Polychaeta of the Indian Museum, Calcutta. Mem. Indian Mus., 12: $1-262,9$ pls. 

$41-92$.

Gathof, J.M. 1984. Eunicidae. In: J.M. Uebelacker \& P.G. Johnson ed. "Taxonomic guide to the polychaetes of the northern Gulf of Mexico", Vol. 6, Chapter 40. 31 pp. Barry A. Vittor \& Associates, Inc. Mobile.

Gray, J.E. 1847. An account of Palolo, a sea worm caten in the Navigator Islands. Proc. zool. Soc. Lond., 15: 17-18.

Grube, A.E. 1870. Beschreibungen neuer oder weniger bekannter von Hrn. Ehrenberg gesammelter Anneliden des rothen Meere. Mber. dt Akad. Wiss. Berl., 1869: 484-521.

Gustus, R.M. 1972. A species of the genus Eunice (Polychaeta) from the Pacific Northwest coast. NW Sci., 46: 257-269.

Hartman, O. 1944. Polychaetous annelids. Part 5. Eunicea. Allan Hancock Pacif. Exped., 10: $1-181,18$ pls.

Imai, T. 1975. On the spawning and early life history of the rock worm, Marphysa sanguinea (Montagu). Aquiculture, 23: 14-20. (In Japanese)

Imajima, M. 1964. Benthic polychaetes collected by the second cruise of the Japanese expedition of deep seas (JEDS-2). Bull. natn. Sci. Mus. Tokyo, 7: 235-254.

- 1967. Errant polychactous annelids from Tsukumo Bay and vicinity of Noto Peninsula, Japan. Ibid., 10: 403-441.

-. \& O. Hartman. 1964. The polychactous anneilds of Japan. Allan Hancock Found. Publ., 26: 1-452.

Izuka, A. 1912. The errantiate Polychaeta of Japan. J. Coll. Sci., Imp. Univ. Tokyo, 30(2): 1262, 24 pls.

Kinberg, J.G.H. 1865. Annulata nova. Oefv. Svenska Vet. Akad. Foerh. Stockholm, 21: 559-574.

Knox, G.A. 1960. Biological results of the Chatham Islands 1954 expedition. Part 3. Polychaeta Errantia. N. Z. Dept. sci. indust. Res., Bull., 139: 77-143.

McIntosh, W.C. 1885. Report on the Annelida Polychaeta collected by H.M.S. Challenger during the years 1873-1876. Rep. sci. Res. "Challenger", Zool., 12: 1-554, 94 pls.

- 1903. Notes from the Gatty Marine Laboratory, S. Andrews, no. 25. 1. On the Eunicidae dredged by H.M.S. PORCUPINE in 1869 and 1870. 2. On Canadian Eunicidae dredged by Dr. Whiteaves, of the Ganadian Geological Survey, in 1871-1873. 3. On Norvegian Eunicidae collected by Ganon Norman. Ann. Mag. nat. Hist., Ser 7, 12: 128-166, 4 pls.

Marenzeller, E. 1879. Sudjapanische Anneliden. I. Denkschr. Akad. Wiss. Wien, Math.-Naturwiss. Kl., 41 : 109 -154, 6 pls.

Menendez, A., J.L. Arias, D. Tolivia \& M. Alvarez-Uria. 1984. Ultrastructure of gill. epithelial cells of Diopatra neapolitana (Annelida, Polychaeta). Zoomorph., 104: 304-309.

Miura, T. 1977a. Eunicid polychaetous annelids from Japan-I. La mer (Bull. Soc. franco-jap. oceanogr.), 15: 1-20.

- 1977b. Eunicid polychaetous annelids from Japan-II. Ibid., 15: 61-81.

- 1979. Eunicid polychaetous annelids from Japan-III. Ibid., 17: 33-42.

_ _ . \& T. Kajihara. 1985. An ecological study of the life histories of two Japanese serpulid worms, Hydroides ezoensis and Pomatoleios kraussii. In: P.A. Hutchings "Proceedings of the First International Polychaete Conference, Sydney" pp. 338-354. Linn. Soc. N. S. W., Sydney.

Moore, J.P. 1903. Polychacta from the coastal slope of Japan and from Kamchatka and Bering Sea. Proc. Acad. nat. Sci. Philad., 55: 40I-490, 5 pls.

Okuda, S. 1937. Polychaetous annelids from the Palau Islands and adjacent waters, the south sea Islands. Bull. biogeogr. Soc. Japan, 7: 257-315.

-1938. Polychaetous annelids from the vicinity of the Mitsui Institute of Marine Biology. Japan. J. Zool., 8: 75-105.

1940. Polychaetous annelids of the Ryukyu Islands. Bull. biogeogr. Soc. Japan, 10: 124.

Peters, W.C.H. 1854. Ueber die Gattung Bdella, Savigny (Limnatis, Moquin-Tandon) und die in Mossanbique beobachteten Anneliden. Bericht Akad. wiss. Berl., 1854: 607-614. 
Pettibone, M.H. 1970. Polychaeta Errantia of the Siboga expedition part IV. Some additional polychaetes of the Polynoidae, Hesionidae, Nereidae, Goniadidae, Eunicidae and Onuphidae, selected as new species by the late Dr. Harmann Augener with remarks on other related species. Siboga-Exped. Monogr., 24 (1b): 119-270.

Poutales, L.F. de. 1863. Contributions to the fauna of the Gulf Stream at great depths. Bull. Mus. comp. Zool. Harv., 1: 103-120.

Quatrefages, M.A. de. 1865. Histoire naturelle des annelides marine et d'eau douce. Vol. 1. 558 pp. Librairie encyclopedique de Roret, Paris.

Rullier, F. 1964. Annélides polychètes (campagne de la 'Calypso' 1959 aux iles du Cap Vert). AnnIs Inst. oceanogr., 41: 113-218.

Savigny, J.G. 1818. Les Annélides. In: J.B. de Lamarck "Histoire naturelle des animaux sans vertebres", Vol. 5: 274-374, Deterville, Paris.

Shisko, J.F. 1981. Five new polychaetes of the families Eunicidae and Onuphidae, collected in 1975 and 1976 during the southern California baseline project. Proc. biol. Soc. Wash., 94: 968-983.

Storch, V., \& G. Alberti. 1978. Ultrastructural observations on the gills of polychaetes. Helgolander wiss. Meeresunters., $31:$ 169-179.

Ten Hove, H.A. 1985. Towards a phylogeny in Serpulidae (Annelida: Polychaeta). In: P.A. Hutchings "Proceedings of the First International Polychaete Conference, Sydney" pp. 181-196. Linn. Soc. N.S.W., Sydney.

Treadwell, A.L. 1922. Leodicidae from Fiji and Samoa. Publ., Carnegie Inst. Wash., 312: 127170.

-. 1926. Polychaetous annelids from Fiji, Samoa, China and Japan. Proc. U.S. natn. Mus. nat. Hist., 69 (15) : 1-20.

Uschakov, P. 1955. Polychaetes of far eastern seas of the U.S.S.R. 445 pp. Soviet Acad. Sci., Moscow. (In Russian).

Webster, H.E. 1884. The annelida from Bermuda, collected by Mr. G. Brown Goode. Bull. U.S. natn. Mus. nat. Hist., 25: 305-327.

Wesenberg-Lund, E. 1949. Polychaetes of the Iranian Gulf. Danish sci. Invest. Iran, Copenhagen, 4: $247-400$. 